JULIANA DA SERRA COSTA LOPES

\title{
UM MODELO INTEGRADO DE SIMULAÇÃO-OTIMIZAÇÃO PARA SUPORTE AO PLANEJAMENTO E À ANÁLISE DE UM NEGÓCIO DE AERONAVES DE PROPRIEDADE COMPARTILHADA
}

Dissertação apresentada à Escola Politécnica da Universidade de São Paulo para obtenção do título de Mestre em Engenharia de Transportes.

SÃO PAULO 
JULIANA DA SERRA COSTA LOPES

\title{
UM MODELO INTEGRADO DE SIMULAÇÃO-OTIMIZAÇÃO PARA SUPORTE AO PLANEJAMENTO E À ANÁLISE DE UM NEGÓCIO DE AERONAVES DE PROPRIEDADE COMPARTILHADA
}

\author{
Dissertação apresentada à Escola Politécnica da \\ Universidade de São Paulo para obtenção do título de \\ Mestre em Engenharia de Transportes. \\ Área de concentração: \\ Planejamento e Operação de Transportes \\ Orientador: \\ Professor Associado \\ Claudio Barbieri da Cunha
}

SÃO PAULO 
Este exemplar foi revisado e alterado em relação à versão original, sob responsabilidade única do autor e com a anuência de seu orientador.

São Paulo, de julho de 2011.

Assinatura do autor

Assinatura do orientador

\section{FICHA CATALOGRÁFICA}

Lopes, Juliana da Serra Costa

Um modelo integrado de simulação-otimização para suporte ao planejamento e à análise de um negócio de aeronaves de propriedade compartilhada / J.S.C. Lopes. -- São Paulo, 2011. $109 \mathrm{p}$.

Dissertação (Mestrado) - Escola Politécnica da Universidade de São Paulo. Departamento de Engenharia de Transportes.

1. Aeronaves 2. Programação inteira e fluxos em rede 3. Metodo de Monte Carlos I. Universidade de São Paulo. Escola Politécnica. Departamento de Engenharia de Transportes II. t. 
Dedico este trabalho a meus pais Tereza e João, aos meus tios Joaquim e Lisiane e à amada e saudosa laiá. 


\section{AGRADECIMENTOS}

Gostaria de agradecer a Deus, pela vida abençoada que tenho.

A meus pais, Tereza e João, meus exemplos e maiores incentivadores. Obrigada pelo lar que, com muito trabalho, vocês criaram para mim e para meu irmão Rafael, cheio de amor e de possibilidades. Tudo que sou na vida devo a vocês e espero sempre fazê-los orgulhosos de mim.

A meu tio, meu padrinho e meu amigo, Joaquim, por ser essa pessoa exemplar, de caráter e lealdade incomparáveis. Obrigada também por ter trazido Lisiane, tão especial e querida, para nossa família.

A Lauro, meu namorado e companheiro, por tanto amor, apoio, carinho e paciência.

Às minhas amigas e companheiras de mestrado, Clicia e Nathalia, por tantas noites em claro estudando e por todos os dias felizes.

Ao meu orientador, Prof. Dr. Claudio Barbieri da Cunha, por ser um excelente professor e ter me incentivado desde a graduação. Obrigada pela confiança, pela dedicação e por tantos conselhos e ensinamentos que tive a honra de receber.

Ao Prof. Dr. Nicolau Dionísio Fares Gualda e ao Dr. Antonini Macedo Pupim por todas as críticas construtivas, experiências e conhecimento compartilhados que, sem sombra de duvidas, colaboraram para aprimorar esta pesquisa. Ao Prof. Dr. Jorge Eduardo Leal Medeiros pela ajuda na elaboração do problema e na obtenção dos dados para esta pesquisa.

Aos professores do Departamento de Engenharia de Transportes da Escola Politécnica, que durante as estimulantes aulas no decorrer da graduação em Engenharia Civil e do programa de Mestrado em Engenharia de Transportes, contribuíram para minha formação. Sinto-me honrada por ser aluna de um corpo docente de tamanha competência.

Minha sincera gratidão a todos. 


\section{RESUMO}

Esta pesquisa aborda o problema de alocação de jatos executivos compartilhados para casos em que a demanda diária é variável. É proposta uma ferramenta auxiliar de planejamento de uma empresa de operação de jatos compartilhados.

São apresentadas as características principais do tipo de negócio que formam o problema estudado neste trabalho. Consideram-se os aspectos de uma empresa que administra jatos de propriedade compartilhada. O cliente adquire uma cota de uma aeronave e quando solicita uma viagem, com poucas horas de antecedência, a empresa deve garantir a realização do voo em uma aeronave da categoria adquirida. Também é de responsabilidade da empresa a gestão da tripulação, o reposicionamento da frota e a manutenção das aeronaves

Este trabalho apresenta o desenvolvimento de uma ferramenta para auxiliar na tomada de decisões estratégicas que envolvem a escolha dos locais de base de operação e o dimensionamento da frota. A metodologia de solução é composta de um modelo de simulação e um de otimização. $O$ modelo de simulação utiliza o método de Monte Carlo para obtenção da demanda de voos dia a dia que gera uma programação de clientes a atender. Os dados da simulação são então estruturados como um problema de fluxo em rede de mínimo custo e é realizada a alocação ótima das aeronaves.

A ferramenta foi construída em ambiente de planilha eletrônica Microsoft Excel e aplicada em um caso prático de jatos executivos compartilhados com múltiplas bases. Foram testadas diversas configurações de bases e políticas operacionais como frota homogênea, frota heterogênea e frota alugada. Os resultados da ferramenta permitem determinar o impacto que a escolha das bases de operação tem no tamanho da frota e no reposicionamento de aeronaves. A metodologia mostrou-se robusta e, em tempo adequado, a ferramenta encontrou a solução ótima para cada configuração testada. 


\section{ABSTRACT}

This research deals with the problem of scheduling jets with fractional ownership in cases where the demand varies daily. It has been devised a tool to support the planning phase of a company that operates shared jets.

The main characteristics of the fractional shared market are presented in this manuscript and the research was developed under the point of view of a provider of fractional ownership. A client becomes a partial owner of an aircraft of a specific model and is entitled to a certain amount of flight hours. When the client requests a flight, usually only a few hours ahead, the fractional provider must guarantee that an aircraft of the requested model is available to the owner at the requested time and place. The provider is responsible for all the operational considerations, including managing the crew and having a well-maintained fleet

This work presents the development of a tool to help making decisions involving the choice of the operational bases and the size of the fleet. The solution methodology is composed of a simulation and a optimization model. Monte Carlo simulation is the method used to obtain the daily flight demand. The results of the simulation are structured as a minimum cost network flow problem to solve optimally the fleet allocation.

This tool has been built in a Microsoft Excel spreadsheet environment and applied to a case of fractional jets with multiple bases. Several configurations and operational policies have been tested, such as operations with homogenous fleet, with heterogeneous fleet and with rented fleet. The results provided by the tool allow the user to evaluate the impact that the choice of the operational bases has on the size of the fleet and on the redeployment of the aircrafts. The methodology presented itself as adequate and the developed tool was able to solve optimally, in acceptable time, the problem for each case. 


\section{SUMÁRIO}

Lista de Figuras

Lista de Tabelas

1. INTRODUÇÃO.............................................................................................

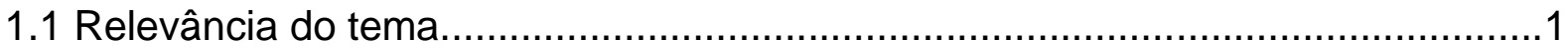

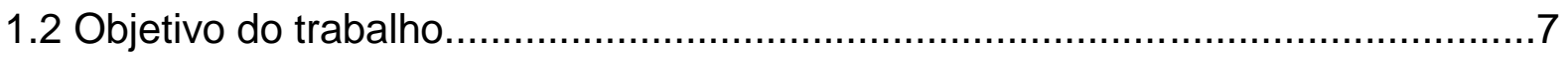

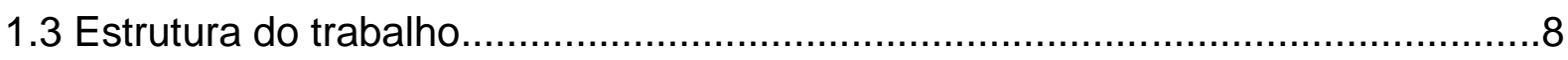

2. REVISÃO BIBLIOGRÁFICA.........................................................................9

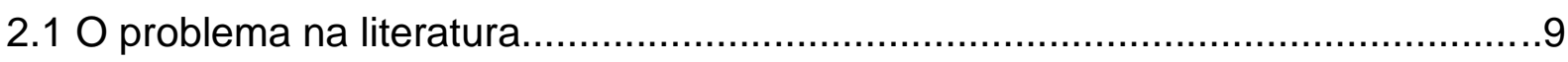

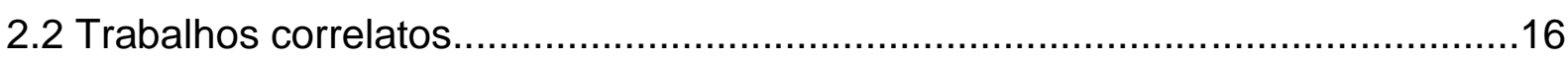

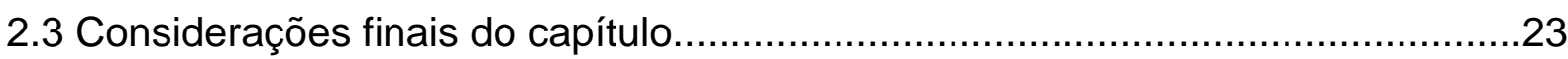

3. CARACTERIZAÇÃO E MODELAGEM DO PROBLEMA DE ALOCAÇÃO DE AERONAVES COMPARTILHADAS...............................................................24

3.1 O negócio de jatos com propriedade compartilhada......................................25

3.2 Caracterização das modalidades de operação de aeronaves compartilhadas....27

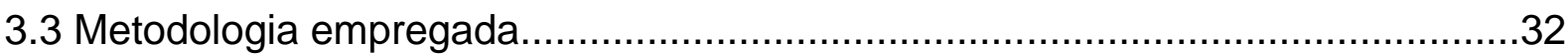

3.4 Geração dos voos diários através de Simulação de Monte Carlo......................34

3.5 Modelo de fluxo em rede para otimização da utilização das aeronaves...............38

3.5.1 Modelo com frota própria homogênea............................................39

3.5.2 Modelo com frota própria heterogênea..............................................46

3.5.3 Modelo com frota homogênea e opção de aluguel...............................55

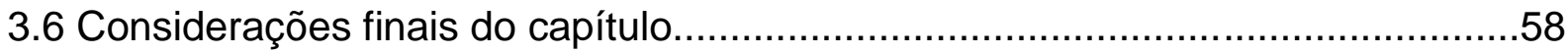

\section{IMPLEMENTAÇÃO DO MODELO EM AMBIENTE DE PLANILHA} ELETRÔNICA.................................................................................................60

4.1 Descrição do ambiente em planilha........................................................

4.2 Exemplo para verificação do modelo........................................................74

4.3 Considerações finais do capítulo........................................................ 79 
5.1 Caso prático do Brasil com frota própria homogênea........................................82

5.2 Caso prático do Brasil com frota própria heterogênea.........................................91

5.3 Caso prático EUA com frota homogênea com opção de aluguel..........................95

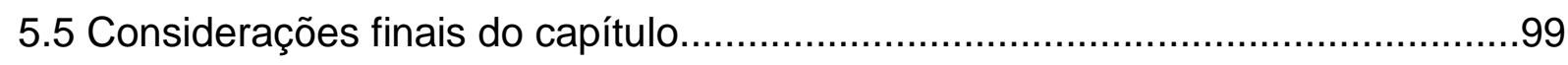

6. CONSIDERAÇÕES E RECOMENDAÇÕES....................................................101

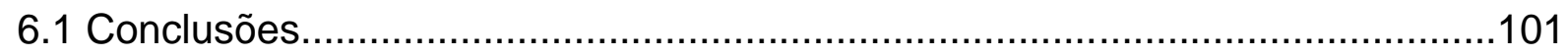

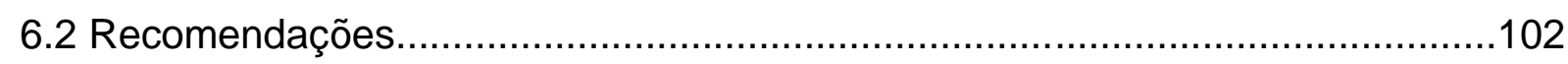




\section{LISTA DE FIGURAS}

Figura 3.1 - Fluxograma de composição de custos

Figura 3.2 - Metodologia de Simulação e Otimização adotada na pesquisa.............33

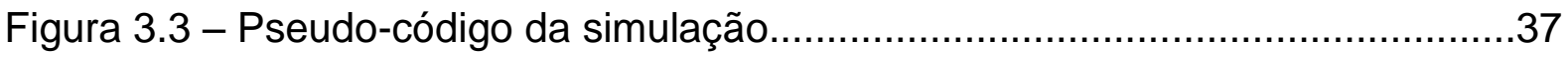

Figura 3.4 - Rede homogênea com nós, bases e voos............................................40

Figura 3.5 - Rede homogênea com Arcos_base_dia, Arcos_base_volta e

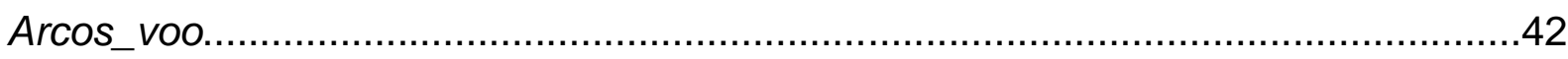

Figura 3.6 - Rede homogênea com Arcos_reposicionamento e Arcos_voo...............43

Figura 3.7 - Rede heterogênea com nós, bases e voos...........................................48

Figura 3.8 - Rede heterogênea com Arco_base_ida_tp2 e Arco_base_volta_tp2....50

Figura 3.9 - Rede heterogênea com Arco_reposicionamento_tp1 e

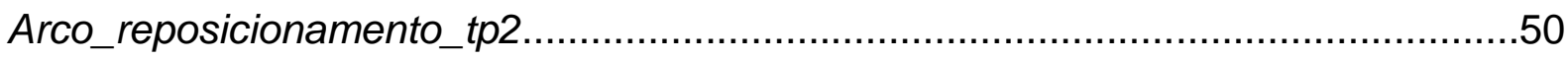

Figura 3.10 - Possível configuração para a rede do problema com frota própria

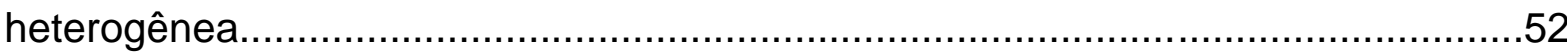

Figura 4.1 - Tela da planilha "Descrição do caso".................................................62

Figura 4.2 - Tela da planilha "Dados de desempenho da frota"...............................64

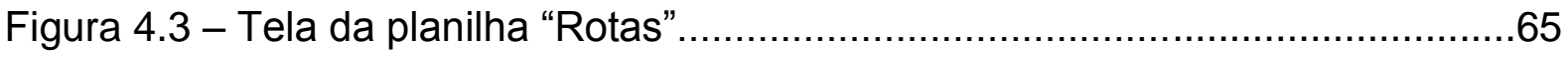

Figura 4.4 - Tela da planilha "Lista de aeroportos"..............................................66

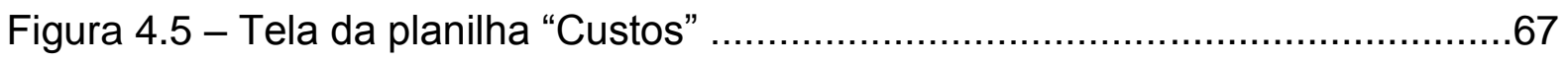

Figura 4.6 - Tela da planilha "Definições do usuário"..............................................69

Figura 4.7 - Tela da planilha "Simulação de Monte Carlo"........................................70

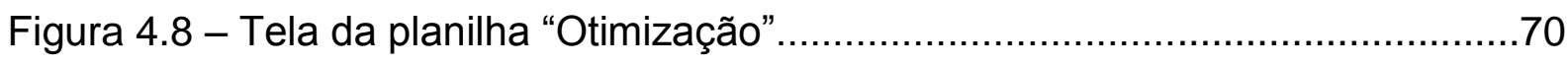

Figura 4.9 - Tela da planilha "Otimização" com a tabela de voos............................71

Figura 4.10 - Tela da planilha "Otimização" com parte da tabela de arcos................71 
Figura 4.11 - Tela da planilha "Otimização" com parte da tabela de equilíbrio dos nós.

Figura 4.12 - Representação da rede com todos os arcos do exemplo de verificação 76

Figura 4.13 - Tela da tabela de arcos do exemplo de verificação. .78

Figura 4.14 - Representação da rede com a solução ótima do exemplo de verificação 79

Figura 5.1 - Mapa com as rotas do caso prático. 82

Figura 5.2 - Entrada de dados para a simulação 84 


\section{LISTA DE TABELAS}

Tabela 1.1 - Diferenças entre serviços de aeronaves compartilhadas.

Tabela 3.1 - Relação de cotas de propriedade compartilhada em função de horas voadas.

Tabela 3.2 - Lista de voos do exemplo de frota própria homogênea. .46

Tabela 3.3 - Relação de nós das bases do exemplo de frota própria homogênea. .46

Tabela 3.4 - Lista de arcos do exemplo de frota própria homogênea. .46

Tabela 3.5 - Lista de voos do exemplo de frota própria heterogênea.

Tabela 3.6 - Lista de voos do exemplo de frota própria heterogênea. .53

Tabela 3.7 - Lista de nós das bases do exemplo de frota própria heterogênea.......53

Tabela 3.8 - Lista de arcos do exemplo de frota própria heterogênea. .53

Tabela 3.9 - Lista de voos do exemplo de frota homogênea com opção de aluguel.

Tabela 3.10 - Lista de nós das bases do exemplo de frota homogênea com aluguel.

Tabela 3.11 - Lista de arcos do exemplo de frota homogênea com opção de aluguel.

Tabela 3.12 - Resumo da formulação matemática. .59

Tabela 4.1 - Lista de arcos do exemplo para verificação do modelo .75

Tabela 4.2 - Lista de nós das bases do exemplo para verificação do modelo. .75

Tabela 4.3 - Lista de arcos do exemplo de verificação do modelo.........................75

Tabela 4.4 - Restrições do exemplo de verificação do modelo..............................76

Tabela 5.1 - Lista de aeroportos do caso prático............................................82

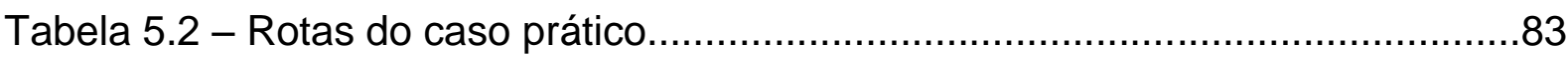

Tabela 5.3 - Resultados da simulação com frota própria homogênea - 15 voos.....85 
Tabela 5.4 - Configuração de bases para a otimização de frota própria homogênea 15 voos.

Tabela 5.5 - Resultados das configurações com frota própria homogênea para 15 voos.

Tabela 5.6 - Resultados da simulação com frota própria homogênea - 30 voos.....89

Tabela 5.7 - Resultados dos cenários com frota própria homogênea para 30 voos.

Tabela 5.8 - Resultados da simulação com frota própria heterogênea - 25 voos....92

Tabela 5.9 - Resultados dos cenários com frota própria heterogênea - 25 voos.....94

Tabela 5.10 - Resultados das configurações com frota própria heterogênea com restrição de distancia de voos de reposicionamento -25 voos.

Tabela 5.11 - Resultados das configurações nos EUA com frota homogênea

Tabela 5.12 - Resultados das configurações nos EUA com frota homogênea e opção de aluguel. 


\section{INTRODUÇÃO}

Esta dissertação trata o problema de planejamento da operação de jatos executivos compartilhados, setor de potencial crescimento na indústria aeronáutica. É focado o assunto com ênfase na etapa de planejamento da empresa, na qual são tomadas decisões referentes à escolha dos locais das bases e ao tamanho da frota.

\subsection{Relevância do tema}

Dentre os diversos meios de transporte, o aéreo é o que oferece maior velocidade para o deslocamento de passageiros e cargas. Desde a década de 1950, a popularidade da aviação só aumentou e esta passou a ser a principal opção para percorrer distâncias médias e grandes. O surgimento de inúmeras empresas aéreas e a demanda de passageiros provocou um crescimento desajustado da aviação comercial e na aviação geral criaram-se novas opções para suprir as deficiências da oferta imprópria do serviço.

Pessoas cujos trabalhos requerem viagens constantes, que buscam alternativas para aeroportos lotados, que querem ir para cidades que não são atendidas pela aviação comercial, que desejam decidir os horários de suas viagens ou que procuram privacidade podem optar por viajar em aeronaves executivas. Quando se trata de viagens em aeronaves executivas, há diversas opções de serviços, principalmente nos EUA.

Alugar uma aeronave é a forma mais descomplicada de viajar. O passageiro contrata o serviço de uma empresa que faz fretamento de aeronaves, ou charter, escolhe o tipo de aeronave em que quer voar, determina seu local de destino, realiza seu voo e paga pelo serviço em função do tempo voado. Entretanto, o passageiro não arca somente com os custos referentes ao voo, mas também com os custos do retorno da aeronave vazia ao seu local de origem após o voo (Thurber, 2010a). 
Outra opção bastante difundida nos EUA é a dos "Jet cards", que funcionam como um cartão de débito. O cliente compra uma quantia de horas e quando solicita um voo, as horas ocupadas na aeronave são descontadas do total de horas do cartão. (Preston, 2009). Ao contrário do que acontece com as aeronaves fretadas, o cliente paga apenas pelo tempo de voo, e os custos de levar a aeronave de volta ao seu local de origem são responsabilidade da empresa operadora do serviço.

Quando há a necessidade de realizar muitos voos, há a opção de comprar uma aeronave. O proprietário da aeronave pode assumir pessoalmente a administração da aeronave e todos os seus requisitos como autorizações, taxas, seguros, manutenções, tripulação e afins; ou o proprietário pode contratar uma empresa para gerenciar sua aeronave e garantir que esteja à disposição sempre que desejado. É uma opção que, ao contrário do fretamento e do "Jet card", exige investimento elevado para a aquisição de aeronave, além dos custos de operação e manutenção, que são arcados pelo proprietário (Thurber, 2010a).

Todavia, existe uma opção intermediária entre possuir uma aeronave e usar um fretamento ou "Jet card". Em 1986 uma companhia norte-americana de charter de jatos denominada NetJets criou um novo serviço para seus clientes. O modelo de negócios conhecido como propriedade compartilhada (do inglês "fractional aircraft ownership"), visa a atender a pessoas que querem desfrutar dos benefícios e conforto de uma aeronave particular, reduzindo os ônus da aquisição e manutenção da mesma.

Dessa maneira, o cliente adere à propriedade compartilhada com a garantia de ter uma aeronave à sua disposição quando necessário, com tripulação preparada, tanque de combustível abastecido, manutenção em ordem, autorização de voo e demais providências necessárias para voar. Mais especificamente, o usuário faz um investimento menor na aquisição de uma cota de propriedade de uma dada aeronave, de certo tipo e padrão, arcando com uma mensalidade para cobrir custos fixos. A cada utilização da aeronave incorre um valor destinado a cobrir os custos variáveis de utilização da mesma, baseado nas horas voadas. Quando o cliente deseja se desligar do serviço pode simplesmente vender sua cota da aeronave (Butler, 2008). 
Dentre todas as opções citadas anteriormente, o cliente é transportado individualmente, sem o compartilhamento da aeronave com outros passageiros que possam ter a mesma origem e/ou o mesmo destino. Uma das virtudes mais importantes dos serviços está relacionada ao fato do usuário ter a flexibilidade de um curto período de tempo entre a decisão e a realização da viagem, além de desfrutar do conforto de evitar conexões em aeroportos lotados, pois pode voar para aeroportos secundários de grandes cidades ou para cidades pequenas que não possuem aeroportos com capacidade para aviões comerciais.

A Tabela 1.1, adaptada das informações disponíveis no site da empresa Flexjet, que atua nos EUA, apresenta as principais diferenças entre os tipos de serviços. Como pode ser visto, a escolha pelo tipo de serviço varia não só em função do preço, mas também em função da necessidade de horas de voos. Para clientes que voam ocasionalmente e não chegam a realizar 25 horas de voo em um ano o fretamento mostra-se como a opção mais econômica. Entretanto, com o fretamento não há a garantia de disponibilidade de aeronave, como acontece com os "Jet cards". A cobrança das horas de voo nos cartões pode variar dependendo do modelo de aeronave escolhida, mas ao adquirir um "Jet card", o cliente garante uma mesma taxa de cobrança que valerá para todas as horas do cartão.

Adquirir a propriedade de uma cota de uma aeronave significa assumir um comprometimento de longo prazo com a empresa prestadora do serviço. É uma opção que exige um investimento inicial mais alto do que a aquisição de um cartão de horas, mas que, dependendo da freqüência de uso, mostra-se mais econômica do que o cartão. Ao final do contrato, o proprietário recupera parte do investimento ao vender sua cota da aeronave. E, finalmente, para clientes cujo uso da aeronave ultrapassa 300 horas por ano, a propriedade total da aeronave é a melhor opção. 
Tabela 1.1 - Diferenças entre serviços de aeronaves compartilhadas

\begin{tabular}{|c|c|c|c|c|}
\hline & $\begin{array}{l}\text { Opções de } \\
\text { adesão }\end{array}$ & $\begin{array}{c}\text { Horas de voo } \\
\text { por ano }\end{array}$ & Custo & $\begin{array}{l}\text { Duração da } \\
\text { adesão }\end{array}$ \\
\hline $\begin{array}{c}\text { Gerenciamento } \\
\text { de aeronave }\end{array}$ & $\begin{array}{l}\text { O cliente adquire a } \\
\text { aeronave e tem } \\
\text { total controle } \\
\text { operacional }\end{array}$ & $\begin{array}{c}\text { Mais de } 300 \\
\text { horas/ano }\end{array}$ & $\begin{array}{c}\text { de US\$5 a } \\
\text { US\$ } 50 \\
\text { milhões }\end{array}$ & $\begin{array}{c}\text { Contrato de } 5 \text { anos } \\
\text { (com despesa } \\
\text { mensal fixa) }\end{array}$ \\
\hline $\begin{array}{l}\text { Propriedade } \\
\text { compartilhada }\end{array}$ & $\begin{array}{l}\text { Cliente adquire } \\
\text { cotas de aeronave } \\
\text { a partir de } 1 / 16\end{array}$ & $\begin{array}{l}\text { de } 50 \text { a } 400 \\
\text { hora/ano }\end{array}$ & $\begin{array}{l}\text { de US\$ } \\
400.000 \text { a } \\
\text { US\$ 9,3 } \\
\text { milhões }\end{array}$ & $\begin{array}{l}\text { Contrato de } 5 \text { anos } \\
\text { (com despesa } \\
\text { mensal fixa) }\end{array}$ \\
\hline Jet Cards & $\begin{array}{l}\text { Cotas horárias de } \\
25,30 \text { ou } 35 \text { horas }\end{array}$ & $\begin{array}{l}\text { de } 25 \text { a } 75 \\
\text { horas/ano }\end{array}$ & $\begin{array}{c}\text { de US\$ } \\
124.900 \mathrm{a} \\
\text { US\$ } 418.600\end{array}$ & $\begin{array}{l}\text { Horas válidas por } \\
\text { um ano. Horas não } \\
\text { usadas podem ser } \\
\text { reembolsadas }\end{array}$ \\
\hline Fretamento & $\begin{array}{c}\text { Solicitação a cada } \\
\text { viagem }\end{array}$ & $\begin{array}{l}\text { de } 1 \text { a } 25 \\
\text { horas/ano }\end{array}$ & $\begin{array}{c}\text { de US\$ } 2070 \\
\text { a US\$ } 9200 \\
\text { por hora (por } \\
\text { trecho) }\end{array}$ & $\begin{array}{c}\text { Sem } \\
\text { comprometimento } \\
\text { de longo prazo }\end{array}$ \\
\hline
\end{tabular}

Fonte: Adaptado de Flexjets, 2010

Outro aspecto importante a ser considerado na escolha do tipo de serviço é referente à responsabilidade civil do proprietário da aeronave. Quando o cliente adere a um serviço de propriedade compartilhada, ele passa a ser dono de uma aeronave, ou seja, de um meio de transporte. Caso aconteça algum acidente, o responsável pela aeronave deve estar especificado nos contratos. Nos EUA, os contratos de prestação de serviço de aeronaves compartilhadas devem ser firmados sob a norma "Part 135" da "Federal Aviation Regulations", que regula também os fretamentos. Essa norma acusa que o controle operacional da aeronave é responsabilidade da empresa prestadora do serviço. Quando o voo é regido pela norma "Part 91, subpart $K$ ", na qual o controle operacional é do proprietário da aeronave, a responsabilidade civil é do cliente e não da empresa. Portanto, em caso de acidentes, com o contrato regido pela norma "Part 135" da "Federal Aviation Regulations" a responsabilidade recai sobre a empresa operadora. Sendo assim, a maior parte das empresas contrata uma seguradora para transferir os riscos da operação (Butler, 2009b). 
O mercado de jatos compartilhados foi o subsetor de maior crescimento dentro da indústria de aeronaves executivas entre dezembro/1998 e dezembro/2003 (Hicks et al., 2005). Entretanto, o impacto da recessão dos últimos anos provocou a queda dos preços das aeronaves usadas e a redução da demanda por voos. De acordo com Thurber (2009a), os resultados financeiros da empresa NetJets em Julho de 2009 foram 43\% menores em relação ao ano anterior, o que representa queda de $81 \%$ nas vendas de aeronaves e de $22 \%$ nos resultados das operações de voos. A crise forçou as empresas operadoras a cancelar as compras de novas aeronaves e a demitir funcionários. Apesar disso, a mesma NetJets apresentou crescimento de $17 \%$ nos resultados do primeiro semestre de 2010 em relação ao mesmo período de 2009 (Trautvetter, 2010), evidenciando uma recuperação parcial do seu mercado.

Enquanto nos EUA o mercado de aviação executiva se recupera, no Brasil também há perspectivas de crescimento do negócio. Segundo Borin e Ribeiro (2010), o setor de aviação geral no Brasil é composto por mais de 400 empresas, com uma frota de aproximadamente 12 mil aeronaves (incluído aviões e helicópteros). Ainda de acordo com Borin e Ribeiro (2010), o potencial da aviação executiva no país está associado à sua extensão: apenas $2 \%$ dos municípios brasileiros são atendidos pela aviação comercial, enquanto que a aviação geral atende a 75\%. Dupim (2010) estima que um quarto da frota total de aeronaves da aviação geral brasileira seja destinada para usos empresariais e que, nos próximos 10 anos, o Brasil representará de $5 \%$ a $7 \%$ da demanda mundial do setor.

O negócio de aeronaves executivas tem sido incentivado não só por companhias aéreas prestadoras do serviço, mas também por fabricantes de aviões que aumentam no mercado a disponibilidade de jatos menores e mais baratos que aeronaves para voos comerciais. Atualmente, empresários têm demonstrado interesse em investir seu capital na aquisição de frota para prestação desses serviços, mas geralmente não possuem experiência na área de aviação.

Neste contexto, os fabricantes de aeronaves, como, por exemplo, a Embraer, oferecem assistência para auxiliar na estruturação do negócio, que rotas operar e quantas aeronaves comprar, a fim de garantir o bom funcionamento. Dessa forma, a fabricante de aeronaves consegue, não só orientar os investidores, mas também 
avaliar cada possível negócio e priorizar e escolher para quem deseja vender suas aeronaves. Para a fabricante, é de extrema importância que o negócio do cliente prospere, pois, caso contrário, diante de dificuldades financeiras, os pagamentos das aeronaves são suspensos e as aeronaves usadas são colocadas à venda no mercado, desvalorizando assim o preço das aeronaves novas.

A aviação executiva compete não só com companhias aéreas tradicionais e com companhias aéreas de baixo custo, mas também com o transporte rodoviário e ferroviário, principalmente nos Estados Unidos e na Europa, onde a oferta dos demais meios de transporte é grande e concorre diretamente com o transporte aéreo de passageiros. Cabe aos operadores além de garantir 0 atendimento à necessidade de transporte do passageiro, torná-lo mais atrativo que as demais opções, oferecendo um serviço diferenciado e eficiente.

Gerenciar este tipo de serviço não é tarefa simples. A demanda é desconhecida e imprevisível, a tripulação trabalha sob regras específicas de jornadas que variam de acordo com a região de atuação, a manutenção é programada e deve ser feita em determinados locais e grande parte dos custos do negócio é arcada pelo operador. A viabilidade econômica depende de alta utilização das aeronaves e por isso é essencial que toda a logística de operação seja muito bem planejada. O sistema como um todo é complexo, o ambiente é dinâmico e permite milhares de combinações e variações de cenários que devem ser atendidos sem prejuízo à operadora, pois ao cliente é garantida a realização da viagem.

O sucesso da operação depende, dentre outros fatores, da estrutura do serviço e das decisões tomadas durante a fase de planejamento, durante a qual não se possuem dados da operação. Esta pesquisa versa sobre análises que devem ser feitas no âmbito mais geral do planejamento de um negócio de jatos compartilhados. O desenvolvimento da ferramenta objetiva fornecer informações necessárias para auxiliar na tomada de decisões estratégicas que envolvem a escolha da frota e, dessa forma, proporcionar ao analista uma visão geral da complexa operação. 


\subsection{Objetivo do trabalho}

A presente pesquisa visa ao desenvolvimento de uma ferramenta para análise e planejamento de uma empresa que administra jatos compartilhados. A ferramenta, ambientada em planilha eletrônica, serve como auxílio nas decisões estratégicas da empresa, tais como escolha das bases de operação e dimensionamento da frota.

É proposta uma abordagem composta de duas fases, que envolvem a simulação das demandas diárias de solicitações de voos, para contornar as dificuldades impostas pela imprevisibilidade da demanda, e a otimização da alocação de aeronaves para o período simulado, através da resolução de um problema de fluxo em rede de custo mínimo a fim de determinar de quais bases devem sair as aeronaves para atender a cada voo. Dessa forma, tem-se informações sobre o número de aeronaves utilizadas em cada base, os voos ociosos de reposicionamento e consegue-se determinar o impacto da escolha dos locais de base no tamanho da frota e no reposicionamento de aeronaves.

Através dos resultados obtidos pela ferramenta, é possível a avaliação do desempenho do modelo de negócio da empresa em sua fase inicial de planejamento estratégico e tático e o estudo de configurações e políticas operacionais antes de sua implantação.

Além das empresas que oferecem esse serviço, a ferramenta proposta pode ser utilizada por fabricantes de aeronaves a fim de verificar a viabilidade de um novo negócio por parte de um potencial cliente, tanto objetivando priorizar clientes em cenários de demanda elevada, como também de modo a evitar fornecer aeronaves para clientes que possam vir a enfrentar dificuldades financeiras que acarretem a sua devolução, algo bastante indesejável para os fabricantes e financiadores desses investimentos. 


\subsection{Estrutura do trabalho}

Este trabalho está organizado em 6 capítulos.

O Capítulo 2 apresenta uma revisão bibliográfica de problemas semelhantes ao abordado, com trabalhos que tratam de programação de viagens e alocação de jatos compartilhados. No capítulo são citadas também fontes sobre abordagem conjunta de modelos que envolvam simulação e otimização, conforme a metodologia desta pesquisa.

No Capítulo 3 é detalhado o problema de jatos compartilhados. Mais especificamente, é estruturado o problema com a caracterização das variáveis, das restrições e dos parâmetros adotados. Na sequência, é apresentada a metodologia de solução proposta.

O Capítulo 4 relata a construção da ferramenta no ambiente de planilha eletrônica. São apresentados os dados de entrada necessários e sua organização nas planilhas, além da interface em VBA que foi desenvolvida para automatizar a ferramenta e para assegurar seu correto funcionamento.

O Capítulo 5 contém testes de desempenho da ferramenta, aplicados em casos práticos de jatos compartilhados no Brasil e nos EUA. São ilustradas algumas análises que podem ser feitas com os resultados advindos da ferramenta, tais como os impactos provocados pela escolha das bases e modificações na frota.

Finalmente, o Capítulo 6 apresenta conclusões e recomendações para a continuidade da pesquisa. 


\section{REVISÃO BIBLIOGRÁFICA}

Este capítulo apresenta uma revisão da literatura acerca do transporte aéreo de passageiros por jatos compartilhados. São abordadas pesquisas focadas na solução do problema de jatos compartilhados e também trabalhos sobre a metodologia utilizada nesta pesquisa, que consiste na integração de simulação e otimização.

\subsection{O problema na literatura}

Thurber (2009b) relata que, em 1986, um empresário chamado Richard Santulli criou nos Estados Unidos a NetJets, a primeira empresa provedora do serviço de operação de jatos executivos compartilhados. Santulli deixou a empresa em 2009, mas a NetJets permanece até os dias de hoje como a maior operadora na aviação executiva. Porém, não é a única, nos EUA há outras 4 grandes operadoras que demandam pesquisas para melhorar sua operação e reduzir os custos.

O primeiro artigo científico escrito sobre jatos compartilhados foi o de Keskinocak e Tayur (1998) (Yao et al., 2008 e Yang et al., 2010). A partir de um problema real de aeronaves de propriedade compartilhada, os autores se desenvolveram uma solução para programar os voos das aeronaves de maneira que os custos operacionais e as multas aplicadas em caso de não atendimento dos clientes fossem minimizados. Após a descrição do problema e de uma boa revisão bibliográfica de problemas similares, os autores apresentaram 3 casos de jatos compartilhados com frota homogênea que foram resolvidos de formas distintas.

Os autores consideraram que a agenda de voos é conhecida previamente e focaram seus esforços em determinar quais voos devem ser atendidos e por qual aeronave disponível da frota. Estruturou-se um caso de pequenas dimensões (até 20 aeronaves e 50 viagens), modelado como um problema de fluxo em rede de mínimo 
custo que obteve solução ótima e foi resolvido utilizando-se o pacote de otimização CPLEX.

Para os outros dois casos, maiores que o anterior e que, devido ao grande número de variáveis, não poderiam mais ser resolvidos pelo CPLEX, foram utilizadas heurísticas que proporcionaram soluções sub-ótimas, mas com tempos de processamento reduzidos. Os autores elaboraram problemas operacionais que abrangeram até 20 aeronaves e 30 viagens para 3 dias de programação e compararam os resultados obtidos pelas heurísticas com a solução ótima. Com 10 aeronaves, a diferença entre a solução ótima e a das heurísticas foi de 1\%. Para problemas com 20 e 30 aeronaves a diferença foi de $2 \%$ em relação à solução ótima. Foram testados 205 problemas e o desvio médio das soluções foi de 1,6\%.

Entretanto, o trabalho de Keskinocak e Tayur (1998) abrangia apenas operação com frota homogênea e, com base nisso, Martin et al. (2003) complementaram o problema operacional de alocação de aeronaves com a adoção de frota heterogênea e inclusão das restrições de tripulação. Foi desenvolvido um sistema para auxiliar uma empresa a otimizar a programação da frota para atender aos seus clientes. $O$ sistema, composto por dois softwares, aloca as aeronaves aos voos (software Flight Ops) e essa programação dos jatos é utilizada como dado de entrada para distribuir a tripulação dentre os voos (software Schedule Miser).

No trabalho de Martin et al. (2003), a alocação das aeronaves teve sua modelagem baseada em um problema de programação de veículos com múltiplas bases (do inglês MDVSP - Multiple-depot vehicle scheduling problem). Cada aeronave é designada a uma base de onde sai no início da operação e foram acrescentadas as restrições de manutenção e de voos programados ao problema. É criada uma agenda que coordena frota e tripulação. Uma equipe de tripulação é designada para certa aeronave de determinada base, durante a operação. Quando a tripulação não está trabalhando, a aeronave fica parada.

Depois de formulado o problema, é feito um pré-processamento dos dados no qual as soluções que não são viáveis, ou seja, que violam alguma das restrições de descanso de tripulação ou de manutenção programa de aeronave, são eliminadas para reduzir as dimensões da formulação e o espaço de procura de soluções pela 
heurística. Através do pacote de otimização CPLEX encontra-se a solução de menor custo de operação.

Essa solução encontrada não é ótima, pois trata a programação das aeronaves e a alocação da tripulação separadamente. Entretanto, é uma solução que obedece a todas as restrições da FAA (sigla de Federal Aviation Administration), agência que regula a aviação civil nos EUA, e é aceitável considerando-se as características da operação. A empresa norte-americana Flight Options adotou o sistema proposto por Martin et al.(2003) em 2000 e no primeiro ano de uso, o mesmo possibilitou reduzir em $18,7 \%$ os voos vazios de reposicionamento de aeronaves e economizar cerca de 4,4 milhões de dólares norte-americanos.

Hicks et al. (2005) relatam como a companhia de jatos compartilhados Bombardier Flexjet organizou seu sistema de tomada de decisões para otimizar sua operação. Com o objetivo de maximizar o uso das aeronaves, da tripulação e das instalações físicas, foram integrados os sistemas previamente independentes de alocação de tripulação, alocação de aeronaves e programação de viagens.

De acordo com os autores, quando a FlexJet iniciou seu negócio de aeronaves compartilhadas, a programação das aeronaves e da tripulação era feita manualmente. Com o crescimento da operação, a alocação diária das aeronaves era modelada como um problema de fluxo em rede e resolvido com o pacote CPLEX. Entretanto, quando a frota ultrapassou 80 aeronaves, o modelo não conseguia atender à todas as restrições. Quando o modelo considerava poucas regras de trabalho da tripulação e restrições de manutenção das aeronaves a resposta demandava tempo excessivo para decisões operacionais e resultava em soluções inadequadas.

Assim, surgiu a necessidade de outra maneira para otimizar a operação e os autores desenvolveram um novo sistema para integrar a otimização da alocação da frota $\mathrm{e}$ da tripulação composto por 3 pacotes: Altitude VBS, Altitude PBS e TOSCA. O pacote Altitude VBS controla o calendário anual dos funcionários da empresa e define quando cada funcionário terá férias, quando estarão em treinamento e quais funcionários estão disponíveis para trabalhar mês a mês. Conhecidas as equipes disponíveis para cada mês, o pacote Altitude PBS determina as folgas e os dias de 
trabalho de cada funcionário para aquele mês. Assim, o sistema tem as informações de quem e de quando a tripulação está disponível para voar e obedece às regras de trabalho da tripulação.

O pacote TOSCA, através de uma heurística com geração de colunas, determina o tipo de aeronave para atender cada voo, em qual base deve estar cada aeronave e quando deve-se realizar manutenção, procurando minimizar o custo total de operação. Define também quando deve haver troca de tripulação para cada aeronave e em qual base deve ser realizada essa troca.

A integração entre frota e tripulação é realizada pelo pacote COMPASS, que verifica no Altitude PBS qual a equipe disponível para determinado dia e aloca a tripulação para cada aeronave listada no TOSCA. Na análise, o software COMPASS considera a qualificação técnica das tripulações disponíveis (nem todos podem atender a todos os voos), os custos de deslocamento das tripulações que tenham que atender a voos em outras localidades e tenta conciliar períodos de manutenção das aeronaves com os períodos de descanso das tripulações. O método de geração de colunas também é utilizado para reduzir as dimensões do problema e o software retorna uma solução sub-ótima de mínimo custo operacional.

Esse sistema integrado desenvolvido por Hicks et al. (2005) proporcionou para a empresa economia de cerca de 27 milhões de dólares por ano e a utilização as aeronaves aumentou em 10\%.A integração dos sistemas permitiu que áreas críticas da empresa, como manutenção de aeronaves e programação de tripulação, tivessem maior interação. Isto facilitou a visão geral para planejamentos de longo prazo, entretanto o modelo desenvolvido foi de programação operacional e não de planejamento.

Stojkovic et al. (2006) abordaram o problema de alocação de aeronaves também com foco na fase operacional. De acordo com os autores, apesar das companhias aéreas determinarem com antecedência as programações de frota e de tripulação, problemas que ocorrem diariamente podem afetar gravemente todo o sistema operacional da empresa. Imprevistos como condições climáticas, turbulências nas rotas, dificuldades técnicas, atrasos de tripulação, congestionamentos nos aeroportos, greves e etc. podem provocar atrasos ou cancelamentos de voos, além 
de trocas de aeronaves e de tripulação, o que provoca impactos na empresa por vários dias.

Os autores propuseram um modelo baseado em fluxo em rede de mínimo custo para contornar os imprevistos diários alterando somente os horários de partida e de chegada e a duração dos voos, sem afetar a alocação das aeronaves e os itinerários da tripulação. Cada voo foi representado por um nó de origem, um de destino e um arco de ligação. Para cada possível alteração foi criado um arco adicional ao do voo, incluindo manutenção, serviços de pátio, transferência e descanso de tripulação e conexão de passageiros. A formulação buscou minimizar o custo total, obedecendo a restrições temporais de disponibilidade das aeronaves e de tripulação.

Porém, assim como todos citados anteriormente, o trabalho de Stojkovic et al. (2006) tratou o problema com ênfase na fase operacional, onde as bases e o dimensionamento da frota já haviam sido determinados, ao contrário do que acontece com o problema abordado neste trabalho.

Sherali et al (2006) apresentam um resumo com modelos desenvolvidos para o problema de alocação de frota encontrados na literatura. Para a alocação de tipos de aeronaves, cada um com capacidade diferente, aos voos agendados, consideraram-se capacidades, disponibilidades dos equipamentos, custos operacionais e rendimentos possíveis.

O artigo de Sherali et al. (2006) mostra um tutorial com abordagens para o problema de alocação de frota que incluem processos de decisão como agendamento de voos, manutenção de aeronaves e alocação de tripulação. Segundo os autores, o problema é tipicamente abordado como um modelo de fluxo em rede e há duas principais tendências na construção da rede: uma na qual os arcos representam conexões na rede ("connection networks") e outra na qual os arcos representam voos ("time-space network")

Espinoza et al. (2008) apresentam uma abordagem de fluxo em rede de mínimo custo para realizar a programação diária de jatos de uma empresa que propunha um serviço de táxi aéreo. O cliente podia solicitar um voo com no mínimo 1 dia de 
antecedência, porém, deveria dividir a aeronave com outros passageiros pagantes com o mesmo destino, situação que não ocorre no serviço de propriedade compartilhada. O problema analisado objetivava alocar aeronaves e tripulação aos voos, com o objetivo de minimizar os custos.

De acordo com Espinoza et al. (2008), para administrar um serviço de táxi aéreo, dois componentes básicos são necessários:

1. Um sistema online que aceita ou rejeita um pedido de voo de um cliente e informa se determinada viagem pode ser realizada e a que preço.

2. Um sistema offline que determine, com mínimo custo, os itinerários das aeronaves e da tripulação para o dia seguinte.

O sistema online de agendamento de voos era baseado em uma heurística de busca que procura, dentre a agenda disponível, se aquele voo pode ou não ser realizado. Ainda segundo Espinoza et al. (2008), há duas abordagens naturais para o problema de alocação de aeronaves do sistema offline. A primeira envolve a modelagem como um problema de fluxo multi-produto em uma rede espaço-tempo de mínimo custo ("integer multicommodity flow problem on a time-space network"). Entretanto, o tamanho da rede e a quantidade de restrições inviabilizam a aplicação desta abordagem para problemas reais de grandes dimensões. A segunda abordagem baseia-se em métodos de geração de colunas em que cada coluna corresponde a um itinerário possível para cada aeronave da frota. Esta abordagem gera um número de variáveis de decisão, uma para cada coluna, que cresce exponencialmente com o tamanho do problema.

Os autores consideraram as duas abordagens, mas nenhuma proporcionou os resultados desejados. O modelo de fluxo em rede só resolvia problemas para uma frota de até 4 aeronaves e o modelo de geração de colunas não conseguia resolver o problema para frota de 20 aeronaves em tempo razoável. Como alternativa, desenvolveram uma nova abordagem com base na modelagem de fluxo em rede, em que um algoritmo agrega nós da rede, reduzindo-a de forma que os arcos representam rotas parciais a serem voadas pelas aeronaves, mas as variáveis correspondem às rotas completas. Essa modelagem gera uma solução viável para o 
problema e um algoritmo de busca na vizinhança que seleciona uma solução melhor (menor custo total) a partir dessa solução viável. Experimentos computacionais mostraram soluções aceitáveis para problemas com até 150 aeronaves

O trabalho de Espinoza et al. (2008) dedicou-se ao problema de taxi aéreo, que apresenta uma diferença básica em relação ao problema de propriedade compartilhada: no taxi aéreo o sucesso da otimização consiste em agregar solicitações de viagens para serem atendidas por um mesmo voo, enquanto na propriedade compartilhada os clientes não dividem uma aeronave durante um voo. Entretanto, apesar das distinções no ponto de vista operacional e, consequentemente, nas restrições da modelagem dos problemas, a abordagem utilizada pelos autores de modelagem de fluxo em rede também é adequada para o caso de propriedade compartilhada, como pôde ser visto nos trabalhos citados anteriormente.

De acordo com Yao et al. (2008) os cinco maiores gastos operacionais de uma empresa que presta o serviço de propriedade compartilhada são:

1. Custos de reposicionamentos - quando aeronaves precisam realizar voos vazios, ou seja, sem clientes, para chegar a um local de onde um cliente deseja partir

2. Custos de upgrade - quando uma aeronave maior (ou de categoria superior) precisa fazer um voo que poderia ser feito por uma aeronave menor

3. Custos de transporte de tripulação - decorrentes da necessidade de deslocar a tripulação para o local de partida de um voo (ou de volta à sua base de operação) utilizando aviação comercial

4. Custos de hora-extra - quando a tripulação precisa trabalhar além do horário previsto

5. Custo de aluguel - caso não haja aeronave disponível para atender a um cliente, torna-se necessário alugar uma aeronave de outra empresa para realizar o voo. 
Yao et al .(2008) fazem uma extensa revisão bibliográfica sobre alocação de jatos compartilhados e apresentam com detalhes as características do problema. Propõem uma metodologia com geração de colunas para otimizar a operação de um período de 3 dias. São feitas também análises do ponto vista econômico para avaliar o impacto que alterações operacionais e táticas como programar ou não a manutenção das aeronaves e variação da demanda têm na operação diária do serviço. Os resultados obtidos com a metodologia desenvolvida pelos autores foram comparados com dados reais de operação da empresa norte-americana Citation Shares.

$\mathrm{Na}$ comparação dos resultados, os autores perceberam que quando as aeronaves entram em manutenção não-programada, os gastos operacionais aumentam significativamente. Perceberam também que se houver uma flexibilidade de 1 hora nos horários de partida dos voos (ou seja, uma tolerância de mais ou menos uma hora do horário programado), os custos de operacionais são reduzidos, pois é possível acomodar melhor os voos de reposicionamento na programação diária das aeronaves, além de reduzir a necessidade de alugar aeronaves de terceiros para atender a voos

\subsection{Trabalhos correlatos}

Como pôde ser visto, a literatura sobre jatos compartilhados aborda o assunto com foco em otimizar a operação. Todos os trabalhos discutidos anteriormente basearam-se em situações reais de empresas prestadoras do serviço e procuraram fornecer soluções de menor custo operacional àquelas aplicadas antes dos estudos. Não obstante, nenhuma pesquisa trata do tema com enfoque no planejamento estratégico. As informações de quantas bases devem ser utilizadas, onde localizar as bases, em que região operar e qual tamanho da frota são conhecidas previamente ao estudo e não há discussão sobre o impacto de como essas decisões afetam a operação do serviço. 
Este trabalho objetiva propor uma ferramenta de auxílio ao planejamento estratégico e tático de uma empresa de jatos compartilhados para fornecer informações que orientem as decisões de escolha de bases, dimensionamento da frota e custos de operação. Nesta fase de planejamento, o negócio não existe e os dados de demanda não estão disponíveis; não há uma lista de voos para serem atendidos no horizonte de planejamento. Para contornar esta dificuldade, adotou-se uma metodologia utilizada na área de Pesquisa Operacional que consiste do emprego conjunto de simulação e otimização.

Morito et al. (1999) utilizaram uma abordagem conjunta de simulação e otimização para resolver um problema logístico do serviço postal japonês. Justificaram que a programação matemática por si só é fraca em expressar fatores que representem o dinamismo do sistema, a não linearidade e a aleatoriedade de eventos, enquanto a simulação é falha em sua capacidade de otimização.

A abordagem natural para eles foi a de unir as duas ferramentas com pontos fortes e fracos complementares, onde a otimização gera uma solução que é simulada e os resultados da simulação são usados para identificar restrições a serem satisfeitas e adicionadas ao modelo de otimização para outra rodada, em um procedimento iterativo até que a solução seja aceitável.

Os passos para aplicação da metodologia de Morito et al .(1999) são:

1. Construção do modelo básico: construção de um modelo básico de otimização que considera os fatores essenciais do problema e também de um modelo de simulação que pode incluir detalhes do sistema.

2. Otimização: resolução do modelo de otimização e obtenção de uma solução "ótima"

3. Simulação: Simulação da solução "ótima" obtida no Passo 2, e avaliação de sua desempenho para verificação se a solução é viável ou não. 
4. Formulação de restrições: se a solução é viável, a verdadeira solução ótima do sistema completo foi encontrada. Caso contrário, identificação das restrições necessárias para tornar a solução viável. Adição das restrições ao modelo matemático e retorno ao Passo 2 para nova otimização.

Diaz e Pérez (2000) estudaram o problema do transporte de cana-de-açúcar em Cuba, que na época produzia, em média, mais de cinco milhões de toneladas de açúcar anualmente. A operação logística da colheita envolve o corte e o transporte de até 50 milhões de toneladas por ano, milhares de trabalhadores, dezenas de máquinas de corte, centenas de tratores e de caminhões em todo o país. Dessa forma, a operação exige planejamento e coordenação para evitar o desperdício dos recursos.

Os autores aplicaram uma metodologia conjunta de simulação e otimização para identificar os gargalos do sistema de transporte da cana de açúcar, elaborar soluções para estes gargalos e de desenvolver um sistema de suporte à decisão de alocação dos recursos diariamente. A metodologia consiste de um determinado número mínimo de rodadas da simulação para criação de um cenário de operação. Esse cenário é então inserido no modelo de otimização, para que sejam alocados equipamentos e mão de obra. Essa resposta é analisada e é feita uma realimentação do sistema.

O modelo de simulação, desenvolvido no ambiente ARENA, forneceu respostas referentes a indicadores de produtividade dos recursos, tempos de espera e outros critérios de desempenho do sistema. As respostas quantitativas serviram para auxiliar a tomada de decisões por parte do Ministério da Indústria Açucareira de Cuba, tais como a alocação dos maquinários para as fábricas.

Conforme visto anteriormente, a alocação de aeronaves compartilhadas é usualmente resolvida através de heurísticas e métodos de relaxação linear, que não fornecem soluções ótimas. Quando se adota a modelagem como fluxo em rede de mínimo custo, a maior dificuldade é de contornar as grandes dimensões que o problema assume quando a frota aumenta e muitos voos precisam ser atendidos. 
Silva (2001) trabalhou com modelos de fluxo em rede para tratar o problema de programação de veículos no sistema de transporte publico. Devido às dimensões do problema, o autor estudou duas técnicas para resolver o problema. Uma consistiu na modelagem como um problema de fluxo em rede com mínimo custo associado a uma técnica de redução de arcos, onde os arcos com altos custos eram substituídos por outros arcos já existentes na rede para reduzir a dimensão total da rede.

A outra técnica adotada por Silva (2001) foi a adaptação do principio de Geração de Colunas da Programação Linear à teoria de fluxo em redes, onde a partir dos custos de uma solução corrente, determinava-se se um arco deveria ou não entrar no domínio para a próxima solução. Para resolver os problemas subjacentes, o autor utilizou o algoritmo primal-dual Out-of-Kilter.

Lawley et al. (2008) apresentam uma abordagem utilizando modelo de fluxo em rede para problemas de programação de entregas de cargas em uma malha ferroviária. $O$ problema de entregas de cargas ferroviárias, tais como carvão e ferro, é uma variante do problema mais geral de alocação de vagões de frete e de programação de trens e é de grande importância para ferrovias comerciais devido ao grande volume de negócios que representa, além de ser complicado por explorar todos os recursos da ferrovia e necessitar minimizar o congestionamento de trens, maximizar a capacidade de atendimento e reduzir as incertezas nos padrões diários de chegadas e partidas dos trens.

De acordo com a bibliografia apresentada por Lawley et al. (2008), modelos espaçotempo são comuns para a modelagem de programação de trens e podem facilmente ser adaptados para lidar com diferentes situações práticas enfrentadas por operadores de ferrovias. O modelo proposto pelos autores é de uma rede espaçotempo, com programação inteira, onde a representação física da rede (fornecedores, clientes, estação, trilhos, etc.) é repetida para cada período de tempo ou de planejamento, dentro de um horizonte de planejamento finito para tomada de decisões táticas.

Com objetivo de maximizar a demanda atendida na ferrovia e minimizar tempos de espera para carregamento e descarregamento das cargas, o modelo consiste de um conjunto de caminhos pela rede que representam os movimentos de um conjunto de 
trens pelo espaço e ao longo do tempo. Foi proposto um algoritmo para resolver esse modelo e estudar suas características computacionais sob um conjunto de demandas realistas e dados de ferrovias.

A pesquisa dos autores difere da bibliografia por eles citada no artigo por considerar simultaneamente capacidades da malha ferroviária, horários de operação, rotas preferenciais e atrasos por congestionamento, o que permitiu a obtenção de soluções altamente detalhadas para planejamento de curto prazo da operação. A metodologia de solução envolve uma heurística para dividir o problema em subproblemas, resolve-los separadamente e assim obter uma solução viável em tempo razoável.

Fink e Reiners (2006) adotaram uma modelagem de fluxo em rede de mínimo custo para otimizar a utilização da frota de uma locadora de carros alemã. As decisões eram de curto prazo (até 2 semanas) para otimizar o transporte e a alocação dos veículos e manter um alto nível de serviço. Os processos logísticos estudados pelos autores abordam o ciclo de vida de um veículo: sua compra e incorporação à frota, alocação a uma das estações de aluguel, transferências entre estações e a sua remoção da frota.

Decisões táticas e estratégicas, tais como as de localização das estações e os tipos de veículos da frota, não foram analisadas. Assim como no caso de aeronaves compartilhadas, a demanda é imprevisível e varia diariamente. Alguns clientes reservam a locação com antecedência enquanto outros alugam veículos sem aviso prévio. Além disso, os clientes podem locar um carro determinada estação e devolve-lo em qualquer dia e em qualquer outra estação, mesmo que esteja localizada do outro lado do país. Por isso, os autores adotaram uma abordagem mais robusta, que aloca para cada estação, em cada período de tempo um número suficiente de carros de cada tipo de veículo, sem maiores detalhes operacionais.

O problema de Fink e Reiners (2006) foi modelado e resolvido como fluxo em rede de mínimo custo com objetivo de maximizar os lucros, minimizando os custos variáveis da operação. Para cada período de tempo, a otimização determina de quais e para que estações (nós da rede) sairão os veículos (variáveis de fluxo) e quantos veículos serão incorporados ou excluídos da frota alocada à cada estação. 
A fim de analisar o modelo desenvolvido, os autores realizaram experimentos com dados reais utilizando um modelo de simulação para validar os resultados obtidos pela otimização para diferentes cenários de demanda. Os resultados indicaram que a abordagem proposta resulta em alta utilização da frota e incrementa de maneira significativa a eficiência das operações.

Acerca do mesmo problema de programação de veículos de locação, Ernst et al. (2010) apresentam uma heurística, baseada no método de relaxação Lagrangeana, que divide o problema geral em um conjunto de grandes problemas de alocação de veículos modelados como fluxo em rede, com restrições que conectam esses problemas. Os autores abordaram o problema do ponto de vista operacional, onde deveriam decidir para cada solicitação de que base será o veículo, obedecendo às restrições de disponibilidade e manutenção.

O trabalho apresentado foi motivado por uma aplicação real e é atualmente utilizada por companhias que alugam veículos de passeio. Testes em conjuntos de dados de tais companhias mostram a praticidade do algoritmo. Os resultados apresentados pelos autores mostraram que a heurística gera boas programações para a alocação dos veículos e que pode ser implementada de maneira paralela em diversos computadores para reduzir o tempo de processamento para redes maiores e com mais dados, sem prejudicar a qualidade das soluções.

Cunha (2003) retrata um problema real em que gerentes de um banco devem realizar visitas aos clientes. Na véspera do dia de planejamento, as visitas são agendadas e os roteiros de visitas dos gerentes devem ser programados. Os gerentes devem ser distribuídos para atender à lista de clientes com horários marcados no dia seguinte. Tal problema de sequenciamento e programação de visitas assume dimensões que tornam impossível a determinação da solução ótima e a utilização de heurísticas passa a ser necessidade na busca de melhores soluções. Entretanto, particularidades do problema de Cunha (2003) permitiram simplificar o problema de maneira que fosse possível a modelagem como um problema de fluxo em rede de mínimo custo com dimensões reduzidas. Dessa forma, foi implementado um sistema que encontrava a solução ótima para cada dia. 
Galvão Junior (2004) estudou a otimização da coleta de resíduos de madeira para atender a centrais energéticas e decompôs sua abordagem em dois problemas com o objetivo de determinar quais fornecedores atenderiam a qual central e de dimensionar e programar a frota de veículos necessária para realizar as coletas dos resíduos e as entregas às centrais. Galvão Junior (2004) implantou a metodologia desenvolvida em ambiente de planilha eletrônica para resolver os problemas utilizando pacotes comerciais de otimização, de maneira similar ao que pretende-se com a pesquisa desenvolvida neste trabalho.

Caetano e Gualda (2009) desenvolveram um modelo de otimização integrando o problema de alocação de frota e o de programação de voos para companhias brasileiras de aviação regular com atuação regional. O modelo utilizou programação linear inteira e formulação em rede espaço-tempo e exige como dados de entrada a demanda potencial para cada voo e a disponibilidade de aeronaves. Com foco no planejamento tático e estratégico das empresas, a resposta do modelo visa definir voos a serem cumpridos e a oferta de assentos em função da demanda. Os autores obtiveram resultados compatíveis com a realidade de empresas brasileiras.

Zambuzi (2010) tratou o problema da movimentação de contêineres vazios entre portos como um problema de fluxo em rede multi-produto. $O$ desequilíbrio entre as demandas e as ofertas de vazios nos portos e a falta de lucro direto gerado pela movimentação de contêineres motivaram o desenvolvimento de um modelo que considera o transporte marítimo e terrestre dos contêineres entre os portos de forma a reduzir o custo das operações. O modelo de fluxo em rede foi implementado em uma planilha eletrônica e aplicado a um problema real, que mostrou redução significativa no custo total.

Cortes (2010) aplicou modelagem de fluxo em rede para o problema de programação de entrega de concreto produzido em centrais dosadoras. $O$ modelo decide a partir de qual central cada cliente deve ser atendido e o horário de carregamento de cada veículo nessa central para maximizar a receita total. Assim como no caso de Zambuzi (2010), o modelo foi implementado com sucesso em planilha eletrônica como parte de um sistema de apoio à decisão. 
Com base no trabalho de Cunha (2003), a ferramenta proposta nesta pesquisa, implementada em ambiente de planilha eletrônica, engloba um modelo otimização para a alocação de jatos compartilhados como fluxo em rede de mínimo custo que encontra a solução ótima de distribuição das aeronaves para cada dia de operação.

\subsection{Considerações finais do capítulo}

A literatura acerca do assunto de aeronaves compartilhadas é relativamente recente. O primeiro artigo foi publicado em 1998 por Keskinocak e Tayur, onde lidaram com o problema de alocação de jatos com frota homogênea. Desde então, as pesquisas sobre o tema concentraram-se em encontrar soluções para melhorar a operação e alocar frota e tripulação da maneira mais econômica possível.

É indiscutível a importância de otimizar a operação, visto que neste tipo de serviço, os custos são arcados pela empresa que gerencia a operação das aeronaves e precisam ser minimizados. Observou-se que, para atender às restrições reais do problema, a modelagem fica muito complicada e a busca por soluções ótimas tornase impossível, sendo necessário optar por heurísticas para determinar soluções melhores.

Contudo, não foram encontrados na literatura pesquisas que se concentrem no planejamento estratégico de uma empresa que gerencia aeronaves compartilhadas, que é o propósito desta pesquisa. A falta de dados é a maior dificuldade para se avaliar alternativas de planejamento a longo prazo. Para contornar esse empecilho, nesta pesquisa adotou-se a metodologia de integrar simulação e otimização.

O modelo de simulação gera dados representativos da demanda por voos e o modelo de otimização busca a solução ótima para aquele determinado cenário. Os próximos capítulo descrevem a estratégia de solução adotada, a implementação da ferramenta no ambiente de planilha eletrônica e as aplicações práticas da ferramenta. 


\section{CARACTERIZAÇÃo E MOdELAGEM DO PROBLEMA DE ALOCAÇÃO DE AERONAVES COMPARTILHADAS}

O problema objeto da presente pesquisa é baseado na necessidade real de uma empresa que fabrica e comercializa jatos compartilhados no tocante à análise da viabilidade de novos negócios. Mais especificamente, o sucesso de uma nova operação pode ser avaliada a partir da frota necessária, bem como dos voos vazios para reposicionamento de aeronaves. Dessa forma, propõe-se uma ferramenta que permite estimar a alocação de aeronaves para uma dada demanda de voos diários, dimensionar a frota e o reposicionamento de aeronaves, em nível estratégico, de análise de viabilidade de negócios em um horizonte de planejamento de meses e anos, não servindo, portanto, para decisões de cunho mais operacional.

A fim de avaliar a operação, é necessário reproduzir a solicitação dos voos pelos clientes que vão surgindo. Como a ferramenta objetiva trabalhar na fase de planejamento e viabilidade de negócios, a operação pode ainda não existir e a demanda diária de voos não ser conhecida. De forma a contornar essa dificuldade, a estratégia adotada é de reproduzir tal demanda através da simulação de Monte Carlo. Uma vez representada a demanda com os resultados da simulação, necessita-se determinar qual aeronave atenderá cada voo. A lista de voos advinda da simulação é organizada como uma rede na qual os aeroportos são representados por nós e os voos são representados por arcos que conectam os nós. Assim, cria-se um problema de fluxo em rede de mínimo custo onde é otimizado o fluxo de aeronaves pelos arcos da rede.

Nas seções seguintes deste capítulo serão apresentados detalhes do mercado de jatos compartilhados, as principais características e hipóteses consideradas para a formulação do problema, a simulação de Monte Carlo, a construção da rede e o modelo matemático de otimização. 


\subsection{O negócio de jatos com propriedade compartilhada}

As características de operação de um negócio de aeronaves com propriedade compartilhada variam de empresa para empresa e são estabelecidas de acordo com a região de operação. No entanto, algumas características são comuns, pois todas as empresas buscam atender aos objetivos do cliente que adentra um programa dessa natureza: conforto, segurança, garantia de serviço, privacidade e economia de tempo (NetJets Inc, 2008). A partir da solicitação de um cliente, a empresa deve disponibilizar, no horário e no local solicitados, uma aeronave da categoria requisitada e com tripulação capacitada (geralmente, só piloto e co-piloto, além de eventualmente um comissário de bordo, dependendo da política da empresa). A aeronave deve estar abastecida, com a manutenção garantida e um plano de voo autorizado.

As condições de adesão ao serviço dependem da frequência de voos realizados por cada cliente. A título de ilustração, a Tabela 3.1 relaciona o plano de adesão em função das horas voadas em até 5 anos de inscrição no programa de propriedade compartilhada da empresa NetJets, onde a aquisição de uma cota de 1/16, que equivale a 50 horas voadas anualmente, custa aproximadamente 400 mil dólares americanos para uma aeronave de 7 lugares, enquanto que para uma aeronave Gulfstream 500, que tem capacidade para até 19 passageiros, a cota de 50\% (ou até 400 horas de ocupação) custa em torno de 10 milhões de dólares americanos. Em geral, o preço dos programas das diversas empresas varia de acordo com a cota adquirida, mas gira entre 1 a 3 dólares por milha voada (Sharkey, 2006) ou 1500 dólares por voo (Morrison, 2009).

Um dos grandes atrativos do negócio é a possibilidade de um cliente fazer viagens imediatas ou de urgência, ou seja, agendar um voo dentro um curto período de antecedência, e ter garantia de que a viagem será realizada, pois a maior parte das empresas assegura a disponibilidade de uma aeronave com períodos mínimos que vão de entre 4 horas até 2 dias de antecedência no caso de voos para destinos internacionais (Martin et al. 2003; Fractional Life, 2009 e Hicks et al., 2005). Ao adquirir uma cota de uma aeronave compartilhada, o cliente tem assegurado o 
direito de ser transportado em uma aeronave daquela categoria ou superior, mas não necessariamente na aeronave da qual é proprietário, o que permite que aeronaves diferentes possam ser alocadas para o mesmo cliente a cada viagem. Algumas empresas, como a NetJets garantem acesso a toda frota de aeronaves disponíveis não só na região onde o serviço foi contratado, mas em qualquer lugar nas regiões em que a empresa opera (Estados Unidos, Europa e Oriente Médio). Entretanto, durante a realização da viagem, o cliente não divide a aeronave com outro passageiro pagante, embora essa seja uma opção que pode ser acertada, dependendo do modelo de negócio da empresa; existe uma vertente do negócio que oferece descontos a passageiros pagantes com o mesmo destino que dividem a mesma aeronave, conforme apontam Espinoza et al. (2008).

Tabela 3.1 - Relação de cotas de propriedade compartilhada em função de horas voadas

\begin{tabular}{|c|c|c|}
\hline Horas voadas/ ano & Cota adquirida & Total voado em 5 anos \\
\hline 50 horas de ocupação & $1 / 16$ & 250 horas \\
\hline 100 horas de ocupação & $1 / 8$ & 500 horas \\
\hline 200 horas de ocupação & $1 / 4$ & 1000 horas \\
\hline 400 horas de ocupação & $1 / 2$ & 2000 horas \\
\hline 800 horas de ocupação & $8 / 8$ & 4000 horas \\
\hline
\end{tabular}

Fonte: Adaptado de NetJets Inc., 2008

Outro importante apelo do serviço é a vantagem de realizar a viagem com a conveniência da escolha do horário de partida e evitar aeroportos lotados, conexões e todo o desconforto de viajar em uma aeronave comercial, já que os jatos têm acesso a aeroportos menores, menos congestionados e geralmente mais próximos dos destinos finais dos clientes, o que proporciona também economia de tempo. Além disso, o serviço permite acesso a lugares não servidos pela aviação comercial, sendo que os destinos de viagem possíveis podem ou não ser determinados pela empresa. Ou seja, a empresa pode oferecer um serviço com rotas pré-definidas ou as rotas podem ser quaisquer, dentro de uma determinada aérea de operação. 
A empresa que oferece o serviço de propriedade compartilhada gerencia toda a frota e é responsável por todos os custos de manutenção e pela administração da operação. O usuário do serviço oferecido arca com os gastos dos voos agendados, mas cabem à empresa os custos de reposicionamento, que consistem em voos realizados com a aeronave vazia (sem clientes pagantes) com a finalidade de deslocar a aeronave de um aeroporto a outro. Visto que estes voos de reposicionamento, embora necessários para a operação, não são cobrados diretamente do cliente, a empresa deve minimizá-los a fim de reduzir as despesas.

Dessa forma, os serviços oferecidos, a frota disponibilizada e as formas de adesão do cliente têm características particulares de acordo com a empresa gerenciadora.

\subsection{Caracterização das modalidades de operação de aeronaves compartilhadas}

Nesta seção são descritas as três modalidades de operação de aeronaves compartilhadas consideradas nesta pesquisa: uma em que se opera com frota própria homogênea, outra em que se opera com frota própria heterogênea e uma terceira que utiliza frota própria homogênea com opção de aluguel de aeronaves de terceiros para atender a determinados voos.

$\mathrm{Na}$ modalidade de operação com frota própria homogênea, como o nome sugere, são consideradas que as aeronaves são idênticas em termos de desempenho e de capacidade das aeronaves. Ou seja, as aeronaves desenvolvem as mesmas velocidades e possuem autonomia de voo equivalentes e conseguem transportar a mesma quantidade de passageiros. Outra característica do modelo é que o operador é detentor de toda a frota, ou seja, todos os custos de manutenção, seguro e operação são de responsabilidade da empresa operadora e não há a possibilidade de alugar aeronaves externas.

Para a modalidade com frota própria heterogênea assumiu-se que a operação pode contar com dois tipos de aeronaves, distintas por capacidade e desempenho. Cada 
cliente adquire sua cota de acordo com a aeronave desejada e, ao solicitar um voo, deve ser atendido por uma aeronave pertencente à categoria associada ou superior. Assim como no caso de frota homogênea, o operador é responsável por toda a frota, que é própria, e não há opção de alugar aeronaves de terceiros.

A terceira modalidade de operação trabalha com frota homogênea, porém permite que sejam utilizadas aeronaves alugadas para atender a determinados voos. O operador possui uma frota própria, de aeronaves iguais, mas caso seja conveniente, pode alugar aeronave de outra empresa para atender a algum voo.

Vale ressaltar que, embora existam outras modalidades de operação, elas podem ser consideradas extensões das alternativas apresentadas anteriormente. Modalidades como frota heterogênea com mais de dois tipos de aeronaves ou de frota própria heterogênea com opção de aluguel são menos comuns mas podem ser considerados na modelagem proposta sem dificuldades.

As três modalidades de operação consideram também as seguintes premissas:

- Todas as viagens solicitadas devem ser atendidas, ou seja, nenhum cliente que requisite um voo deve ter sua viagem não atendida por falta de aeronave disponível;

- Um cliente não compartilha a aeronave com o outro cliente durante uma viagem; caso dois clientes desejem realizar voos com origem e destino idênticos, no mesmo dia e no mesmo horário, os mesmos não serão alocados na mesma aeronave;

- Para o caso de frota heterogênea, o cliente só pode ser atendido por uma aeronave diferente da solicitada se houver a opção de utilizar uma aeronave de categoria superior, sem prejuízos ao conforto do passageiro e ao horário da viagem. Não é permitido o uso de uma aeronave de categoria inferior à solicitada; 
- Os custos de reposicionamento de aeronaves são do operador; caso aeronaves precisem fazer voos de reposicionamento, sem clientes, os custos diretos são incluídos no cômputo do custo total, sendo, portanto, uma parcela que compõe a função objetivo a ser minimizada;

- A operação é feita somente em uma região pré-determinada. Todas as rotas possíveis são previamente determinadas pelo operador em termos dos locais de origem e destino. A princípio, isso é um fato importante para a simulação a partir da qual vão ser gerados os voos, pois no simulador as rotas a serem cumpridas são sorteadas aleatoriamente dentre uma lista de voos pré-definida;

- Todos os aeroportos têm disponibilidade para receber qualquer aeronave da frota, ou seja, não há restrição de pouso em nenhum aeroporto da área de operação para qualquer tipo de aeronave;

- As bases das aeronaves são os locais que servem de garagem e também onde são realizadas as operações de manutenção. Os aeroportos que servirão de base são pré-definidos pelo usuário para cada cenário analisado. São conhecidos a quantidade de bases, a localização de cada base e o respectivo número de aeronaves disponíveis em cada base;

- Todas as aeronaves devem retornar à sua respectiva base de origem ao final do dia de operação para a realização de manutenção, e também a fim de atender às normas de descanso de tripulação;

- A modelagem considera um "turn around time" (tempo necessário para preparar a aeronave para o próximo voo, incluindo procedimentos que englobam a troca de tripulação, quando for o caso, e o abastecimento da aeronave) que pode variar de $15 \mathrm{~min}$ a $30 \mathrm{~min}$;

- O tempo de viagem de cada rota é calculado em função da distância voada, com base no desempenho da aeronave padrão no caso de frota homogênea e das aeronaves que compõem a frota heterogênea. 
Algumas premissas expostas anteriormente são simplificadoras, tendo em vista a complexidade do problema, a finalidade da ferramenta e o grau de incerteza nos dados de entrada de uma operação que ainda não iniciou. Na prática, algumas restrições podem não ser válidas, mas são razoáveis, dentro da necessidade de simplificação para a modelagem. Assim, ressalvas devem ser feitas na consideração das premissas. Por exemplo, a imposição do atendimento de todas as viagens, é um recurso para determinar qual é a frota realmente necessária para a operação e, na prática, é uma restrição que pode não existir.

Da mesma forma, o custo total de reposicionamento das aeronaves é importante para avaliar a viabilidade do negócio e, portanto, a adoção da premissa de que o operador arca com tais custos é coerente com o objetivo final da ferramenta. Além disso, assumir que não há restrição de pouso em nenhum dos aeroportos da área de operação também é uma medida simplificadora, tendo em vista que, principalmente nos aeroportos de grande movimentação, há restrição de horários para operação de jatos executivos e muitas vezes não há "slots" nem hangares disponíveis para novas operações.

A operação para este tipo de negócio com aeronaves pequenas poderia ser realizada não só em aeroportos, mas também em aeródromos, onde há somente pistas de pouso e decolagem e não necessariamente em um aeroporto, com terminal de passageiros e demais infra-estrutura agregada para receber passageiros e cargas. Entretanto, o termo aeroporto será usado indistintamente ao longo do texto.

Na presente pesquisa, a composição dos custos, foi baseada no relatório publicado pelo Aviation Research Group/ U.S. Inc. (ARG/US). Esse relatório fornece dados relacionados aos custos de operação de aeronaves executivas nos EUA. Os custos considerados são divididos em custos por base de operação e custos por voos. As despesas computadas de cada base são referentes às instalações físicas e à frota alocada em cada base. O custo anual fixo de instalações representa os custos de aluguel de hangar, de despesas administrativas de escritório e outros serviços necessários (limpeza, seguros, etc.). 
Os valores de custo anual da frota alocada em cada base são compostos por custos fixos anuais, tais como seguro de responsabilidade civil, seguros dos equipamentos, autorizações para operação e serviços diversos como manutenção dos softwares, serviços de meteorologia e afins; e por custos de tripulação. De acordo com o que foi informado à autora desta dissertação por uma empresa fabricante de aeronaves, seus clientes normalmente consideram três pilotos e dois co-pilotos para cada aeronave da base.

Os custos por voo podem ser expressos em função da distância voada ou do tempo de voo. Tais custos por voo representam consumo de combustível, valores referentes à trabalhos de manutenção e taxas diversas de operação (que incluem taxas aeroportuárias, catering, suprimentos e despesas de tripulação).

A Figura 3.1 ilustra a composição dos custos seguida nesta pesquisa.

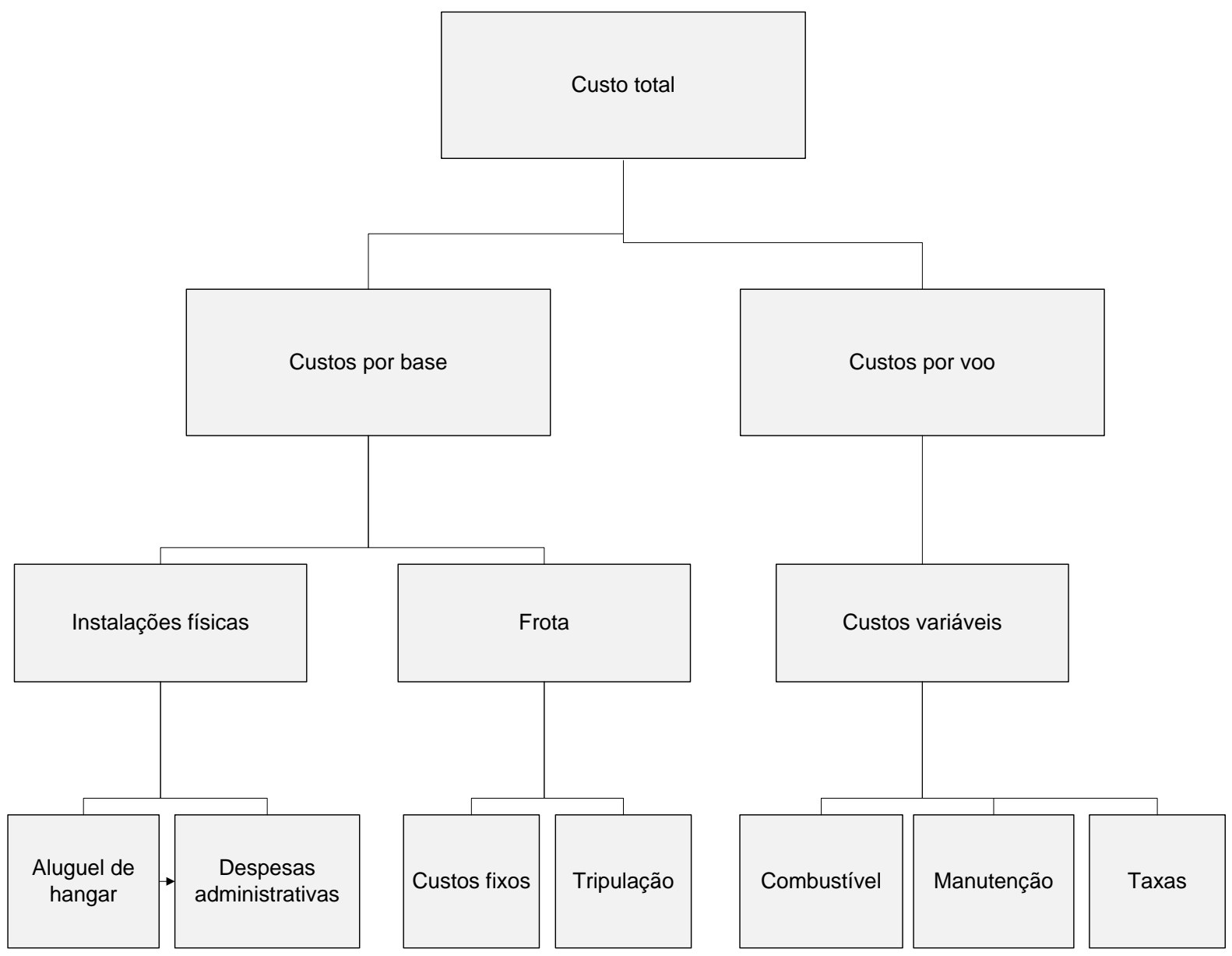

Figura 3.1 - Fluxograma de composição de custos 
Estabelecidas as modalidades de operação e as premissas, parte-se para a modelagem dos problemas para um período de planejamento. Para cada dia do horizonte planejado é gerada uma tabela de voos e determina-se a alocação das aeronaves de modo a minimizar o número de aeronaves necessárias e a distância (ou tempo) total de reposicionamento de aeronaves. Em outras palavras, para cada dia de um horizonte de simulação busca-se otimizar a alocação de aeronaves a fim de minimizar o custo total.

A partir da lista de solicitações de voos a serem atendidos advinda da simulação de Monte Carlo, é construída uma rede para otimizar a alocação das aeronaves. A solução ótima do problema de fluxo em rede determina a frota necessária e os percursos de reposicionamento para cada dia com o mínimo custo total.

\subsection{Metodologia empregada}

A ferramenta proposta opera em duas etapas. A primeira etapa consiste na simulação de um determinado período de dias (estipulado pelo usuário) no qual é gerada uma lista de voos programados para serem atendidos pela empresa. A simulação é feita pelo método de Monte Carlo e utiliza como dados de entrada informações do problema modelado, tais como que rotas pretende operar e o desempenho da frota. A segunda etapa é a alocação de aeronaves para atender à agenda de voos gerada pela simulação. O problema é então otimizado através de fluxo em rede de mínimo custo e são determinadas as aeronaves de cada base para atender aos voos com mínimo custo de deslocamento total.

A ferramenta, envolvendo os modelos de simulação de Monte Carlo e de fluxo em rede de mínimo custo, foi implantada em ambiente de planilha eletrônica do tipo Microsoft Excel utilizando linguagem de programação VBA - "Visual Basic for Applications". Para a otimização foi utilizado o pacote de otimização What's Best! ${ }^{\circledR}$ 9.0, que permite a solução de modelos lineares, não-lineares e inteiros de otimização dentro do ambiente de planilha eletrônica. 
A Figura 3.2 a seguir resume a metodologia empregada neste trabalho.

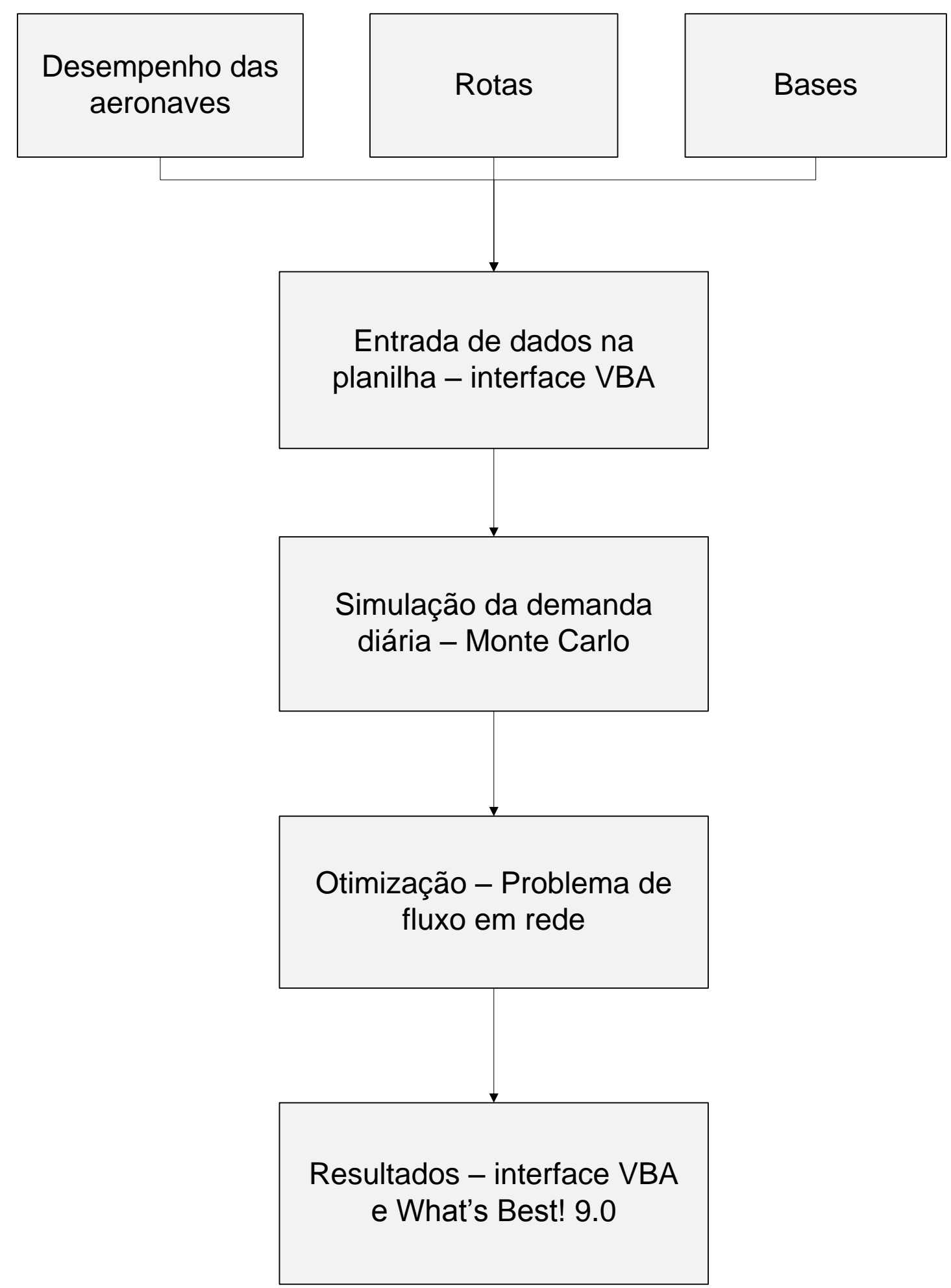

Figura 3.2 - Metodologia de Simulação e Otimização adotada na pesquisa 


\subsection{Geração dos voos diários através de Simulação de Monte Carlo}

A imprevisibilidade da demanda pelo serviço de jatos compartilhados é um dos maiores fatores de incerteza considerados na fase inicial de planejamento das operações e de análise de viabilidade do negócio. Durante a fase de planejamento estratégico, o objetivo principal é o de determinar a necessidade ótima da utilização da frota de aeronaves e da localização bases, além de analisar o modelo de operação mais adequado à empresa.

Antes de implantar o negócio, o operador dispõe de apenas dados gerais sobre o mercado, tais como que rotas pretende operar, mas sem conhecimento da demanda real de voos. A simulação apresenta-se como uma ferramenta para contornar essa imprevisibilidade da demanda e manter o foco no dimensionamento ótimo da frota de aeronaves.

O método de simulação de Monte Carlo data de 1949, quando Nicholas Metropolis e Stanislaw Ulam escreveram sobre a maneira utilizada para contornar a dificuldade de lidar com equações de partículas nucleares. De acordo com Metropolis e Ulam (1949), ao invés de trabalhar com complexas equações da teoria cinética de gases, integrais múltiplas e derivações laplacianas, foi utilizada uma abordagem estatística para simular o comportamento das partículas. Com parâmetros que refletem as distribuições iniciais dos elementos, produz-se um novo conjunto de dados através da geração de valores aleatórios com distribuição probabilística igual à dos dados iniciais. Com esses valores, os parâmetros determinísticos (objetivos da análise) são obtidos algebricamente por equações mais simples.

Segundo os autores, o nome do método foi uma homenagem à cidade de Monte Carlo, famosa por seu cassino, cujos jogos de sorte (tais como roleta e dados) possuem comportamento aleatório. Quando se jogam dados, são conhecidas as faixas de resultados possíveis e suas probabilidades de ocorrência, assim como as faixas de valores possíveis para as variáveis determinísticas da simulação, porém, não é sabido o valor específico para cada jogada ou o valor que cada variável vai adotar em determinado período de tempo. 
No problema abordado nesta dissertação, as solicitações dos clientes têm comportamento aleatório, assim como os jogos dos cassinos. Não é possível prever de antemão que clientes solicitarão voos dia-a-dia, quais rotas serão escolhidas (ou seja, qual o aeroporto de origem e qual o de destino de cada voo) e tampouco os horários de partida dos voos. Conforme o objetivo desta dissertação, o problema é estudado na fase de planejamento e análise de viabilidade do negócio. Nesse contexto, foi estruturado um esquema de simulação baseado em Simulação de Monte Carlo para representar o comportamento das solicitações dos clientes durante a operação de uma empresa de jatos compartilhados.

O objetivo da simulação é gerar uma agenda diária de voos a serem atendidos pelas aeronaves disponíveis que reproduza a operação da empresa. Assim, os parâmetros de saída da simulação devem ser o número de voos por dia, os horários de partida dos voos, os aeroportos de origem e destino de cada voo e o tipo de aeronave solicitada.

O primeiro passo da simulação consiste em estruturar uma base de dados para servir como dados de entrada da simulação. Neste caso, as informações necessárias para alimentar a simulação consistem das rotas operadas, da probabilidade de ocorrência de cada rota, da localização dos aeroportos que podem servir de base e também de dados de desempenho das aeronaves que fazem parte da frota.

A simulação permite obter a tabela de voos de cada dia do horizonte de planejamento. A definição de quantos dias serão simulados depende da análise que será feita. Períodos muito curtos não conseguem proporcionar resultados que representem significativamente a operação e, portanto, as conclusões sobre a localização de bases e números de aeronaves não são representativas.

Além da quantidade de dias do período simulado, cabe ao usuário informar na ferramenta de simulação a quantidade máxima e mínima de voos diários e a probabilidade de solicitação de cada tipo de aeronave, dados que representam a variabilidade diária da demanda. Assim, um dia do período simulado pode ter quantidades diferentes de voos solicitados do que o dia anterior. Na simulação, uma 
solicitação de voo por um cliente é caracterizada por 4 parâmetros: local de origem, horário de partida, local de destino e tipo de aeronave. Os demais parâmetros do voo (tempo de voo e distância voada) são determinados em função desses parâmetros iniciais.

O processo de geração dos voos para cada dia inicia-se com o sorteio de um número aleatório, segundo distribuição uniforme. Tal número, associado aos valores de máximo e mínimo de voos definidos previamente, determina a quantidade de voos do dia.

Em seguida, para cada um dos voos daquele dia, sorteia-se um numero aleatório para definir o horário de partida do voo e outro para escolher a rota dentre uma matriz de possíveis rotas com suas respectivas probabilidades de ocorrerem. Finalmente, sorteia-se o último numero aleatório para o tipo de aeronave.

Conhecidos tais atributos, calcula-se a distância do voo. Cada rota é definida por um aeroporto de origem e de destino, com coordenadas conhecidas. Através de uma fórmula que leva em consideração correções em função da curvatura da Terra, calcula-se a distância de voo entre os dois aeroportos. O tempo de voo é determinado em função da distância: relaciona-se o desempenho da aeronave com a distância voada.

Esses procedimentos, sumarizados na Figura 3.3, são repetidos para cada voo de cada dia, para todos os dias do período de simulação estipulado pelo usuário no início do processo. Ao final desse processo de geração aleatória de voos diários tem-se uma lista representativa de solicitações de viagens de clientes potenciais do negócio. Cada voo tem horário de saída, local de partida e destino determinados. A lista diária de voos é elaborada para o período determinado pelo usuário e, como os dados de entrada da simulação buscam representar características do negócio real, tenta-se reproduzir a demanda para o período. A partir desse ponto, tem-se dados suficientes para a construção da rede diária e para otimizar a alocação da frota de aeronaves para cada dia do horizonte de planejamento. 
Vale ressaltar que o procedimento de geração de voos por simulação de Monte Carlo é genérico o suficiente para acomodar qualquer nível de detalhamento da demanda, tais como variações por tipo de dia da semana, por semana do mês, por mês e por período do ano (férias, festas, etc.) sem perda de generalidade do modelo. Também é importante frisar que o modelo de simulação foi construído para contornar a imprevisibilidade da demanda para o planejamento estratégico de um negócio que ainda não foi implantando. Caso se deseje analisar um caso com demanda conhecida, o procedimento da simulação pode ser eliminado ou adaptado para representar a demanda real.

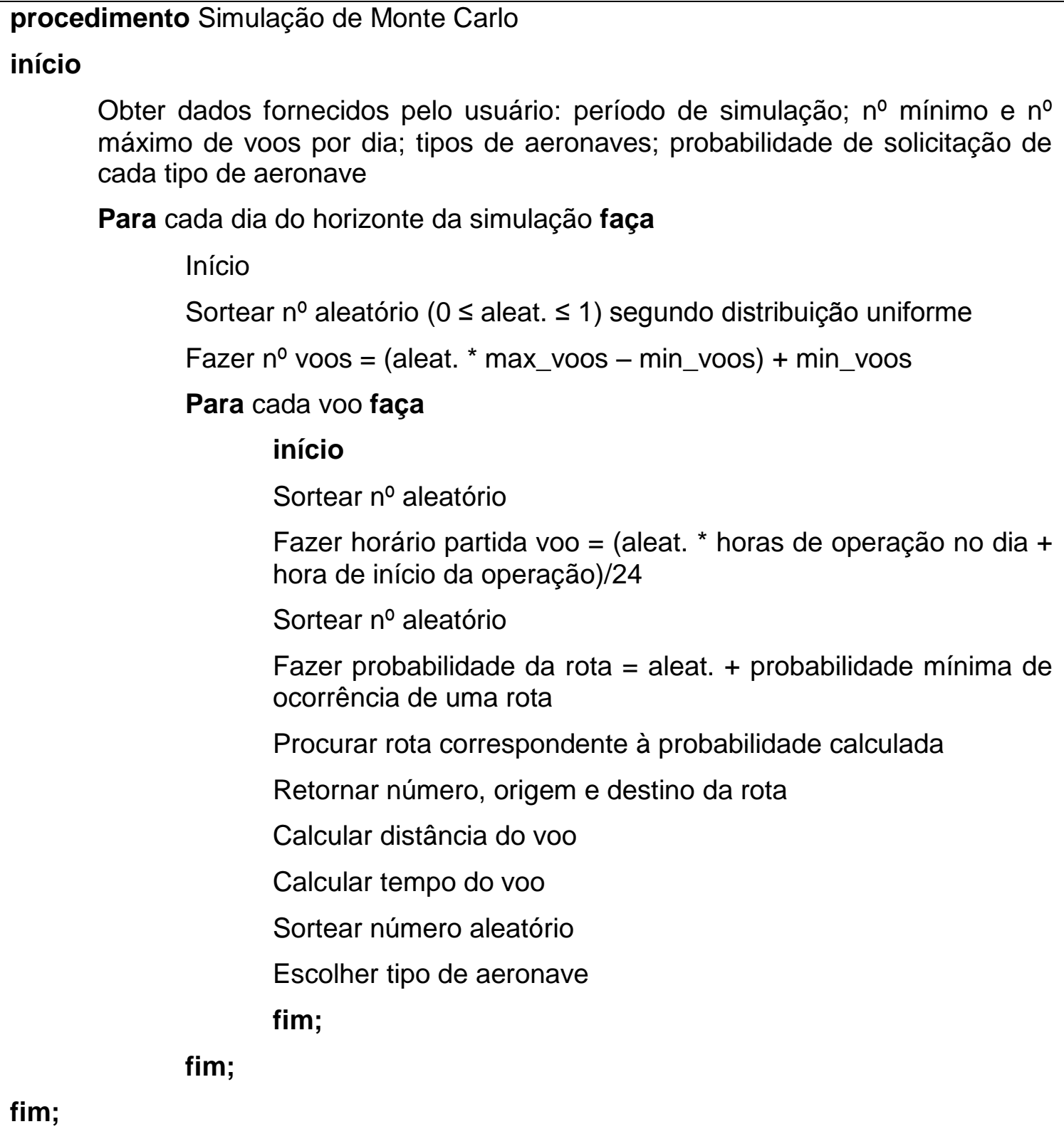
máximo de voos por dia; tipos de aeronaves; probabilidade de solicitação de cada tipo de aeronave

Para cada dia do horizonte da simulação faça

Início

Sortear $\mathrm{n}^{\circ}$ aleatório $(0 \leq$ aleat. $\leq 1)$ segundo distribuição uniforme

Fazer no voos $=$ (aleat. * max_voos - min_voos $)+$ min_voos

Para cada voo faça

início

Sortear $\mathrm{n}^{\circ}$ aleatório

Fazer horário partida voo $=$ (aleat. * horas de operação no dia + hora de início da operação)/24

Sortear $\mathrm{n}^{\circ}$ aleatório

Fazer probabilidade da rota $=$ aleat. + probabilidade mínima de ocorrência de uma rota

Procurar rota correspondente à probabilidade calculada

Retornar número, origem e destino da rota

Calcular distância do voo

Calcular tempo do voo

Sortear número aleatório

Escolher tipo de aeronave

fim;

fim;

fim; 


\subsection{Modelo de fluxo em rede para otimização da utilização das aeronaves}

Conforme visto na seção anterior, ao final do processo de simulação das solicitações de voos para cada dia de operação dentro de um horizonte de planejamento, tem-se como dados de entrada para a otimização uma lista de voos de um dia originada na simulação. Os voos têm rotas com origem e destino conhecidos, horário de partida, tempo de viagem e tipo de aeronave. Todos os voos devem obrigatoriamente ser realizados e as aeronaves podem ser deslocadas de qualquer uma das bases, contanto que retornem para a mesma base no final do dia de operação.

Para o modelo matemático, as bases de operação devem ser definidas antes da otimização. Também deve ser pré-definida a frota de aeronaves alocada em cada base de forma que, no início da otimização, sejam conhecidos quantas aeronaves (e de quais aeroportos) estão disponíveis para atender à lista de voos. Deve-se dimensionar a quantidade de aeronaves para que o número de aeronaves em cada base seja suficientemente grande para assegurar que sejam utilizadas tantas aeronaves quanto necessário em cada dia de modo a obter a solução de mínimo custo. Exceção deve ser feita no caso de alguma base possuir alguma limitação de tamanho que restrinja a quantidade de aeronaves disponíveis para operação.

O problema definido pelo conjunto de voos que necessitam ser operados em cada dia da simulação pode ser estruturado como um problema de fluxo em rede analogamente aos trabalhos de Martin et al. (2003), Keskinocak e Tayur (1998), Hicks et al. (2005), Espinoza et al. (2008). A modelagem em rede é uma maneira eficiente de representar o problema e proporciona ganhos à modelagem e à representação matemática.

O modelo proposto objetiva determinar a distribuição das aeronaves, ou seja, diz de que base vai sair cada aeronave para atender determinado voo e que voos vão ser atendidos por aeronaves reposicionadas. Portanto, essa necessidade de que a solução seja inteira é atendida na modelagem do problema ao impor apenas unidades inteiras de fluxo nos arcos da rede (Ahuja et al. (1993)). 
Para um maior aprofundamento dos conceitos de modelagem como problema de fluxo em rede de mínimo custo sugere-se o trabalho de Ahuja et al. (1993). Aqui são descritos apenas os aspectos mais importantes do modelo e de sua construção. A fim de facilitar a compreensão, foi construído um exemplo prático para cada modalidade de operação estudada neste trabalho: frota própria homogênea, frota própria heterogênea e frota homogênea com opção de aluguel.

\subsubsection{Modelo com frota própria homogênea}

Seja $G=(N, A)$ uma rede espaço-tempo composta por um conjunto $N$ de nós e $A$ de arcos.

O conjunto dos $|N|$ nós é formado pelos aeroportos de origem e destino de cada voo sorteado para aquele dia e pelas bases. Cada nó corresponde a um local (de partida ou chegada) em um determinado horário, de forma que dois voos que tenham os mesmos locais de origem e destino, porém realizados em horários distintos, são representados por nós distintos: um para cada aeroporto e em cada horário. Dois voos com mesmos locais de origem e destino e no mesmo horário, embora improváveis, também são representados por nós distintos com a finalidade de obedecer à imposição de que dois clientes não dividam a mesma aeronave durante um voo, ou seja, dois voos devem ser realizados.

Os aeroportos que são origem e destino de voos fazem parte do subconjunto de Nós_intermediários, enquanto as bases formam o subconjunto Nós_base. Cada voo gerado na simulação é representado por um arco que conecta um nó de origem ao seu correspondente nó de destino em determinado horário. Os voos são classificados em ordem crescente pelo seu horário de partida e recebem uma numeração que vai de $v=1$ a $N V$ voos para aquele dia.

A numeração dos nós está relacionada com a numeração $(v)$ dos voos: o de origem recebe numeração $(2 v)$ e o de destino $(2 v+1)$. Dessa forma, é possível identificar facilmente cada voo durante a otimização. Sabe-se, por exemplo, que o voo 1 corresponde a um arco que liga o nó 2 ao nó 3 ou que o nó 10 é origem do voo 5, cujo nó correspondente à extremidade de destino é 011. 
$\mathrm{Na}$ Figura 3.4 tem-se $N V=5$ voos, numerados de $v=1,2, \ldots, 5$ e indicados, respectivamente, pelos arcos $(2,3),(4,5),(6,7),(8,9)$ e $(10,11)$ que são denominados Arco_voo. Esses voos são gerados no modelo de simulação e ordenados cronologicamente por horário de partida dos voos para cada dia.

Cada Arco_voo de um voo v conecta um nó de origem (2v) ao nó de destino da viagem, $(2 v+1)$. Todos estes arcos devem ser voados por somente uma aeronave e obedecer aos horários estipulados na simulação: horário de partida, tempo de viagem e horário de chegada.

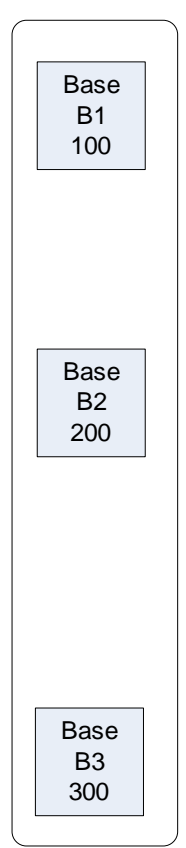

Nós_base

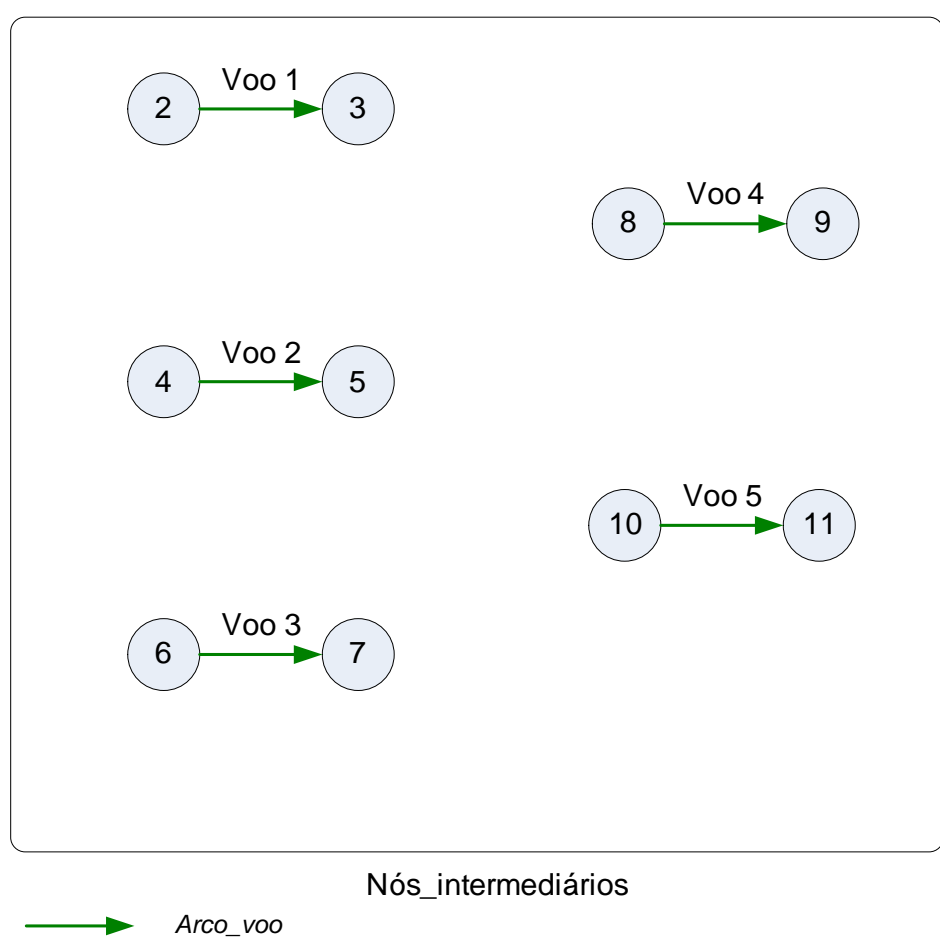

Figura 3.4 - Rede homogênea com nós, bases e voos

Cada base de onde partem as aeronaves e para onde devem retornar no final do dia de operação é representada por dois nós. Antes da otimização, são conhecidas a quantidade de bases $(b)$, a localização e a frota de aeronaves de cada base $\left(f_{b}\right)$. A cada uma das $B$ bases ( $B_{1}$ a $B_{b}$ ) são associados dois nós: o nó (b00) representa a base de partida das aeronaves (nó fonte ou "source") e o outro (b01) representa o destino das aeronaves quando voltam para a respectiva base. Seguindo essa forma de numeração, a base $B_{1}$ é representada pelos nós 100 e 101; a $B_{2}$ por 200 e 201 e assim por diante. 
O próximo passo para a estruturação da rede é a inserção dos arcos que conectam os nós. Todos os arcos têm como atributos: nós de origem e destino, horário de partida, tempo de viagem, horário de chegada e custo. O conjunto de arcos é composto por 4 tipos de arcos: Arco_voo, Arco_base_ida, Arco_base_volta e Arco_reposicionamento.

Os arcos do conjunto Arco_voo, descritos anteriormente, representam os voos da lista gerada na fase de simulação. Tais arcos conectam os nós de origem $(2 v)$ e destino $(2 v+1)$ de cada voo. São criados $N V$ Arco_voo, ou seja, tantos arcos quanto o número de voos da lista originada na simulação.

Os arcos do conjunto Arco_base, por sua vez, são subdivididos em 2 tipos: Arco_base_ida e Arco_base_volta. Os arcos do tipo Arco_base_ida são arcos que ligam os nós de partida das bases (b00) aos nós de origem dos voos $(2 v)$. Para cada nó de origem (2v) de voo são criados arcos a partir de cada uma das bases, gerando $(v * b)$ arcos. Conforme pode ser visto na Figura 3.5, tem-se os arcos do tipo Arco_base_ida ligando cada uma das três bases $\left(B_{1}, B_{2}, B_{3}\right)$ aos nós 2, 4, 6, 8 e 10, correspondentes às origens dos voos 1 a 5 , respectivamente.

Analogamente, os arcos do tipo Arco_base_volta ligam os nós de destino $(2 v+1)$ de cada um dos voos $v$ aos nós de retorno das bases (b01). Assim como nos arcos do tipo Arco_base_ida, cada nó de destino de voo é ligado a cada base por um arco. Esse tipo de arco é necessário para assegurar a restrição de que todas as aeronaves devem voltar às respectivas bases no final do dia. Adicionalmente, essa forma de construção possibilita o retorno das aeronaves a qualquer instante em que não possam ser mais aproveitados para outros voos e não necessariamente no final do dia. No caso do exemplo mostrado na Figura 3.5, os arcos do tipo Arco_base_volta correspondem a ligações dos nós 3, 5, 7, 9 e 11 a cada um dos três nós $(101,201$ e 301) que representam o retorno a cada uma das três bases. 


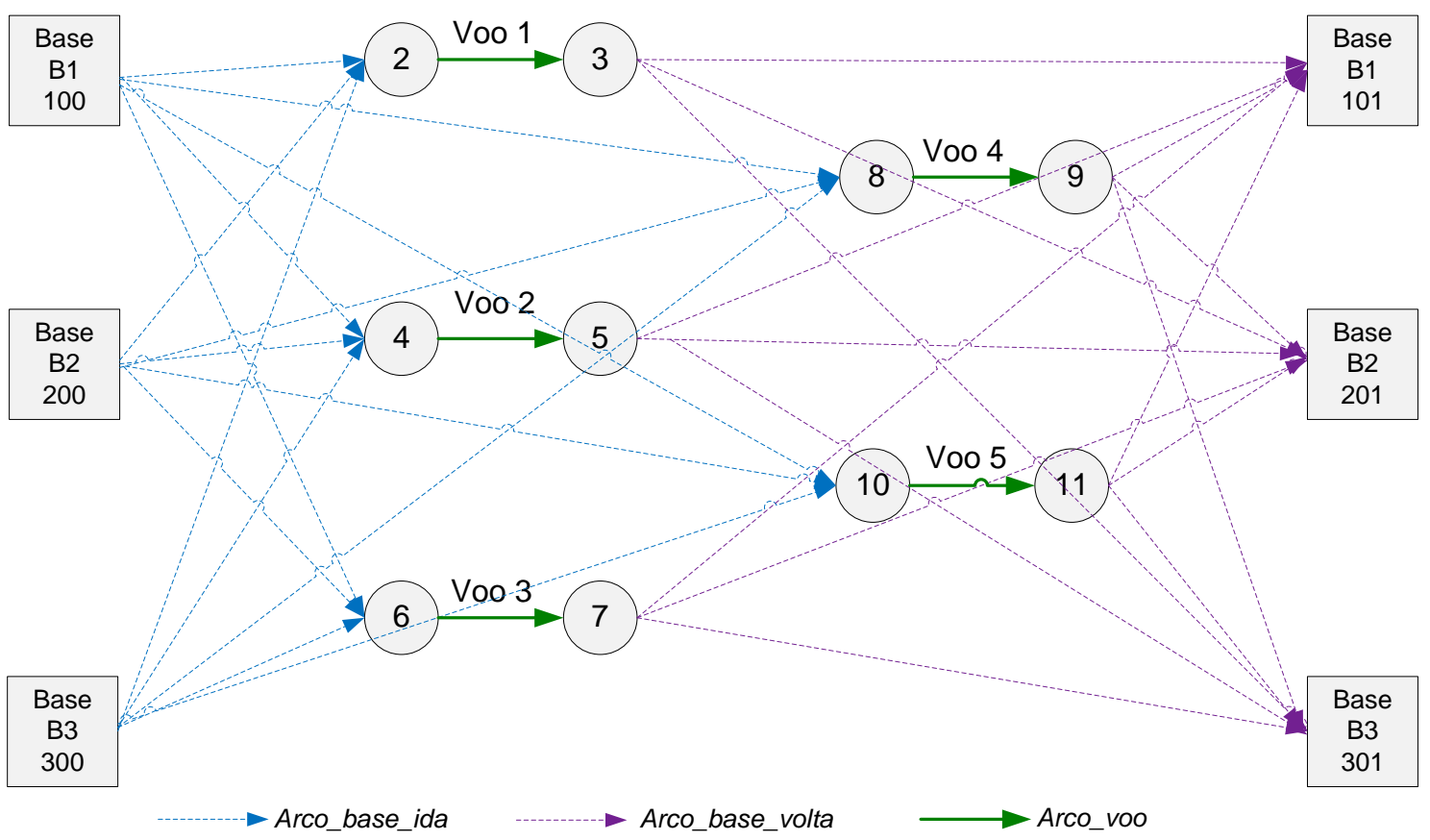

Figura 3.5 - Rede homogênea com Arcos_base_ida, Arcos_base_volta e Arcos_voo

É comum as aeronaves realizarem voos vazios, sem clientes, para reposicionamento. "Deadheading" ou percurso ocioso é o termo que indica os voos vazios de reposicionamento das aeronaves. São voos de conexão, em que a aeronave, após a conclusão de um voo solicitado por um cliente, parte para outro aeroporto para atender a outro voo solicitado por outro cliente. A aeronave tem que sair do nó de chegada de um voo para o nó de origem de outro voo, como pode ser visto na Figura 3.6. Os arcos do conjunto Arco_reposicionamento ligam os nós ímpares $(2 v+1)$ aos nós de origem dos próximos voos.

No exemplo da Figura 3.6, a partir do nó 3 são criados arcos conectando-o aos nós 8 e 10, o que significa que a mesma aeronave que voa o voo 1 pode ser alocada aos voos 4 ou 5, respeitando os respectivos horários de partida. Analogamente, a mesma aeronave que realiza o voo 2 também pode ser utilizada para o voo 4 ou para o voo 5 sem ocasionar atraso na partida do mesmo.

Somente são criados arcos de reposicionamento para voos que obedeçam às restrições temporais que possibilitam o uso da mesma aeronave. A distância entre nós não restringe a criação desses arcos e a viabilidade horária é a única condição limitante à criação dos arcos do conjunto Arco_reposicionamento. Determina-se o horário possível para cada aeronave considerando-se o horário em que a aeronave 
fique disponível após realizar um determinado voo, adicionado ao tempo de viagem vazia até o local de origem de um próximo voo e ao "turn around time", tempo de preparação da aeronave para outro voo. Caso esse horário calculado em que se torna possível a utilização da aeronave seja anterior ao horário de partida do próximo voo a ser atendido, esse arco do conjunto Arco_reposicionamento é criado na rede. É necessário enfatizar que essa condição de viabilidade horária para criação do arco pressupõe que a aeronave seja alocada e possa permanecer aguardando no aeroporto até o horário de partida do voo seguinte a ser voado. Por esse motivo, no exemplo da Figura 3.6 não são criados arcos ligando o nó 3 aos nós 4 e 6 e nem o nó 5 ao nó 6 .

Também vale ressaltar que os arcos do conjunto Arco_reposicionamento criados na rede não representam necessariamente um percurso aéreo. Pode ocorrer de ser viável utilizar, por exemplo, a aeronave do voo 2 para o voo 5 e o nó 5 (destino do voo 2) e o nó 10 (origem do voo 5) serem no mesmo aeroporto. Neste caso, o arco do conjunto Arco_reposicionamento que conecta os nós 5 e 10 representa apenas que a aeronave deve esperar no aeroporto até o horário de partida do próximo voo, sendo sua distância percorrida igual a zero.
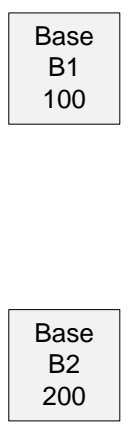

200
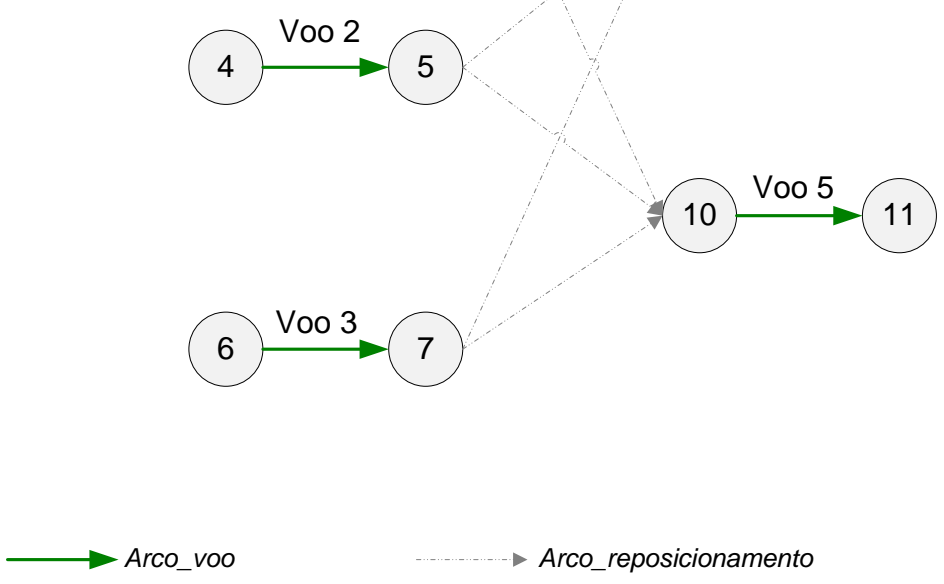

Arco reposicionamento
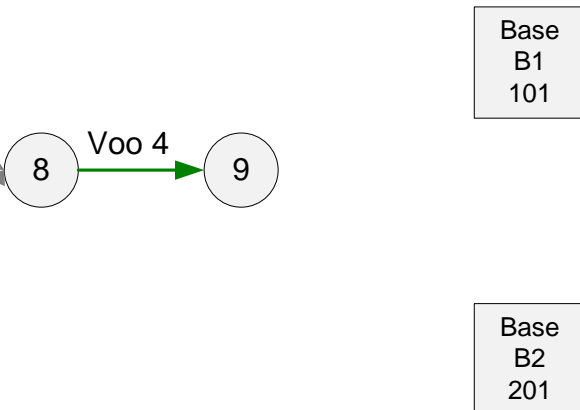

B2
201

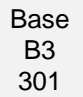

Figura 3.6 - Rede homogênea com Arcos_reposicionamento e Arcos_voo 
A cada arco $(i, j) \in A$ percorrido por uma aeronave da base $b$ está associado um custo $c_{i j}{ }^{b}$. Os custos dos voos somam o consumo de combustível a valores referentes a trabalhos técnicos de manutenção da aeronave para o voo e taxas diversas de operação (como taxas aeroportuárias, catering, suprimentos e despesas da tripulação).

As variáveis de decisão do problema são dadas por $x_{i j}^{b}$ e correspondem aos fluxos de aeronaves nos $\operatorname{arcos}(i, j) \in A$. Mais especificamente, $x_{i j}^{b}=1$ se uma aeronave da base $b$ utiliza o $\operatorname{arco}(i, j)$ e zero caso contrário. A formulação matemática do problema é apresentada a seguir:

Minimizar: $z(x)=\sum_{b \in B} \sum_{(i, j) \in A} c_{i j}^{b} x_{i j}^{b}$

Sujeito às seguintes restrições:

$$
\begin{aligned}
& \sum_{b \in B} x_{i j}^{b}=1 \quad \forall(i, j) \in \text { Arco_voo } \\
& \sum_{(i, j) \in \text { Arco_base_ida }} x_{i j}^{b} \leq f_{b} \quad \forall b \in B \\
& \sum_{b \in B} x_{i j}^{b}=\sum_{b \in B} x_{j i}^{b} \quad \forall j \in M N o s \_b a s e ; \forall b \in B ; \forall(i, j) \in A \\
& \sum_{(i, j) \in \text { Arco_base_ida }} x_{i j}^{b}=\sum_{(j, i) \in \text { Arco_base_volta }} x_{j i}^{b} \quad \forall b \in B \\
& \sum_{b \in B} x_{i j}^{b} \leq 1 \quad \forall(i, j) \in A \backslash \text { Arco_voo }_{-} \quad \forall b \in B \\
& x_{i j}^{b} \in \theta_{1}: \quad \forall(i, j) \in A
\end{aligned}
$$


A função objetivo (3.1) representa a minimização dos custos, $c_{i j}{ }^{b}$, dos arcos voados em toda a rede.

A restrição (3.2) impõe que o fluxo em cada um dos arcos do tipo Arco_voo é igual a um, o que significa que a cada um dos voos programados deve ser alocada uma e somente uma aeronave.

A expressão (3.3) determina que o número de aeronaves utilizadas não deve exceder a frota alocada para cada base. A verificação deve ser feita base a base, garantindo que o total de aeronaves que parte de uma base não supere a frota alocada àquela base, dada por $f_{b}$.

A restrição (3.4) corresponde ao equilíbrio de fluxo nos nós intermediários da rede; em outras palavras, uma aeronave que entre em um nó intermediário obrigatoriamente deve sair dele. Ou seja, ao final do dia de operação, nenhuma aeronave permanece nos aeroportos que não são base.

Analogamente, deve ser obedecido o equilíbrio de fluxo nos nós base de acordo com a restrição (3.5), de forma que as aeronaves que saiam de uma base retornem à mesma no final da operação.

Cada arco da rede só pode ser percorrido por no máximo uma aeronave, conforme a restrição (3.6).

Finalmente, a restrição (3.7) garante que as variáveis de decisão de fluxo nos arcos devem ser binárias.

A título de ilustração e para permitir uma maior clareza quanto à montagem da rede espaço-tempo, as Tabelas 3.2, 3.3 e 3.4 indicam os voos, os nós das bases e os arcos para o exemplo da Figura 3.4. 
Tabela 3.2 -Lista de voos do exemplo de frota própria homogênea

\begin{tabular}{|c|c|c|}
\hline Voos $(\boldsymbol{v})$ & Nós Origem (2v) & Nós Destino (2v+1) \\
\hline 1 & 2 & 3 \\
\hline 2 & 4 & 5 \\
\hline 3 & 6 & 7 \\
\hline 4 & 8 & 9 \\
\hline 5 & 10 & 11 \\
\hline
\end{tabular}

Tabela 3.3 - Relação de nós das bases do exemplo de frota própria homogênea

\begin{tabular}{|c|c|c|c|}
\hline Base (b) & $\begin{array}{c}\text { Nós Origem } \\
(\mathbf{b 0 0 )}\end{array}$ & $\begin{array}{c}\text { Nós Destino } \\
\text { (b01) }\end{array}$ & Frota base \\
\hline 1 & 100 & 101 & $f_{1}$ \\
\hline 2 & 200 & 201 & $f_{2}$ \\
\hline 3 & 300 & 301 & $f_{3}$ \\
\hline
\end{tabular}

Tabela 3.4 - Lista de arcos do exemplo de frota própria homogênea

\begin{tabular}{|c|c|}
\hline Arcos & Nós (Origem, Destino) \\
\hline Arco_base_ida & $\begin{array}{l}(100,2)(100,4)(100,6)(100,8)(100,10) \\
(200,2)(200,4)(2006)(200,8)(200,10) \\
(300,2)(300,4)(300,6)(300,8)(300,10)\end{array}$ \\
\hline Arco_base_volta & $(3,101)(5,101)(7,101)(9,101)(11,101)$ \\
& $(3,201)(5,201)(7,201)(9,201)(11,201)$ \\
& $(3,301)(5,301)(7,301)(9,301)(11,301)$
\end{tabular}

\subsubsection{Modelo com frota própria heterogênea}

No caso de operação com frota própria heterogênea, a principal diferença em relação ao modelo anterior com frota homogênea é a quantidade de arcos criados na rede, uma vez que devem ser criados todos os arcos discutidos anteriormente para cada tipo de aeronave, conforme detalhado a seguir, utilizando um exemplo para ilustração. 
Assumindo-se a Tabela 3.5 como exemplo de resultado da simulação e dado de entrada da otimização, em que para cada voo é definido um tipo de aeronave. Neste exemplo, a frota conta com dois tipos $k$ de aeronaves $(k=1,2)$, distintas em desempenho e em tamanho. Este fato implica em diferenças não só no número de passageiros que podem ser transportados, mas também no tempo que as diferentes aeronaves necessitam para cobrir o mesmo percurso, dentre outras considerações.

Clientes cuja adesão permitem solicitar aeronaves do tipo 1 podem ser atendidos por aeronaves do tipo 1 e do tipo 2, de categoria superior; enquanto que clientes cuja adesão permitem solicitar aeronaves do tipo 2 só podem ser atendidos por esse tipo. Como pode ser visto na Tabela 3.5, o voo $v=4$ corresponde a uma solicitação de uma aeronave do tipo 2, enquanto os demais voos $(v=1,2,3$ e 5$)$ correspondem a solicitações de voo com aeronaves do tipo 1.

Vale ressaltar que, apesar de o exemplo tratar de apenas dois tipos de aeronaves, o modelo matemático permite a generalização para mais tipos. Entretanto, no nível de planejamento adotado nesta pesquisa, em que o grau de incerteza é muito elevado e as informações disponíveis são poucas, é razoável considerar somente 2 tipos.

Tabela 3.5 - Lista de voos do exemplo de frota própria heterogênea

\begin{tabular}{|c|c|c|c|}
\hline Voos $(v)$ & Nós Origem (2v) & Nós Destino $(\mathbf{2 v + 1 )}$ & Tipo da aeronave $(k)$ \\
\hline 1 & 2 & 3 & 1 \\
\hline 2 & 4 & 5 & 1 \\
\hline 3 & 6 & 7 & 1 \\
\hline 4 & 8 & 9 & 2 \\
\hline 5 & 10 & 11 & 1 \\
\hline
\end{tabular}

Da mesma maneira que para o problema com frota homogênea, são criados dois nós para cada uma das bases $\left(B_{1}\right.$ a $\left.B_{b}\right)$ onde se localizam as aeronaves: o nó que representa a origem das aeronaves no início do dia de operação (b00) e o nó destino das aeronaves no final do período (b01). Adicionalmente, a frota disponível em cada base é dada por $f_{b}^{k}$, onde $b$ corresponde à base e $k$ ao tipo de aeronave. 
Os arcos do conjunto Arco_voo, de forma análoga ao caso de frota homogênea, são organizados em ordem crescente pelo horário de partida e numerados de $v=1$ a $N V$. Porém, os arcos possuem mais um atributo. Além de origem, destino e horário de partida, os arcos são caracterizados também pelo tipo de aeronave. Criam-se dois tipos de arcos do conjunto Arco_voo: Arco_voo_tp1 para aeronaves do tipo $k=1$ e Arco_voo_tp2 para aeronaves do tipo $k=2$. Para o exemplo, como pode ser visto na Figura 3.7, são criados arcos do tipo Arco_voo_tp1 para atender somente aos voos que requisitem a aeronave do tipo $k=1$ e do tipo Arco_voo_tp2 para atender não só os voos que requisitem aeronaves do tipo $k=2$, mas também para os demais.

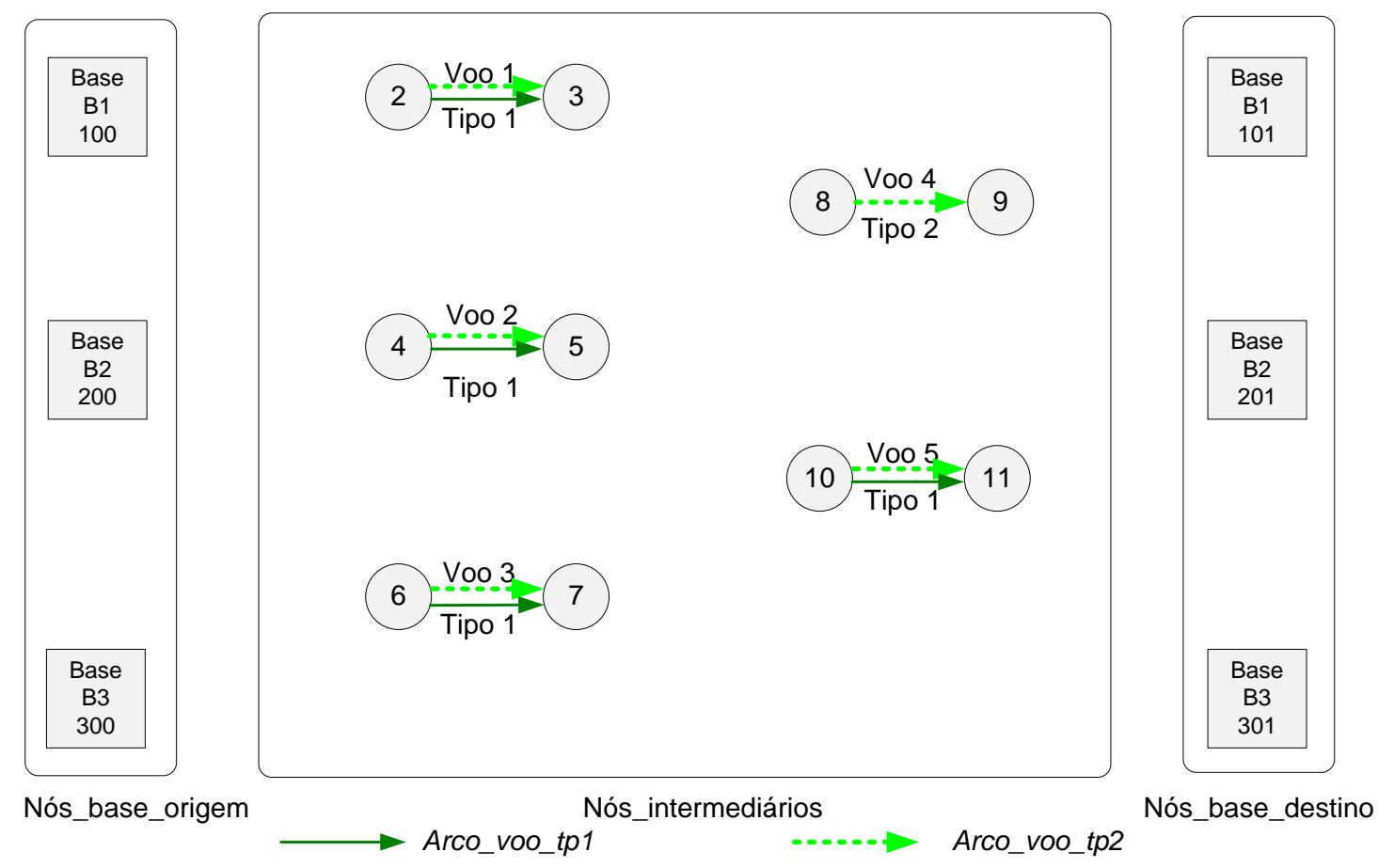

Figura 3.7 - Rede heterogênea com nós, bases e voos

Para os demais conjuntos de arcos da rede, são gerados também dois tipos de cada arco, de acordo com a aeronave que irá percorrê-lo:

- Arco_base_ida_tp1, que partem das bases (b00) para todos os nós (2v) de origem de voos que necessitem aeronave do tipo 1

- Arco_base_ida_tp2, que partem das bases (b00) para todos os nós (2v) de origem de voos que necessitem aeronave do tipo 1 e do tipo 2 (atendendo à condição de que um cliente só pode ser atendido por aeronave da mesma 
categoria solicitada ou então por categoria superior, são criados os arcos que possibilitem que aeronaves do tipo 2 atendam qualquer voo caso seja vantajoso).

- Arco_base_volta_tp1, que conectam os nós de destino de voos $(2 v+1)$ aos nós finais das bases (b01).

- Arco_base_volta_tp2, análogos aos Arco_base_volta_tp1

- Arco_reposicionamento_tp1, que ligam os nós intermediários ímpares $(2 v+1)$ aos nós intermediários pares (2v) que são origens dos próximos voos. Não são criados arcos do tipo Arco_reposicionamento_tp1 ligando nós que sejam origem de voos que requisitem aeronave do tipo 2 .

- Arco_reposicionamento_tp2, que conectam os nós $(2 v+1)$ aos nós $(2 v)$

Como pode ser visto no exemplo da Figura 3.8, são criados arcos do tipo Arco_base_ida_tp2 ligando cada uma das bases (100, 200 e 300) ao nó 2. Apesar do pedido do voo 1 (que liga os nós 2 e 3) requerer uma aeronave do tipo 1, uma aeronave maior pode ser utilizada caso o nó 3 corresponda ao mesmo aeroporto que o nó 8 do voo 4 e as restrições horárias permitam, caso o custo de enviar uma aeronave do tipo 2 para realizar os dois voos seja menor. Por outro lado, uma aeronave do tipo 1 não pode ser enviada para realizar o voo 4, uma vez que é necessário uma aeronave maior. Dessa forma, não são criados os arcos do tipo Arco_base_ida_tp1 das bases para o nó 8, origem desse voo.

As mesmas restrições aplicam-se para os percursos ociosos. De modo a respeitar as condições previamente explicadas, não são criados arcos do tipo Arco_reposicionamento_tp1 para nós que sejam origem de voos com aeronave do tipo 2. Note-se que, por exemplo, no nó 8 da Figura 3.9 não chega nenhum arco do tipo Arco_reposicionamento_tp1 enquanto no nó 10, origem de um voo do tipo 1, chegam dois arcos, um do tipo Arco_reposicionamento_tp1 e outro do tipo Arco_reposicionamento_tp2. 


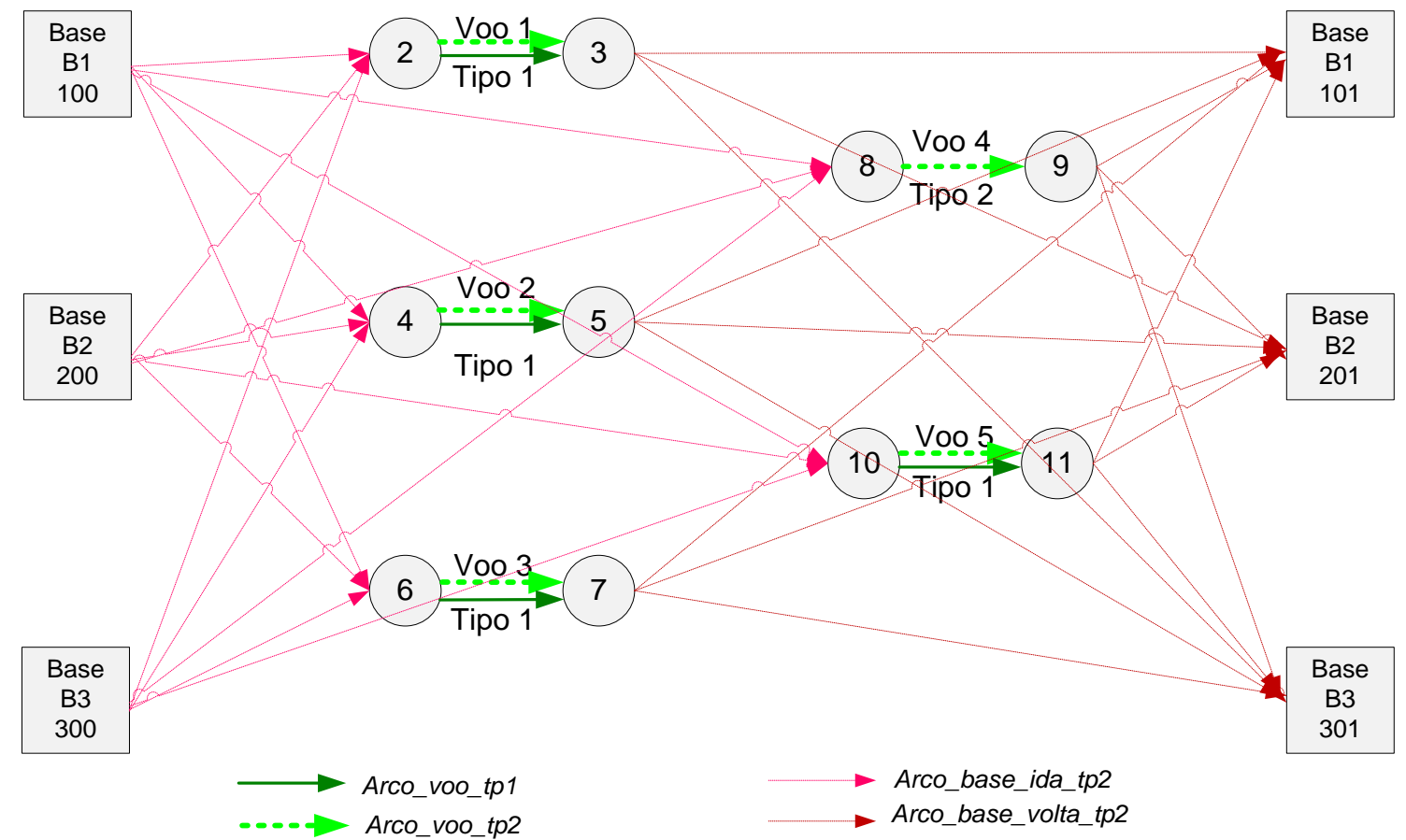

Figura 3.8 - Rede heterogênea com Arco_base_ida_tp2 e Arco_base_volta_tp2
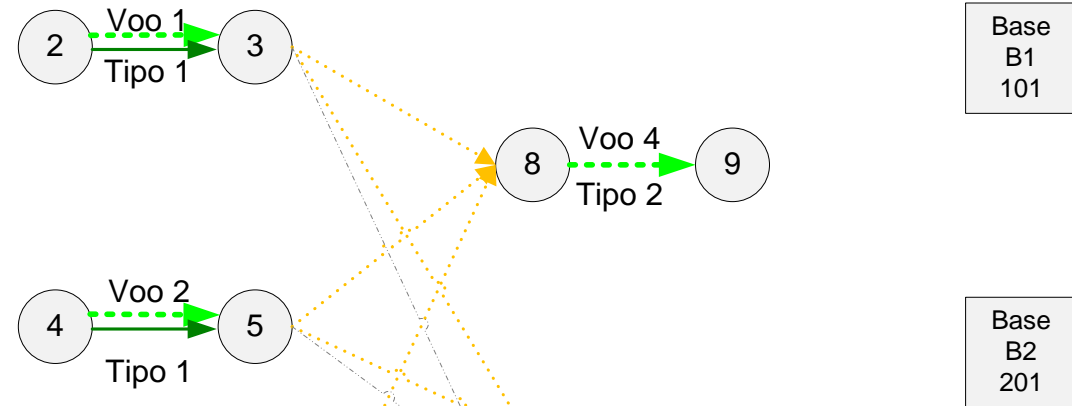

Tipo 1 
A título de ilustração, a Figura 3.10 apresenta uma possível configuração para a rede do exemplo apresentando anteriormente. Observa-se que foi alocada uma aeronave do tipo 1 da base $B 1$ para atender ao voo $2 \mathrm{e}$ em seguida ela retorna à base de origem através do Arco_base_volta_tp1 $(3,101)$. Da base $B_{2}$ sai um Arco_base_ida_tp2 para atender ao voo 3 e a mesma aeronave percorre o Arco_reposicionamento $(7,8)$ para realizar o voo 4 , que requisitou uma aeronave do tipo 2. Após o voo 4 a aeronave retornou à base pelo Arco_base_volta_tp2 $(9,201)$. A base $B_{3}$ origina um Arco_base_ida_tp1 que leva uma aeronave ao nó 4 para realizar o voo 2, seguido de um Arco_reposicionamento_tp1 até o nó 10 para que a mesma aeronave voe o voo 5 e retorne à base $B_{3}$ pelo Arco_base_volta_tp 1 .

Naturalmente, assim como a criação dos arcos da rede é distinta por tipo de aeronave, essa diferenciação também repete-se na formulação matemática do problema de frota própria heterogênea.

As variáveis de decisão, ou seja, os fluxos de aeronaves nos arcos da rede, são, definidas por $x_{i j}^{k b}=1$ se uma aeronave do tipo $k$ da base $b$ utiliza o arco $(i, j)$ e zero caso contrário.

Para o exemplo prático de 3 bases e 5 voos tem-se as Tabelas 3.6, 3.7 e 3.8 de voos, nós e arcos da rede, respectivamente. 


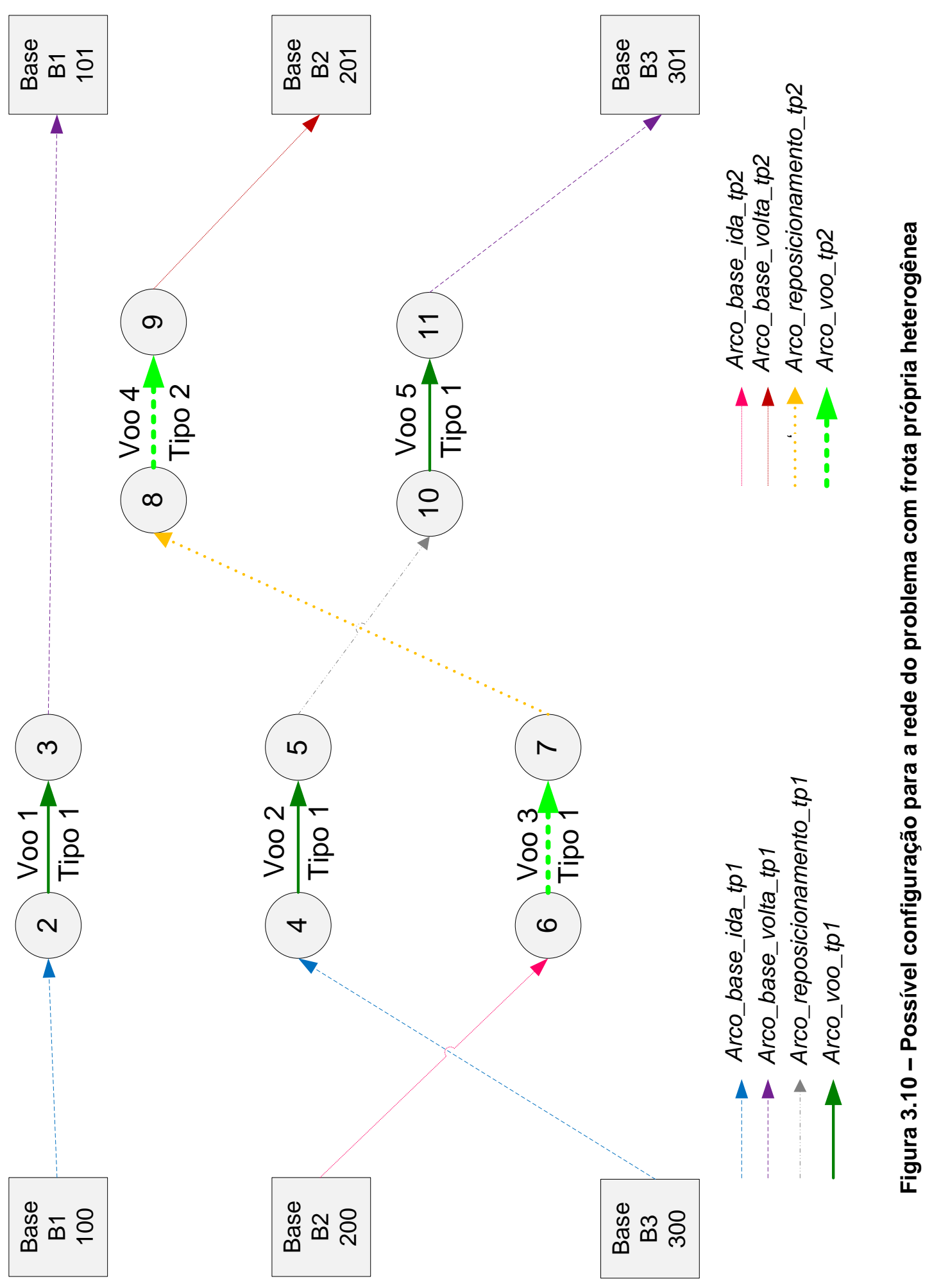


Tabela 3.6 -Lista de voos do exemplo de frota própria heterogênea

\begin{tabular}{|c|c|c|c|}
\hline Voos (v) & Nós Origem (2v) & Nós Destino $(\mathbf{2} \boldsymbol{v}+\mathbf{1})$ & Tipo de aeronave $(\boldsymbol{k})$ \\
\hline 1 & 2 & 3 & 1 \\
\hline 2 & 4 & 5 & 1 \\
\hline 3 & 6 & 7 & 1 \\
\hline 4 & 8 & 9 & 2 \\
\hline 5 & 10 & 11 & 1 \\
\hline
\end{tabular}

Tabela 3.7- Lista de nós das bases do exemplo de frota própria heterogênea

\begin{tabular}{|c|c|c|c|c|}
\hline Base (b) & $\begin{array}{c}\text { Nós Origem } \\
(\mathbf{b 0 0 )}\end{array}$ & $\begin{array}{c}\text { Nós Destino } \\
\text { (b01) }\end{array}$ & $\begin{array}{c}\text { Frota base } \\
\text { tipo 1 }\end{array}$ & $\begin{array}{c}\text { Frota base } \\
\text { tipo 2 }\end{array}$ \\
\hline 1 & 100 & 101 & $f_{1}^{1}$ & $f_{1}^{2}$ \\
\hline 2 & 200 & 201 & $f_{2}^{1}$ & $f_{2}^{2}$ \\
\hline 3 & 300 & 301 & $f_{3}^{1}$ & $f_{3}^{2}$ \\
\hline
\end{tabular}

Tabela 3.8 - Lista de arcos do exemplo de frota própria heterogênea

\begin{tabular}{|c|c|c|}
\hline \multicolumn{2}{|c|}{ Arcos } & Nós (Origem, Destino) \\
\hline \multirow{2}{*}{ Arco_base_ida } & Arco_base_ida_tp1 & $\begin{array}{l}(100,2)(100,4)(100,6)(100,10) \\
(200,2)(200,4)(2006)(200,10) \\
(300,2)(300,4)(300,6)(300,10)\end{array}$ \\
\hline & Arco_base_ida_tp2 & $\begin{array}{l}(100,2)(100,4)(100,6)(100,8)(100,10) \\
(200,2)(200,4)(2006)(200,8)(200,10) \\
(300,2)(300,4)(300,6)(300,8)(300,10)\end{array}$ \\
\hline \multirow{2}{*}{ Arco_base_volta } & Arco_base_volta_tp1 & $\begin{array}{l}(3,101)(5,101)(7,101)(11,101) \\
(3,201)(5,201)(7,201)(11,201) \\
(3,301)(5,301)(7,301)(11,301)\end{array}$ \\
\hline & Arco_base_volta_tp2 & $\begin{array}{l}(3,101)(5,101)(7,101)(9,101)(11,101) \\
(3,201)(5,201)(7,201)(9,201)(11,201) \\
(3,301)(5,301)(7,301)(9,301)(11,301)\end{array}$ \\
\hline \multirow{2}{*}{ Arco_reposicionamento } & Arco_reposicionamento_tp1 & $(3,10)(5,10)(7,10)$ \\
\hline & Arco_reposicionamento_tp2 & $(3,8)(3,10)(5,8)(5,10)(7,8)(7,10)$ \\
\hline \multirow{2}{*}{ Arco_voo } & Arco_voo_tp 1 & $(2,3)(4,5)(6,7)(10,11)$ \\
\hline & Arco_voo_tp2 & $(2,3)(4,5)(6,7)(8,9)(10,11)$ \\
\hline
\end{tabular}


Seja $c_{i j}^{k b}$ o custo de uma aeronave do tipo $k$ da base $b$ percorrer $\mathrm{o}$ arco $(i, j)$.

O problema de alocação de aeronaves compartilhadas com frota própria heterogênea pode ser formalizado da seguinte forma:

Minimizar $\quad z(x)=\sum_{k \in K} \sum_{b \in B} \sum_{(i, j) \in A} c_{i j}^{k b} x_{i j}^{k b}$

Sujeito às seguintes restrições:

$$
\begin{array}{cc}
\sum_{k \in K} \sum_{b \in B} x_{i j}^{k b}=1 & \forall(i, j) \in \text { Arco_voo } \\
\sum_{(i, j) \in \text { Arco_base_ida }} x_{i j}^{k b} \leq f_{b}^{k} & \forall b \in B ; \quad \forall k \in K \\
\sum_{k \in K} \sum_{b \in B} x_{i j}^{k b}=\sum_{k \in K} \sum_{b \in B} x_{j i}^{k b} & \forall j \in \text { Nós_intermediários } \\
\sum_{(i, j) \in \text { Arco_base_ida }} x_{i j}^{k b}=\sum_{(j, i) \in \text { Arco_base_volta }} x_{j i}^{k b} & \forall b \in B, \forall k \in K, \forall(i, j) \in A ; \\
\sum_{k \in K} \sum_{b \in B} x_{i j}^{k b} \leq 1 & \forall b \in B, \forall k \in K \\
& \forall(i, j) \in A-\text { Arco_voo }
\end{array}
$$

A formulação matemática para o problema de frota heterogênea corresponde a uma generalização da formulação do problema de frota homogênea. A função objetivo (3.8) procura minimizar os custos de todos os arcos voados na rede.

As restrições também seguem a formulação anterior. A restrição (3.9) assegura que todos os clientes sejam atendidos e os voos realizados por somente uma aeronave. Ou seja, a soma dos fluxos nos Arco_voo deve ser unitária e a verificação deve ser feita para tipo de aeronave, base a base. 
A restrição (3.10) limita o número total de aeronaves utilizadas de cada tipo e de cada base para que não supere mais do que a frota, por tipo, da base, dada por $f_{k b}$.

A restrição (3.11) impõe a verificação do equilíbrio de fluxo dos nós intermediários para que nenhuma aeronave permaneça nos aeroportos que não são base ao final do dia de operação. Verifica-se também, na restrição seguinte (3.12), o equilíbrio de fluxo nos nós base para garantir o retorno das aeronaves às bases.

Através da restrição (3.13) garante-se que qualquer arco da rede seja percorrido por no máximo uma aeronave. E a restrição (3.14) obriga que as variáveis de decisão de fluxo nos arcos sejam binárias.

\subsubsection{Modelo com frota homogênea e opção de aluguel}

Este modelo de operação considera que exista uma frota própria do operador, homogênea e disponível para atender aos voos solicitados. Contudo, há a opção de alugar aeronaves de terceiros para atender a alguns voos. O uso ou não dessa opção de aluguel é uma decisão do modelo matemático. Ou seja, caso exista algum voo em que, mesmo que haja aeronave da frota própria disponível, compense o atendimento com aeronave alugada, o modelo matemático decidirá pela opção que proporcionar o menor custo. Outra possível alternativa é utilizar essa opção de aluguel caso a frota própria não tenha aeronaves suficientes para atender a todos os clientes.

As condições de criação da rede para este modelo são semelhantes ao caso com frota heterogênea. São considerados dois tipos de aeronaves:

- Tipo 1 - aeronave pertencente à frota própria

- Tipo 2 - aeronave pertencente à frota disponível para aluguel

Para ambos os tipos considerados na modelagem, na prática, as aeronaves são da mesma categoria, portanto, não cabe ao cliente indicar em que aeronave quer voar. 
Nesse contexto, os resultados da simulação (e, consequentemente, os dados de entrada da otimização) são apresentados como uma simulação de frota homogênea, sem distinção entre tipos de aeronaves nos voos, como no modelo apresentado na seção 3.4.1.

De maneira similar aos casos apresentados anteriormente neste trabalho, são gerados os conjuntos de nós Nós_base e Nós_intermediários e os conjuntos de arcos: Arco_voo, Arco_base_ida, Arco_base_volta e Arco_reposicionamento, além dos sub-conjuntos por tipo de aeronave. A frota de cada base é expressa por $f_{b}^{k}$, sendo $k$ o indicador do tipo da aeronave (própria ou alugada).

Uma particularidade da formulação adotada nesta pesquisa reside na condição de não considerar as aeronaves de aluguel para voos de "deadheading", ou seja, para cada aeronave alugada só é alocado um voo. O modelo considera apenas que a aeronave alugada vai até o aeroporto de origem do voo e realiza o voo. Deslocamentos posteriores da aeronave alugada são ignorados na modelagem, pois normalmente o custo do voo com uma aeronave alugada já considera o custo de reposicionamento, de modo que não é necessário explicitá-lo no modelo. Em síntese, não são criados Arco_reposicionamento para essas aeronaves, ficando esses arcos restritos às aeronaves da frota própria.

A formulação matemática para este problema de frota homogênea com opção de alugar aeronaves externas é idêntica à do problema de frota heterogênea. Tem-se as Tabelas 3.9, 3.10 e 3.11 com, respectivamente, os voos, nós e arcos da rede de frota homogênea com opção de aluguel.

Para um exemplo de 5 voos e 2 bases com frota própria, considerou-se que para a base $B_{3}$ serão utilizadas somente aeronaves alugadas. É importante observar que, nesse caso, os valores, apresentados na Tabela 3.10 de frota do tipo 2 (alugada) para as bases $B_{1}$ e $B_{2}$ são iguais a zero pois neste exemplo somente a base $B_{3}$ possui a opção de aeronaves alugadas. Isto, porém, pode ser modificado ao se atribuir valores diferentes para as frotas, de forma que qualquer uma das bases pode conter não só aeronaves próprias, mas também podem ter aeronaves disponíveis para locação. 
Tabela 3.9 -Lista de voos do exemplo de frota homogênea com opção de aluguel

\begin{tabular}{|c|c|c|}
\hline Voos $(\boldsymbol{v})$ & Nós Origem (2v) & Nós Destino (2v + 1) \\
\hline 1 & 2 & 3 \\
\hline 2 & 4 & 5 \\
\hline 3 & 6 & 7 \\
\hline 4 & 8 & 9 \\
\hline 5 & 10 & 11 \\
\hline
\end{tabular}

Tabela 3.10- Lista de nós das bases do exemplo de frota homogênea com aluguel

\begin{tabular}{|c|c|c|c|c|}
\hline Base (b) & $\begin{array}{c}\text { Nós Origem } \\
\text { (b00) }\end{array}$ & $\begin{array}{c}\text { Nós Destino } \\
\text { (b01) }\end{array}$ & $\begin{array}{c}\text { Frota base } \\
\text { tipo 1 }\end{array}$ & $\begin{array}{c}\text { Frota base } \\
\text { tipo 2 }\end{array}$ \\
\hline 1 & 100 & 101 & $f_{1}^{1}$ & 0 \\
\hline 2 & 200 & 201 & $f_{2}^{1}$ & 0 \\
\hline 3 & 300 & 301 & 0 & $f_{3}^{2}$ \\
\hline
\end{tabular}

Tabela 3.11 - Lista de arcos do exemplo de frota homogênea com opção de aluguel

\begin{tabular}{|c|c|c|}
\hline \multirow{2}{*}{ Arcos } & Nós (Origem, Destino) \\
\hline \multirow{2}{*}{ Arcobase_ida } & Arco_base_ida_tp1 & $\begin{array}{l}(100,2)(100,4)(100,6)(100,8)(100,10) \\
(200,2)(200,4)(2006)(200,8)(200,10)\end{array}$ \\
\cline { 2 - 4 } & Arco_base_ida_tp2 & $(300,2)(300,4)(300,6)(300,8)(300,10)$ \\
\hline \multirow{2}{*}{ Arco_base_volta } & Arco_base_volta_tp1 & $\begin{array}{l}(3,101)(5,101)(7,101)(9,101)(11,101) \\
(3,201)(5,201)(7,201)(9,101)(11,201)\end{array}$ \\
\cline { 2 - 4 } & Arco_base_volta_tp2 & $(3,301)(5,301)(7,301)(9,301)(11,301)$ \\
\hline \multirow{2}{*}{ Arco_voo } & Arco_voo_tp1 & $(2,3)(4,5)(6,7)(8,9)(10,11)$ \\
\hline & Arco_voo_tp2 & $(2,3)(4,5)(6,7)(8,9)(10,11)$ \\
\cline { 2 - 4 } & Arco_reposicionamento_tp1 & $(3,8)(3,10)(5,8)(5,10)(7,8)(7,10)$ \\
\hline
\end{tabular}


As variáveis de decisão são definidas pelos fluxos nos arcos da rede, expressas por $x_{i j}^{k b}=1$ se uma aeronave do tipo $k$ da base $b$ utiliza o arco $(i, j)$ e zero caso contrário. Define-se $c_{i j}{ }^{k b}$ como o custo de uma aeronave do tipo $k$ da base $b$ percorrer o arco $(i, j)$. A formulação matemática é idêntica à apresentada para o caso de frota própria heterogênea na seção 3.4.2, nas equações 3.8 a 3.14 .

\subsection{Considerações finais do capítulo}

Neste capítulo foram descritas as principais características do negócio de aeronaves compartilhadas. As propriedades comuns às empresas foram consideradas na elaboração dos modelos tratados nesta pesquisa: operação com frota própria homogênea, com frota própria heterogênea e com frota homogênea com opção de aluguel de outras aeronaves. Adicionalmente, foram apresentados os fatores ponderados no cálculo dos custos dos voos.

Na sequência da definição dos problemas, estruturou-se a metodologia de solução, constituída de duas etapas: simulação e otimização.

A simulação, feita pelo método de Monte Carlo, possibilita lidar com a imprevisibilidade das demandas dos negócios. A estrutura construída permite realizar a simulação utilizando uma base de dados e produzir uma agenda diária de voos para determinado período de acordo com o modelo de operação que se deseja analisar.

Os resultados da simulação servem de dados de entrada da otimização. Dia a dia, a lista de voos é organizada em uma rede para determinar o fluxo de aeronaves nos arcos que proporcione o mínimo custo para o problema. Detalhadamente, foram descritos neste capítulo todas as particularidades da definição dos arcos e nós das redes de cada modelo. A formulação matemática pode ser encontrada resumida na Tabela 3.12 
Tal metodologia de solução foi implementada em uma planilha eletrônica e aplicada em um caso prático, conforme descrito no próximo capítulo.

Tabela 3.12- Resumo da formulação matemática

\begin{tabular}{|c|c|c|c|}
\hline & $\begin{array}{l}\text { Frota própria } \\
\text { homogênea }\end{array}$ & Frota própria heterogênea & $\begin{array}{l}\text { Frota homogênea com } \\
\text { opção de aluguel }\end{array}$ \\
\hline $\begin{array}{l}\text { Função } \\
\text { objetivo }\end{array}$ & $\begin{array}{c}\text { Minimizar } \\
z(x)=\sum_{b \in B} \sum_{(i, j) \in A} c_{i j}^{b} x_{i j}^{b}\end{array}$ & $z(x)=\sum_{k \in K} \sum_{b \in B} \sum_{(i, j) \in A} c_{i j}^{k b} x_{i j}^{k b}$ & $z(x)=\sum_{k \in K} \sum_{b \in B} \sum_{(i, j) \in A} c_{i j}^{k b} x_{i j}^{k b}$ \\
\hline $\begin{array}{l}\text { Todos os voos } \\
\text { atendidos por } 1 \\
\text { aeronave }\end{array}$ & $\begin{array}{c}\sum_{b \in B} x_{i j}^{b}=1 \\
\forall(i, j) \in \text { Arco_voo }\end{array}$ & $\begin{array}{l}\sum_{k \in K} \sum_{b \in B} x_{i j}^{k b}=1 \\
\forall(i, j) \in \text { Arco_voo }\end{array}$ & $\begin{array}{l}\sum_{k \in K} \sum_{b \in B} x_{i j}^{k b}=1 \\
\forall(i, j) \in \text { Arco_voo }\end{array}$ \\
\hline $\begin{array}{l}\text { Não usar mais } \\
\text { aeronaves do } \\
\text { que a frota }\end{array}$ & $\begin{array}{c}\sum_{(i, j) \in \text { Arco_base_ida }} x_{i j}^{b} \leq f_{b} \\
\forall b \in B\end{array}$ & $\begin{array}{c}\sum_{(i, j) \in \text { Arco_base_ida }} x_{i j}^{k b} \leq f_{b}^{k} \\
\forall b \in B ; \forall k \in K\end{array}$ & $\begin{array}{c}\sum_{(i, j) \in \text { Arco_base_ida }} x_{i j}^{k b} \leq f_{b}^{k} \\
\forall b \in B ; \forall k \in K\end{array}$ \\
\hline $\begin{array}{l}\text { Equilíbrio de } \\
\text { fluxo nos nós } \\
\text { intermediários }\end{array}$ & $\begin{array}{c}\forall \in \in B \in \text { Nós_intermediários; } \\
\forall b \in B ; \forall(i, j) \in A\end{array}$ & $\begin{array}{c}\sum_{k \in K} \sum_{b \in B} \sum_{k \in k} \sum_{b \in B} j i \\
\forall j \in \text { Nós_intermediários; } \\
\forall b \in B \quad, \forall k \in K \forall(i, j) \in A ;\end{array}$ & $\begin{array}{c}\sum_{k \in K} \sum_{b \in B} \sum_{k \in K} \sum_{b \in B} j i{ }_{i j} \\
\forall j \in \text { Nós_intermediários; } \\
\forall b \in B, \forall k \in K \forall(i, j) \in A\end{array}$ \\
\hline $\begin{array}{l}\text { Equilíbrio de } \\
\text { fluxo nos nós } \\
\text { base }\end{array}$ & $\begin{array}{c}\sum_{(i, j) \in \text { base_ida }} x_{i j}^{b}=\sum_{(j, i) \in \text { base_volta }} x_{j i}^{b} \\
\forall b \in B\end{array}$ & $\begin{array}{c}\sum_{(i, j) \in \text { base_ida }} x_{i j}^{k b}=\sum_{(j, i) \in \text { base }_{-} \text {volta }} x_{j i}^{k b} \\
\forall b \in B, \forall k \in K\end{array}$ & $\begin{array}{c}\sum_{(i, j) \in \text { base_ida }} x_{i j}^{k b}=\sum_{(j, i) \in \text { base_volta }} x_{j i}^{k b} \\
\forall b \in B, \forall k \in K\end{array}$ \\
\hline $\begin{array}{l}\text { Somente } 1 \\
\text { aeronave por } \\
\quad \text { arco }\end{array}$ & $\begin{array}{c}: \sum_{b \in B} x_{i j}^{b} \leq 1 \\
\forall(i, j) \in A-A_{1}{ }^{b} c o_{-} v o o \\
\forall b \in B\end{array}$ & $\begin{array}{c}\sum_{k \in K} \sum_{b \in B} x_{i j}^{k b} \leq 1 \\
\forall b \in B, \forall k \in K, \\
\forall(i, j) \in A-A r c o \_v o o\end{array}$ & $\begin{array}{l}\sum_{k \in K} \sum_{b \in B} x_{i j}^{k b} \leq 1 \\
\forall b \in B, \forall k \in K, \\
\forall(i, j) \in A-\text { Arco_voo }^{\prime} ;\end{array}$ \\
\hline $\begin{array}{l}\text { Variáveis } \\
\text { binárias }\end{array}$ & $x_{i j}^{b} \in \theta 1$ & $x_{i j}^{k b} \in \theta 1$ & $x_{i j}^{k b} \in \theta 1$ \\
\hline
\end{tabular}




\section{IMPLEMENTAÇÃO DO MODELO EM AMBIENTE DE PLANILHA ELETRÔNICA}

Conforme visto anteriormente, o objetivo desta pesquisa visa a elaboração de uma ferramenta de suporte ao planejamento e à análise de um negócio de aeronaves compartilhadas. Construiu-se a ferramenta para gerar a agenda de voos e para otimizar a alocação das aeronaves como uma planilha no programa Microsoft ${ }^{\circledR}$ Office Excel que contém a estrutura de solução e permite análises e avaliações do negócio, tais como se a quantidade e a localização das bases são apropriadas ou se o tamanho da frota está adequado à operação.

A implantação da ferramenta em ambiente de planilha eletrônica é uma opção coerente com o objetivo proposto. Planilhas eletrônicas têm um papel importante na Pesquisa Operacional, pois proporcionam uma plataforma eficiente para 0 desenvolvimento de softwares e ferramentas comerciais e por apresentaram vantagens na distribuição dessas ferramentas para os usuários (LeBlanc, 2008). A intenção de servir como uma ferramenta de planejamento é concordante com sua construção no Microsoft ${ }^{\circledR}$ Excel, um ambiente amplamente conhecido e consolidado que proporciona uma interface simples e direta.

A interface para o usuário da ferramenta e o modelo matemático foram escritos utilizando a linguagem de programação VBA - "Visual Basic for Applications" e para a otimização adotou-se o pacote de otimização What's Best! ${ }^{\circledR} 9.0 .3 .3$, com a licença Industrial, que suporta até 16000 restrições e 32000 variáveis.

A automatização das funções utilizando o VBA não só reduz o risco de erros, como facilita a utilização por usuários que não dominam pesquisa operacional e a implementação dos modelos matemáticos em ambiente de planilha. Além disso, agiliza o uso da ferramenta, uma vez que a operação manual seria muito mais demorada e sujeita a erros, tendo em vista a necessidade de montar o modelo matemático manualmente, caso a caso.

A seguir são apresentadas as planilhas, sua organização, a entrada de dados e como o usuário deve operar a ferramenta, além da descrição do que é realizado de 
maneira automática pela interface desenvolvida em VBA. Adicionalmente, é apresentado um exemplo para verificação da ferramenta.

\subsection{Descrição do ambiente em planilha}

A ferramenta consiste de uma pasta de trabalho do programa Microsoft ${ }^{\circledR}$ Excel, composta por 11 planilhas divididas entre dados de entrada, solução do problema e resultados. De acordo com o que foi apresentado no Capítulo 3, as planilhas devem armazenar os dados das rotas, dos aeroportos que servirão de base e do desempenho das aeronaves da frota, para assim permitir que a operação seja devidamente representada através da simulação de Monte Carlo e otimizada dia a dia pelo modelo matemático implementado na planilha.

Optou-se por desenvolver rotinas em VBA para facilitar e organizar a entrada de dados, assim como para automatizar tanto a simulação quanto a otimização, principalmente a construção da rede espaço-tempo, e as expressões matemáticas que definem a função objetivo e as restrições. Foi criada uma planilha distinta para a cada tipo de informação requerida: dados de desempenho das aeronaves da frota; rotas operadas; aeroportos que podem ser base e custos de operação. A primeira planilha, chamada de "Descrição do caso" e apresentada na Figura 4.1, contém as premissas e as características da operação analisada, que foram descritas no Capítulo 3 deste trabalho. Esta planilha serve como um guia para orientar o usuário em relação o conteúdo da ferramenta, as hipóteses consideradas, os dados de entrada necessários, a estratégia de solução adotada e os resultados esperados. 

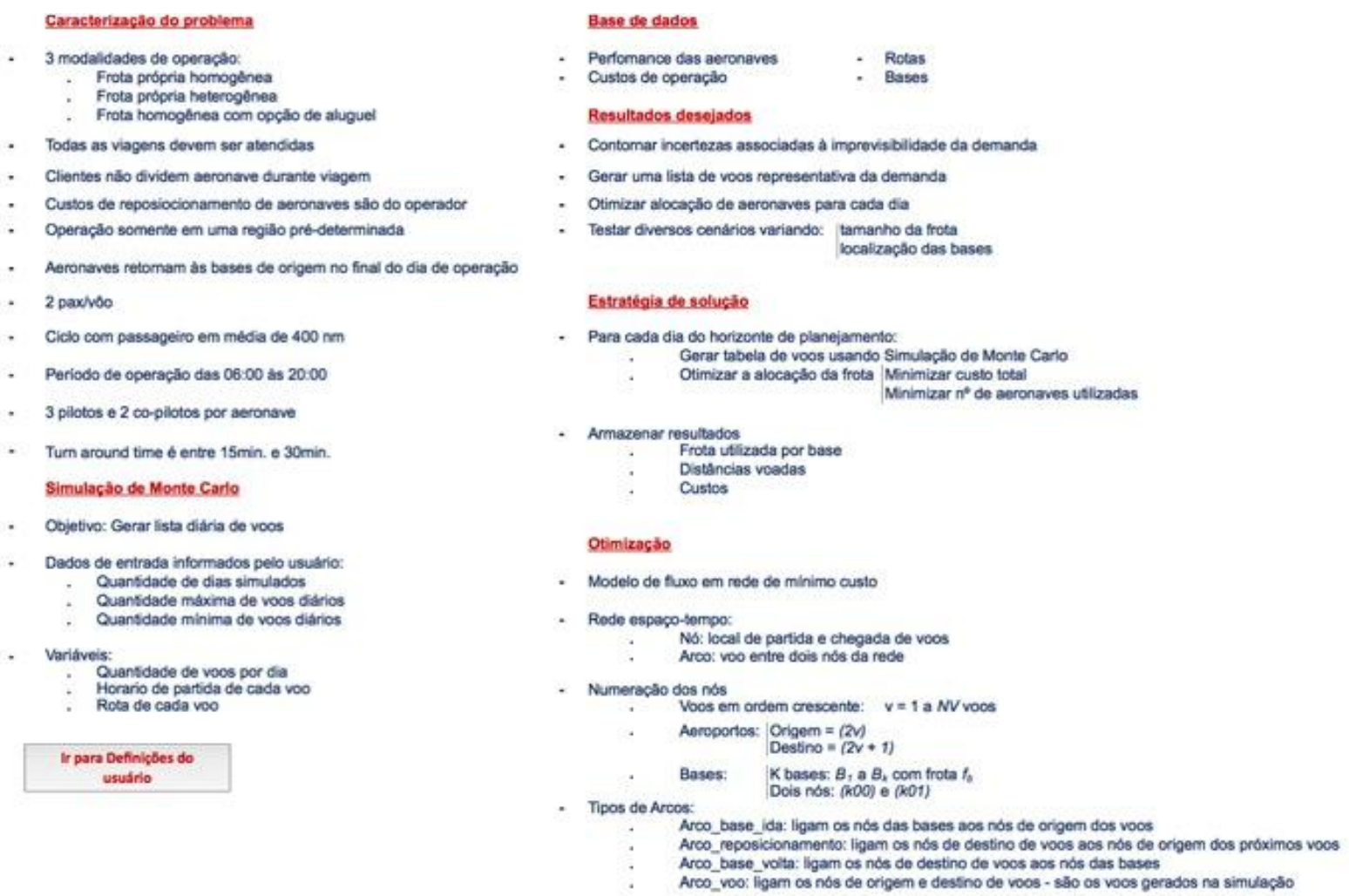

Figura 4.1 - Tela da planilha "Descrição do caso"

$\mathrm{Na}$ planilha "Dados de desempenho da frota", mostrada na Figura 4.2, são armazenadas as informações referentes ao desempenho das aeronaves. Tais dados devem ser explícitos para cada tipo de aeronave a fim de determinar o tempo de voo em função da distância voada. Na Figura 4.2 observa-se que a primeira coluna da tabela deve ser preenchida com o modelo da aeronave. A ferramenta foi construída para aceitar até dois tipos de aeronaves, de forma coerente com os modelos matemáticos propostos. Porém, simples alterações no código em VBA permitem a consideração de mais tipos, pois o modelo matemático aceita a inserção de mais variáveis, conforme foi mostrado no capítulo anterior.

$\mathrm{Na}$ coluna seguinte, a distância de vôo em milhas náuticas. A terceira coluna é preenchida automaticamente durante a inserção dos dados com a conversão da distância em milhas náuticas para valores em quilômetros. O limite máximo para o preenchimento da tabela é o limite de linhas do programa Microsoft ${ }^{\circledR}$ Excel (65.536 linhas para a versão 2007). Não há limite mínimo de quantas faixas de distância devem ser preenchidas nem de quanto deve ser a distância entre as faixas, contanto que as faixas de distâncias abranjam todas as rotas. Observa-se na Figura 4.2 que 
as faixas foram preenchidas de $10 \mathrm{em} 10 \mathrm{mn}$. Entretanto, o preenchimento poderia ter sido feito, por exemplo, de 20 em $20 \mathrm{mn}$ ou de 5 em $5 \mathrm{mn}$. Caso um voo resulte em uma distância intermediária às faixas da planilha realiza-se uma interpolação para encontrar o tempo de voo intermediário. Todavia, deve-se destacar que a qualidade da simulação depende da qualidade dos dados de entrada. Assim, quanto maior a especificidade das faixas de distância, mais fiéis à realidade serão os resultados.

A quarta coluna é referente ao número de passageiros. Neste caso, são consideradas duas opções que devem ser preenchidas: com a aeronave sem passageiros para voos vazios de reposicionamento e com passageiros na aeronave para os voos gerados na simulação, pois há diferença de tempo de voo entre a aeronave vazia e a com passageiro. Tal distinção é necessária para definir o tempo de vôo, calculado com base no desempenho da aeronave ao percorrer determinada distância, que é preenchido como um número decimal na coluna seguinte. Finalmente, a sexta coluna é preenchida automaticamente com a transformação do tempo de voo para o formato hh:mm:ss. Caso não haja diferença significativa entre o desempenho da aeronave com ou sem passageiros, a planilha aceita que seja inserida apenas uma linha por faixa de distância, sem considerar a diferença entre aeronave vazia e cheia. 


\begin{tabular}{|c|c|c|c|c|c|}
\hline Aeronave & Dist. (nm) & Dist. (km) & $\mathrm{n}^{\circ}$ passageiros & Block Time (h) & Formato horario \\
\hline Phenom 100 & 10 & 19 & 2 & 0,32 & 12:19:11 AM \\
\hline Phenom 100 & 10 & 19 & 0 & 0,31 & 12:18:37 AM \\
\hline Phenom 100 & 20 & 37 & 2 & 0,35 & $12: 21: 14$ AM \\
\hline Phenom 100 & 20 & 37 & 0 & 0,34 & $12: 20: 39$ AM \\
\hline Phenom 100 & 30 & 56 & 2 & 0,39 & 12:23:16 AM \\
\hline Phenom 100 & 30 & 56 & 0 & 0,38 & $12: 22: 42$ AM \\
\hline Phenom 100 & 40 & 74 & 2 & 0,42 & 12:25:19 AM \\
\hline Phenom 100 & 40 & 74 & 0 & 0,41 & $12: 24: 45$ AM \\
\hline Phenom 100 & 50 & 93 & 2 & 0,46 & $12: 27: 21$ AM \\
\hline Phenom 100 & 50 & 93 & 0 & 0,45 & $12: 26: 47$ AM \\
\hline Phenom 100 & 60 & 111 & 2 & 0,49 & 12:29:24 AM \\
\hline Phenom 100 & 60 & 111 & 0 & 0,48 & 12:28:50 AM \\
\hline Phenom 100 & 70 & 130 & 2 & 0,52 & 12:31:27 AM \\
\hline Phenom 100 & 70 & 130 & 0 & 0,51 & $12: 30: 52$ AM \\
\hline Phenom 100 & 80 & 148 & 2 & 0,56 & $12: 33: 29$ AM \\
\hline Phenom 100 & 80 & 148 & 0 & 0,55 & $12: 32: 55$ AM \\
\hline Phenom 100 & 90 & 167 & 2 & 0,59 & $12: 35: 32$ AM \\
\hline Phenom 100 & 90 & 167 & 0 & 0,58 & $12: 34: 57$ AM \\
\hline Phenom 100 & 100 & 185 & 2 & 0,63 & $12: 37: 34$ AM \\
\hline Phenom 100 & 100 & 185 & 0 & 0,62 & $12: 37: 00$ AM \\
\hline Phenom 100 & 110 & 204 & 2 & 0,66 & 12:39:37 AM \\
\hline Phenom 100 & 110 & 204 & 0 & 0,65 & 12:39:12 AM \\
\hline Phenom 100 & 120 & 222 & 2 & 0,69 & $12: 41: 39$ AM \\
\hline Phenom 100 & 120 & 222 & 0 & 0,69 & $12: 41: 24$ AM \\
\hline Phenom 100 & 130 & 241 & 2 & 0,73 & $12: 43: 42$ AM \\
\hline Phenom 100 & 130 & 241 & 0 & 0,73 & $12: 43: 36$ AM \\
\hline Phenom 100 & 140 & 259 & 2 & 0,76 & $12: 45: 45$ AM \\
\hline Phenom 100 & 140 & 259 & 0 & 0,76 & $12: 45: 48$ AM \\
\hline Phenom 100 & 150 & 278 & 2 & 0,80 & $12: 47: 47$ AM \\
\hline Phenom 100 & 150 & 278 & 0 & 0,80 & $12: 48: 00$ AM \\
\hline Phenom 100 & 160 & 296 & 2 & 0,83 & $12: 49: 50$ AM \\
\hline Phenom 100 & 160 & 296 & 0 & 0,84 & $12: 50: 12$ AM \\
\hline Phenom 100 & 170 & 315 & 2 & 0,86 & $12: 51: 52$ AM \\
\hline Phenom 100 & 170 & 315 & 0 & 0,87 & $12: 52: 24$ AM \\
\hline Phenom 100 & 180 & 333 & 2 & 0,90 & 12:53:55 AM \\
\hline Phenom 100 & 180 & 333 & 0 & 0,91 & 12:54:36 AM \\
\hline Phenom 100 & 190 & 352 & 2 & 0,93 & 12:55:57 AM \\
\hline Phenom 100 & 190 & 352 & 0 & 0,95 & $12: 56: 48$ AM \\
\hline Phenom 100 & 200 & 370 & 2 & 0,97 & 12:58:00 AM \\
\hline Phenom 100 & 200 & 370 & 0 & 0,98 & 12:59:00 AM \\
\hline Phenom 100 & 210 & 389 & 2 & 1,00 & 1:00:06 AM \\
\hline Phenom 100 & 210 & 389 & 0 & 1,02 & 1:01:06 AM \\
\hline
\end{tabular}

Figura 4.2 - Tela da planilha "Dados de desempenho da frota"

Na planilha "Rotas", são inseridas as rotas dos voos possíveis de serem solicitados pelos clientes. Conforme as premissas de operação apresentadas no Capítulo 3, as rotas são pré-determinadas dentro da área de operação do serviço. Cada rota é representada pelos seus aeroportos de origem e de destino. Devem ser informados os dados de longitude e latitude de cada aeroporto, assim como a probabilidade de haver uma solicitação de voo para cada rota. As distâncias das rotas podem ser preenchidas pelo usuário ou pode-se utilizar para o cálculo uma fórmula que obtém a distância através de latitude e longitude dos aeroportos de origem e destino. As rotas devem ser preenchidas na planilha e são ordenadas automaticamente em 
ordem decrescente em relação à probabilidade de ocorrência, conforme ilustra a Figura 4.3.

\begin{tabular}{|c|c|c|c|c|c|c|c|c|c|c|}
\hline \multirow[b]{2}{*}{ № Rota } & \multirow[b]{2}{*}{ Rota } & \multirow[b]{2}{*}{ Origem } & \multirow[b]{2}{*}{ Destino } & \multirow[b]{2}{*}{$\begin{array}{c}\text { Distância da Rota } \\
(\mathbf{k m})\end{array}$} & \multirow[b]{2}{*}{ Prob. Rota } & \multirow[b]{2}{*}{$\begin{array}{c}\text { Prob. } \\
\text { Acumulada }\end{array}$} & \multicolumn{2}{|c|}{ Origem } & \multicolumn{2}{|c|}{ Destino } \\
\hline & & & & & & & Ion1 & lat1 & Ion2 & lat2 \\
\hline 1 & SBSP-SBRJ & SBSP & SBRJ & 365,4391517 & $14,944 \%$ & $0,0 \%$ & $-46,655833$ & $-23,625556$ & $-43,1622$ & $-22,90972$ \\
\hline 2 & SBSP-SBBR & SBSP & SBBR & 872,6846496 & $6,134 \%$ & $14,9 \%$ & $-46,655833$ & $-23,625556$ & $-47,9122$ & $-15,86222$ \\
\hline 3 & SBSP-SBCT & SBSP & SBCT & 330,6048216 & $5,351 \%$ & $21,1 \%$ & $-46,655833$ & $-23,625556$ & $-49,1731$ & $-25,5275$ \\
\hline 4 & SBSP-SBPA & SBSP & SBPA & 837,5526673 & $5,023 \%$ & $26,4 \%$ & $-46,655833$ & $-23,625556$ & $-51,1711$ & $-29,99389$ \\
\hline 5 & SBGL-SBBR & SBGL & SBBR & 913,6379051 & $4,188 \%$ & $31,5 \%$ & $-43,25$ & $-22,809444$ & $-47,9122$ & $-15,86222$ \\
\hline 6 & SBSP-SBCF & SBSP & SBCF & 523,9762833 & $3,793 \%$ & $35,6 \%$ & $-46,655833$ & $-23,625556$ & $-43,9714$ & $-19,62389$ \\
\hline 7 & SBGR-SBGL & SBGR & SBGL & 336,3315009 & $3,409 \%$ & $39,4 \%$ & $-46,472778$ & $-23,435$ & $-43,25$ & $-22,80944$ \\
\hline 8 & SBSP-SBFL & SBSP & SBFL & 488,0128487 & $2,834 \%$ & $42,8 \%$ & $-46,655833$ & $-23,625556$ & $-48,5517$ & $-27,66972$ \\
\hline 9 & SBPA-SBGR & SBPA & SBGR & 865,2253875 & $2,605 \%$ & $45,7 \%$ & $-51,171111$ & $-29,993889$ & $-46,4728$ & $-23,435$ \\
\hline 10 & SBVT-SBGL & SBVT & SBGL & 417,6014013 & $2,498 \%$ & $48,3 \%$ & $-40,286389$ & $-20,257778$ & $-43,25$ & $-22,80944$ \\
\hline 11 & SBSP-SBGO & SBSP & SBGO & 822,418124 & $2,149 \%$ & $50,8 \%$ & $-46,655833$ & $-23,625556$ & $-49,2261$ & $-16,62944$ \\
\hline 12 & SBGL-SBCF & SBGL & SBCF & 361,7149379 & $2,002 \%$ & $52,9 \%$ & $-43,25$ & $-22,809444$ & $-43,9714$ & $-19,62389$ \\
\hline 13 & SBSP-SBGL & SBSP & SBGL & 359,1502098 & $1,946 \%$ & $54,9 \%$ & $-46,655833$ & $-23,625556$ & $-43,25$ & $-22,80944$ \\
\hline 14 & SBSP-SBNF & SBSP & SBNF & 413,460588 & $1,814 \%$ & $56,9 \%$ & $-46,655833$ & $-23,625556$ & $-48,6481$ & $-26,87972$ \\
\hline 15 & SBSP-SBBH & SBSP & SBBH & 503,4182055 & $1,737 \%$ & $58,7 \%$ & $-46,655833$ & $-23,625556$ & $-43,9508$ & $-19,85167$ \\
\hline 16 & SBGR-SBBR & SBGR & SBBR & 855,091593 & $1,721 \%$ & $60,4 \%$ & $-46,472778$ & $-23,435$ & $-47,9122$ & $-15,86222$ \\
\hline 17 & SBGR-SBCT & SBGR & SBCT & 358,4649395 & $1,708 \%$ & $62,1 \%$ & $-46,472778$ & $-23,435$ & $-49,1731$ & $-25,5275$ \\
\hline 18 & SBPA-SBGL & SBPA & SBGL & 1121,240216 & $1,680 \%$ & $63,9 \%$ & $-51,171111$ & $-29,993889$ & $-43,25$ & $-22,80944$ \\
\hline 19 & SBPA-SBCT & SBPA & SBCT & 534,1341438 & $1,589 \%$ & $65,5 \%$ & $-51,171111$ & $-29,993889$ & $-49,1731$ & $-25,5275$ \\
\hline 20 & SBCF-SBBR & SBCF & SBBR & 590,7682956 & $1,526 \%$ & $67,1 \%$ & $-43,971389$ & $-19,623889$ & $-47,9122$ & $-15,86222$ \\
\hline 21 & SBUL-SBSP & SBUL & SBSP & 551,0945021 & $1,501 \%$ & $68,6 \%$ & $-48,224722$ & $-18,883056$ & $-46,6558$ & $-23,62556$ \\
\hline 22 & SBVT-SBSP & SBVT & SBSP & 755,5096881 & $1,467 \%$ & $70,1 \%$ & $-40,286389$ & $-20,257778$ & $-46,6558$ & $-23,62556$ \\
\hline
\end{tabular}

Figura 4.3 - Tela da planilha "Rotas"

Os aeroportos que podem ser bases de operação são definidos na planilha "Lista de aeroportos", mostrada na Figura 4.4. Assim como nas demais planilhas, o limite máximo para o preenchimento da lista de aeroportos candidatos a base é o limite de linhas do Excel. Entretanto, na prática, uma operação não tem mais de 2 ou 3 bases, exceto se o número de voos e a cobertura geográfica for grande. Assim, a lista de candidatos a base é reduzida e o usuário pode elaborar uma lista inicial baseada em fatores como freqüência de voos e disponibilidade física nos aeroportos.

Além de latitude e longitude de cada aeroporto candidato a base, devem ser informados também os valores referentes aos custos fixos de operação anuais das instalações, como aluguel de hangar e despesas administrativas relacionadas à cada possível base. Nesses valores de despesas das bases podem também ser incluídos custos de estoque de peças de manutenção quando for o caso de a base ser local de manutenção das aeronaves da frota. 


\begin{tabular}{|c|c|c|c|c|c|c|}
\hline \multirow{3}{*}{$\begin{array}{l}\text { Base } \\
\text { SBBH }\end{array}$} & \multirow{3}{*}{$\begin{array}{l}\text { Longitude } \\
-43,9508333\end{array}$} & \multirow{3}{*}{$\begin{array}{l}\text { Latitude } \\
-19,851667\end{array}$} & \multicolumn{4}{|c|}{ Custos Instalações } \\
\hline & & & \multicolumn{2}{|c|}{$\begin{array}{l}\text { Despesas de aluguel } \\
\text { de hangar/escritório }\end{array}$} & \multicolumn{2}{|c|}{$\begin{array}{c}\text { Despesas } \\
\text { administrativas }\end{array}$} \\
\hline & & & $\$$ & $27.564,00$ & $\$$ & $2.275,00$ \\
\hline SBBR & $-47,9122222$ & $-15,862222$ & $\$$ & $27.564,00$ & $\$$ & $2.275,00$ \\
\hline SBBT & $-48,5952778$ & $-20,585$ & $\$$ & $27.564,00$ & $\$$ & $2.275,00$ \\
\hline SBCF & $-43,9713889$ & $-19,623889$ & $\$$ & $27.564,00$ & $\$$ & $2.275,00$ \\
\hline SBCG & $-54,6697222$ & $-20,468889$ & $\$$ & $27.564,00$ & $\$$ & $2.275,00$ \\
\hline $\mathrm{SBCH}$ & $-52,6611111$ & $-27,133611$ & $\$$ & $27.564,00$ & $\$$ & $2.275,00$ \\
\hline $\mathrm{SBCT}$ & $-49,1730556$ & $-25,5275$ & $\$$ & $27.564,00$ & $\$$ & $2.275,00$ \\
\hline SBFI & $-54,4844444$ & $-25,599722$ & $\$$ & $27.564,00$ & $\$$ & $2.275,00$ \\
\hline SBFL & $-48,5516667$ & $-27,669722$ & $\$$ & $27.564,00$ & $\$$ & $2.275,00$ \\
\hline SBGL & $-43,25$ & $-22,809444$ & $\$$ & $27.564,00$ & $\$$ & $2.275,00$ \\
\hline SBGO & $-49,2261111$ & $-16,629444$ & $\$$ & $27.564,00$ & $\$$ & $2.275,00$ \\
\hline SBGR & $-46,4727778$ & $-23,435$ & $\$$ & $27.564,00$ & $\$$ & $2.275,00$ \\
\hline SBJV & $-48,8008333$ & $-26,223333$ & $\$$ & $27.564,00$ & $\$$ & $2.275,00$ \\
\hline SBKP & $-47,1338889$ & $-23,006389$ & $\$$ & $27.564,00$ & $\$$ & $2.275,00$ \\
\hline SBLO & $-51,1361111$ & $-23,329722$ & $\$$ & $27.564,00$ & $\$$ & $2.275,00$ \\
\hline SBMG & $-52,3527778$ & $-26,498333$ & $\$$ & $27.564,00$ & $\$$ & $2.275,00$ \\
\hline SBMK & $-43,8202778$ & $-16,704444$ & $\$$ & $27.564,00$ & $\$$ & $2.275,00$ \\
\hline SBML & $-49,9263889$ & $-22,195$ & $\$$ & $27.564,00$ & $\$$ & $2.275,00$ \\
\hline
\end{tabular}

Figura 4.4 - Tela da planilha "Lista de aeroportos"

Na planilha "Custos" são preenchidos os dados anuais de custos da operação. A composição dos custos na planilha baseia-se no relatório anual produzido pelo Aviation Research Group/ U.S. Inc. (ARG/US), conforme visto no Capítulo 3.Dessa forma, tem-se na tabela o preço da aeronave, os custos por missão, os custos variáveis, os custos fixos das aeronaves, os custos periódicos, os de tripulação e das instalações. Como pode ser observado na Figura 4.5, optou-se por manter a tabela em inglês para seguir a organização do relatório, porém, isto em nada afeta a operação da ferramenta. 


\begin{tabular}{|c|c|c|c|c|c|c|c|}
\hline \multirow{5}{*}{ GENERAL } & PRODUCTION AIRCRAFT & \multicolumn{2}{|r|}{ EMBRAER } & \multicolumn{2}{|r|}{ EMBRAER } & \multicolumn{2}{|r|}{ EMBRAER } \\
\hline & \multirow{2}{*}{\multicolumn{2}{|c|}{ Model }} & Tipo 1 & \multicolumn{2}{|r|}{ Tipo 2} & \multirow{2}{*}{\multicolumn{2}{|c|}{ Charter }} \\
\hline & & & Phenom 100 & \multicolumn{2}{|c|}{ Phenom 300} & & \\
\hline & Category (1-6) & \multicolumn{2}{|r|}{1} & \multirow{2}{*}{\multicolumn{3}{|c|}{$\$ 7.610 .000,00$}} & \\
\hline & B\&CA Equipped Price & $\$$ & $3.600 .000,00$ & & & & \\
\hline MISSION COSTS & Flight Time & & $0+55$ & & $0+48$ & & \\
\hline \multirow[t]{3}{*}{$300 \mathrm{~nm}$} & Direct Cost & $\$$ & 615,78 & & & & \\
\hline & Fuel Expense & $\$$ & 490,97 & & & & \\
\hline & Per-Mile Cost & $\$$ & 2,05 & $\$$ & 3,60 & $\$$ & 3,00 \\
\hline \multirow[t]{4}{*}{$600 \mathrm{~nm}$} & Flight Time & & $1+50$ & & $1+32$ & & \\
\hline & Direct Cost & $\$$ & $1.231,54$ & & & & \\
\hline & Fuel Expense & $\$$ & 791,64 & & & & \\
\hline & Per-Mile Cost & $\$$ & 2,05 & $\$$ & 3,60 & & \\
\hline \multirow[t]{4}{*}{$1000 \mathrm{~nm}$} & Flight Time & & $3+04$ & & $2+31$ & & \\
\hline & Direct Cost & $\$$ & $2.060,08$ & & & & \\
\hline & Fuel Expense & $\$$ & $1.208,40$ & & & & \\
\hline & Per-Mile Cost & $\$$ & 2,06 & & & & \\
\hline VARIABLE COSTS & Fuel Expense & $\$$ & 535,61 & $\$$ & 858,22 & & \\
\hline \multirow{5}{*}{ (Hourly) } & Maintenance Hrs/Flight Hr. & & 0,36 & & 0,69 & & \\
\hline & Svc. Ctr. Maint. Labor Expense & $\$$ & 31,99 & $\$$ & 61,41 & & \\
\hline & Scheduled Parts Expense & $\$$ & 31,73 & $\$$ & 70,77 & & \\
\hline & Miscellaneous Trip Expense & $\$$ & 72,44 & $\$$ & 70,67 & & \\
\hline & Total Variable & $\$$ & 671,76 & $\$$ & $1.328,74$ & $\$$ & 800,00 \\
\hline \multirow{6}{*}{$\begin{array}{r}\text { FIXED COSTS } \\
\text { (Annual) }\end{array}$} & Hull Insurance & $\$$ & $9.000,00$ & $\$$ & $17.503,00$ & $\$$ & $13.000,00$ \\
\hline & Liability Insurance & $\$$ & $4.125,00$ & $\$$ & $11.800,00$ & $\$$ & $7.000,00$ \\
\hline & Hull Insurance per $\$ 100$ & $\$$ & 0,25 & & & & \\
\hline & Liability Insurance per \$M & $\$$ & 165,00 & & & & \\
\hline & Maint. Software Programs & & - & & & & \\
\hline & Miscellaneous Services & $\$$ & $2.802,00$ & $\$$ & $4.000,00$ & $\$$ & $5.000,00$ \\
\hline \multirow[t]{6}{*}{ PERIODIC COSTS } & Mid-Life/Hot Section Inspection & & - & & & & \\
\hline & Engine Overhaul & & - & & & & \\
\hline & Overhaul Interval & & $3500 t$ & & & & \\
\hline & Paint & & - & & & & \\
\hline & Interior Refurbishment & & - & & & & \\
\hline & Modern./Modif./Upgrade & $\$$ & $21.200,00$ & $\$$ & $20.000,00$ & & \\
\hline \multirow[t]{2}{*}{ PERSONNEL } & Captain Salary & $\$$ & $64.663,00$ & $\$$ & $90.000,00$ & $\$$ & $64.663,00$ \\
\hline & First Officer Salary & $\$$ & $47.533,00$ & $\$$ & $47.533,00$ & $\$$ & $47.533,00$ \\
\hline \multirow[t]{2}{*}{ TRAINING } & Pilot Initial (per pilot) & & - & $\$$ & $11.100,00$ & & \\
\hline & Maintenace Initial & & - & & & & \\
\hline \multirow{2}{*}{$\begin{array}{r}\text { FACILITIES } \\
\text { (Annual) }\end{array}$} & Hangar/Office Lease Expense & $\$$ & $27.564,00$ & $\$$ & $36.600,00$ & $\$$ & $27.564,00$ \\
\hline & Miscellaneous Office Expense & $\$$ & $2.275,00$ & $\$$ & $2.275,00$ & $\$$ & $2.275,00$ \\
\hline \multirow[t]{2}{*}{ CUSTOS BASES } & Base tipo A (onsite stock) & & & & & & \\
\hline & Base tipo B & & & & & & \\
\hline
\end{tabular}

Fonte: Aircraft Operating Costs Guide 2009

Figura 4.5 - Tela da planilha "Custos"

Na planilha, os valores dos custos devem ser preenchidos de acordo com o tipo de aeronave. Vale ressaltar que, apesar da adoção desta estrutura de custos nesta pesquisa, o usuário da ferramenta pode alterá-la ou até mesmo adotar outra. Caso a análise seja de um negócio existente e os valores reais da operação sejam conhecidos, o usuário só precisa preencher a tabela de Custos com os valores correspondentes. Da mesma forma, caso não sejam conhecidos todos os valores de 
custo da tabela, o usuário pode preencher apenas os valores de custo por milha voada e custo variável total (respectivamente, "Per-mile Cost" e "Total Variable" na Figura 4.5). Nesse contexto, a flexibilidade da ferramenta permite que o usuário teste alterações nos valores dos custos para analisar variações nos cenários de operação, como aumento excessivo no preço do combustível ou nos seguros.

Assim como na planilha "Custos", as demais planilhas descritas anteriormente podem ter seus valores alterados facilmente. É necessário apenas preencher as tabelas que se deseja alterar nas planilhas correspondentes e apertar o botão "Prosseguir" existente em cada uma. Após a inserção dos dados de entrada iniciais, o usuário opera a ferramenta através da planilha "Definições do usuário", exibida na Figura 4.6. É nela que se define o período de simulação, ou seja, a quantidade de dias para os quais serão gerados voos. Também devem ser incluídos na planilha os valores máximo e mínimo de voos por dia. De acordo com o que foi visto no capítulo anterior, esse intervalo que representa a quantidade de voos diários deve corresponder ao tamanho da operação. Por exemplo, para uma operação com poucas aeronaves e poucas rotas, não faz sentido um número grande de voos diários.

Adicionalmente, na planilha "Definições do usuário" informam-se os modelos de aeronaves da frota utilizada, assim como as probabilidades de que cada tipo de aeronave seja requisitado em um voo. A quantidade de aeronaves disponíveis em cada base deve ser tal que permita que haja aeronaves suficientes para atender a todos os voos. Em seguida, o botão "Ir para Simulação" encaminha o usuário para a planilha "Simulação de Monte Carlo", onde o tipo de simulação pode ser escolhido: com frota homogênea, com frota heterogênea e com opção de aluguel. 


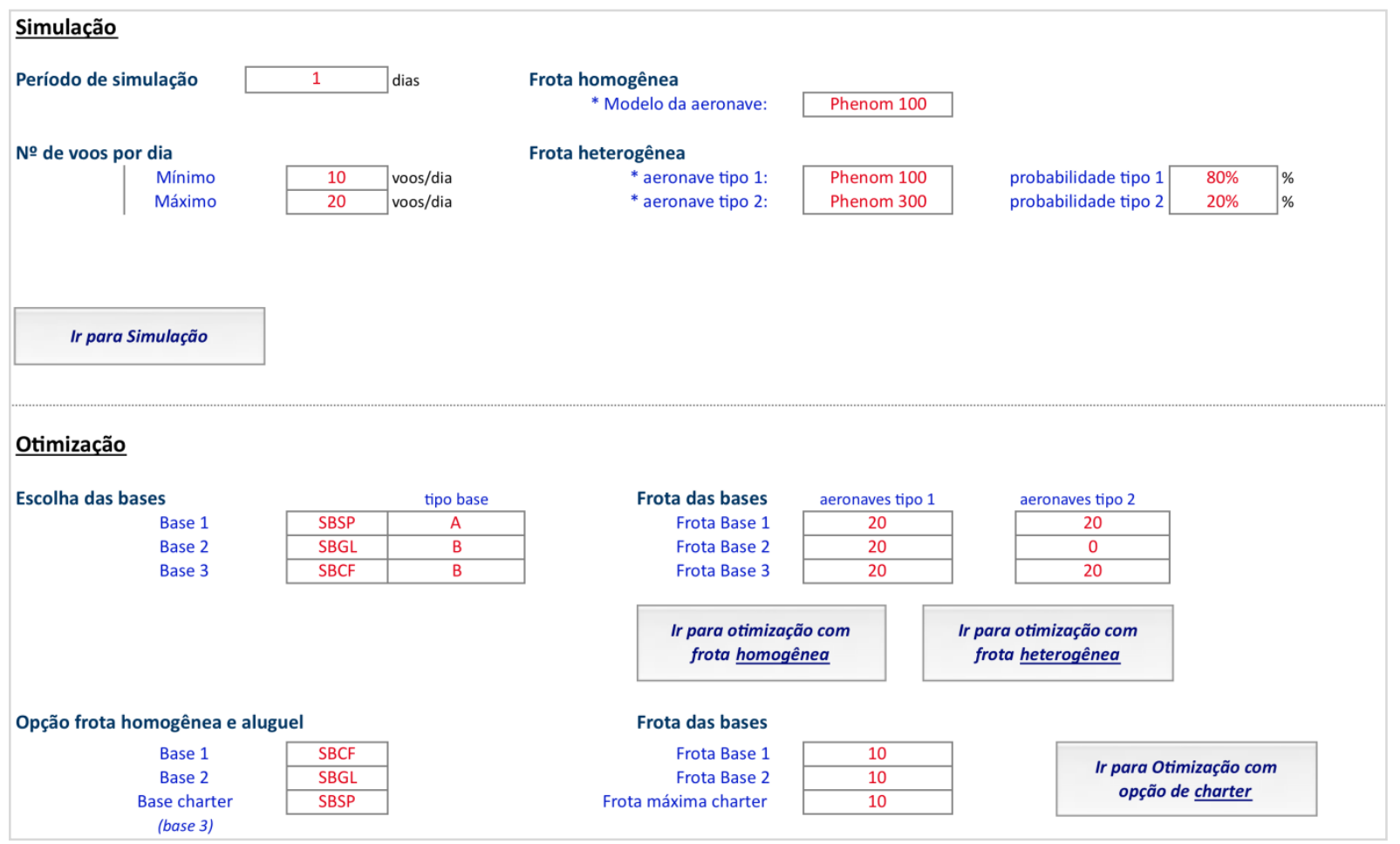

Figura 4.6- Tela da planilha "Definições do usuário"

A simulação é realizada na planilha "Simulação de Monte Carlo", mostrada na Figura 4.7. Conforme o que foi descrito na seção 3.3 - Geração dos voos diários através de Simulação de Monte Carlo, a simulação produz, para cada um dos os dias do horizonte de planejamento, uma lista de voos representativa da demanda da modalidade de operação escolhida pelo usuário: frota homogênea, frota heterogênea ou frota homogênea e opção de aluguel. São sorteados números aleatórios para a determinação do número de voos do dia, do horário de partida, da rota e do tipo de aeronave, caso seja frota heterogênea. Essa rotina é repetida para todos os voos de cada dia e para todos os dias do período de simulação. Gerada a agenda diária de vôos para cada dia do período definido pelo usuário, retorna-se para a planilha de "Definições do usuário". 


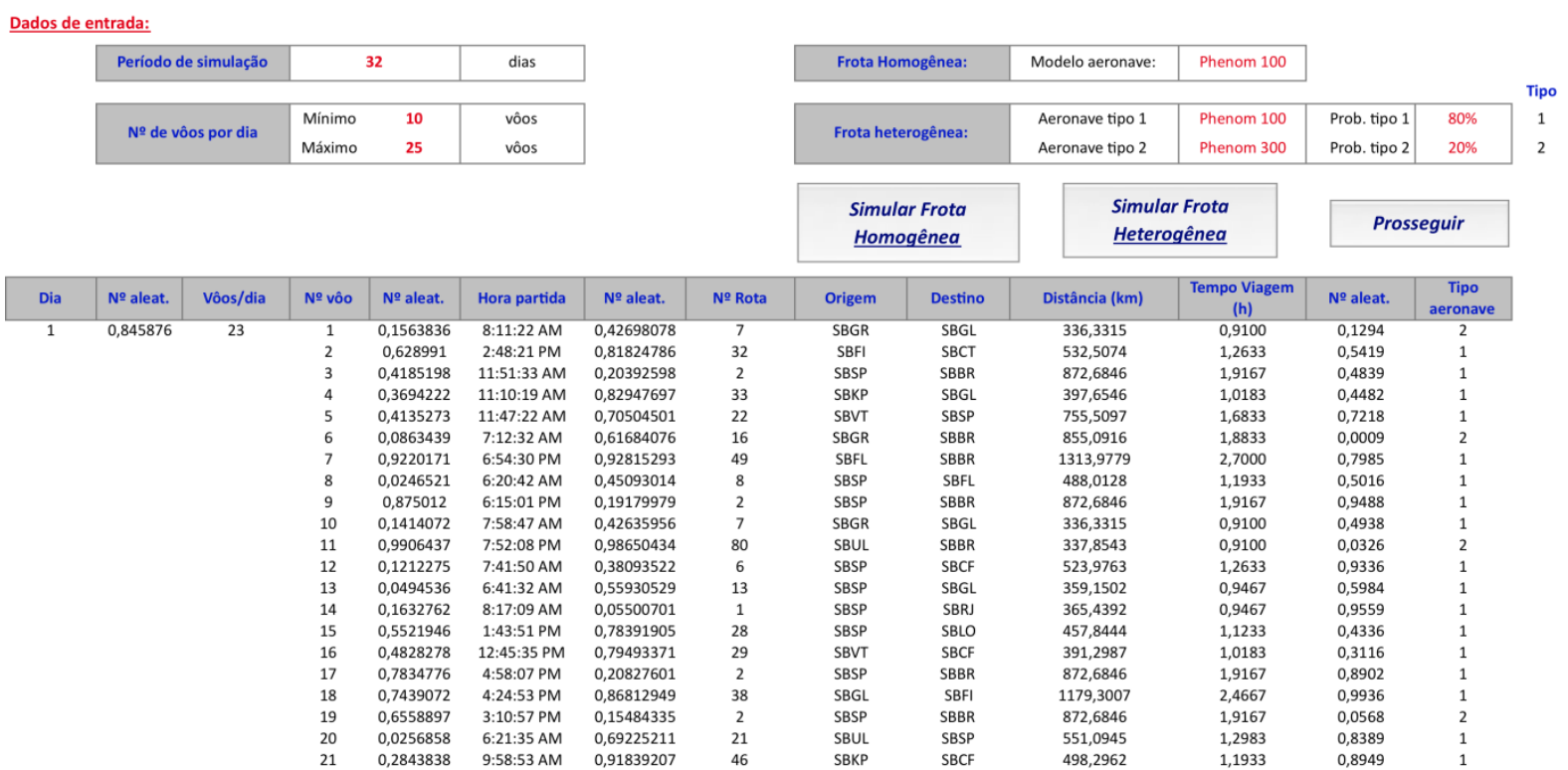

Figura 4.7 - Tela da planilha "Simulação de Monte Carlo"

Gerados todos os voos para todos os dias do período analisado, deve ser feita a otimização. Cabe ao usuário preencher na planilha "Definições do usuário" quais aeroportos servirão como base e qual a distribuição da frota nessas bases. Através do programa de interface em VBA, são automaticamente transferidas as informações para a planilha de "Custos" com a finalidade de calcular os custos das bases e da frota. A interface em VBA então encaminha o usuário para a planilha de otimização, reproduzida na Figura 4.8, onde é construído o grafo espaço-tempo para cada dia simulado.

\begin{tabular}{|c|c|c|c|c|c|c|c|c|c|c|c|c|c|}
\hline $\begin{array}{c}\text { Otimizar Frota } \\
\text { homogênea }\end{array}$ & B2 & \multirow{2}{*}{$\begin{array}{l}100 \\
200\end{array}$} & $\begin{array}{c}\text { Nome base } \\
\text { SBSP } \\
\end{array}$ & $\begin{array}{l}\text { Longitude } \\
-46,65583333\end{array}$ & $\begin{array}{c}\text { Latitude } \\
-23,62555556\end{array}$ & 101 & \multirow[t]{2}{*}{$\begin{array}{l}\text { № aeronaves em } \\
\text { cada base: }\end{array}$} & $\frac{\mathrm{tipo} 1}{0}$ & $\frac{\mathrm{tipo} 2}{0}$ & \multirow[t]{2}{*}{$\begin{array}{l}\text { Custo anual da } \\
\text { base: }\end{array}$} & 0 & & $\begin{array}{l}\text { Turn around time } \\
00: 15 \\
\end{array}$ \\
\hline $\begin{array}{l}\text { Otimizar Frota } \\
\text { heterogênea }\end{array}$ & B2 & & SBGL & $-43,25$ & $-22,80944444$ & 201 & & 25 & 25 & & 19075725 & & \\
\hline $\begin{array}{c}\text { Otimizar opşão } \\
\text { charter }\end{array}$ & 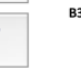 & 300 & SBCF & $-43,97138889$ & $-19,62388889$ & 301 & & 25 & 25 & & 19075725 & & Contador de dias \\
\hline vồs & № nó (2i) & Origem (2i) & № nó $(2 i+1)$ & Destino $(2 i+1)$ & Distância (km) & h1 & Tempo Viagem & h2 & Ion1 & lat1 & Ion2 & lat2 & Tipo aeronave \\
\hline 1 & 2 & SBSP & 3 & SBCG & 896,8892 & 7:43:41 AM & 1:57:00 AM & 9:40:41 AM & $-46,65583333$ & $-23,62555556$ & $-54,66972222$ & $-20,46888889$ & 1 \\
\hline 2 & 4 & SBGR & 5 & SBBR & 855,0916 & 7:56:57 AM & 1:53:00 AM & 9:49:57 AM & $-46,47277778$ & $-23,435$ & $-47,912222222$ & $-15,86222222$ & 1 \\
\hline 3 & 6 & SBGR & 7 & SBCF & 496,240464 & 9:22:11 AM & 1:11:36 AM & 10:33:47 AM & $-46,47277778$ & $-23,435$ & $-43,97138889$ & $-19,62388889$ & 1 \\
\hline 4 & 8 & SBSP & 9 & SBCF & 523,9762833 & 9:22:36 AM & 1:15:48 AM & 10:38:24 AM & $-46,65583333$ & $-23,62555556$ & $-43,97138889$ & $-19,62388889$ & 2 \\
\hline 5 & 10 & SWKN & 11 & SBSP & 685,9344201 & 11:04:03 AM & 1:34:42 AM & 12:38:45 PM & $-52,32805556$ & $-28,244722222$ & $-46,65583333$ & $-23,62555556$ & 2 \\
\hline 6 & 12 & SBSP & 13 & SBRJ & 365,4391517 & 11:23:50 AM & 12:56:48 AM & 12:20:38 PM & $-46,65583333$ & $-23,62555556$ & $-43,162222222$ & $-22,90972222$ & 1 \\
\hline 7 & 14 & SBSP & 15 & SBFL & 488,0128487 & 1:52:50 PM & 1:11:36 AM & 3:04:26 PM & $-46,65583333$ & $-23,62555556$ & $-48,55166667$ & $-27,66972222$ & 1 \\
\hline 8 & 16 & SBSP & 17 & SBRJ & 365,4392 & 2:03:41 PM & 12:56:48 AM & 3:00:29 PM & $-46,65583333$ & $-23,62555556$ & $-43,162222222$ & $-22,90972222$ & 1 \\
\hline 9 & 18 & SBUL & 19 & SBBH & 460,8433 & 2:10:27 PM & 1:07:24 AM & 3:17:51 PM & $-48,22472222$ & $-18,88305556$ & $-43,95083333$ & $-19,85166667$ & 2 \\
\hline 10 & 20 & SBSP & 21 & SBGO & 822,4181 & 2:15:42 PM & 1:49:00 AM & 4:04:42 PM & $-46,65583333$ & $-23,62555556$ & $-49,22611111$ & $-16,62944444$ & 1 \\
\hline 11 & 22 & SBSP & 23 & SBRJ & 365,4391517 & 2:23:16 PM & 12:56:48 AM & 3:20:04 PM & $-46,65583333$ & $-23,62555556$ & $-43,162222222$ & $-22,909722222$ & 1 \\
\hline 12 & 24 & SBSP & 25 & SBPA & 837,5526673 & 4:01:00 PM & 1:51:00 AM & 5:52:00 PM & $-46,65583333$ & $-23,62555556$ & $-51,17111111$ & $-29,99388889$ & 1 \\
\hline 13 & 26 & SBUL & 27 & SBBR & 337,8543 & 4:38:23 PM & 12:54:36 AM & 5:32:59 PM & $-48,224722222$ & $-18,88305556$ & $-47,912222222$ & $-15,862222222$ & 1 \\
\hline 14 & 28 & SBKP & 29 & SBGL & 397,6546 & 5:15:03 PM & 1:01:06 AM & 6:16:09 PM & $-47,13388889$ & $-23,00638889$ & $-43,25$ & $-22,80944444$ & 1 \\
\hline 15 & 30 & SBGL & 31 & SBBR & 913,6379051 & 5:15:51 PM & 1:59:00 AM & 7:14:51 PM & $-43,25$ & $-22,80944444$ & $-47,912222222$ & $-15,862222222$ & 1 \\
\hline 16 & 32 & SBGL & 33 & SBBR & 913,6379 & 5:42:29 PM & 1:59:00 AM & 7:41:29 PM & $-43,25$ & $-22,80944444$ & $-47,912222222$ & $-15,86222222$ & 2 \\
\hline 17 & 34 & SBSP & 35 & SBRJ & 365,4392 & 6:02:58 PM & 12:56:48 AM & 6:59:46 PM & $-46,65583333$ & $-23,62555556$ & $-43,162222222$ & $-22,909722222$ & 1 \\
\hline
\end{tabular}

Figura 4.8 - Tela da planilha "Otimização" 
O grafo espaço-tempo é construído automaticamente pela ferramenta a partir dos dados de entrada, que incluem os voos do dia, a localização das bases e a frota alocada em cada base, de acordo com o descrito no Capítulo 3. Para cada dia, são criadas 3 tabelas: a de voos, a de arcos e a de equilíbrio dos nós.

Os voos do dia, gerados na simulação, são organizados em uma tabela de voos e numerados em ordem crescente pelo horário de partida, conforme mostra a Figura 4.9 .

\begin{tabular}{|c|c|c|c|c|c|c|c|c|c|c|c|c|c|}
\hline Vôos & $\begin{array}{c}\text { № nó } \\
\text { (2i) }\end{array}$ & $\begin{array}{l}\text { Origem } \\
\text { ( } 2 \mathrm{i})\end{array}$ & $\begin{array}{l}\text { № nó } \\
(2 i+1)\end{array}$ & $\begin{array}{l}\text { Destino } \\
(2 \mathrm{i}+1)\end{array}$ & $\begin{array}{c}\text { Distância } \\
\text { (km) }\end{array}$ & h1 & $\begin{array}{l}\text { Tempo } \\
\text { Viagem }\end{array}$ & h2 & Ion1 & lat1 & Ion2 & lat2 & $\begin{array}{c}\text { Tipo } \\
\text { aeronave }\end{array}$ \\
\hline 1 & 2 & SBSP & 3 & SBRJ & 365,4392 & $09: 11: 56$ & $00: 56: 48$ & 10:08:44 & $-46,6558$ & $-23,6256$ & $-43,1622$ & $-22,91$ & 2 \\
\hline 2 & 4 & SBGR & 5 & SBFI & 844,7248 & $11: 06: 12$ & 01:51:00 & $12: 57: 12$ & $-46,4728$ & $-23,435$ & $-54,4844$ & $-25,6$ & 2 \\
\hline 3 & 6 & SBSP & 7 & SBBR & 872,6846 & 11:06:34 & 01:55:00 & $13: 01: 34$ & $-46,6558$ & $-23,6256$ & $-47,9122$ & $-15,862$ & 2 \\
\hline 4 & 8 & SBSP & 9 & SBGL & 359,1502 & $13: 06: 38$ & $00: 56: 48$ & $14: 03: 26$ & $-46,6558$ & $-23,6256$ & $-43,25$ & $-22,809$ & 1 \\
\hline 5 & 10 & SBSP & 11 & SBCF & 523,9763 & $17: 08: 17$ & $01: 15: 48$ & $18: 24: 05$ & $-46,6558$ & $-23,6256$ & $-43,9714$ & $-19,624$ & 1 \\
\hline 6 & 12 & SBSP & 13 & SBCT & 330,6048 & $17: 14: 40$ & $00: 52: 24$ & 18:07:04 & $-46,6558$ & $-23,6256$ & $-49,1731$ & $-25,528$ & 1 \\
\hline 7 & 14 & SBVT & 15 & SBSP & 755,5097 & $17: 32: 02$ & 01:41:00 & 19:13:02 & $-40,2864$ & $-20,2578$ & $-46,6558$ & $-23,626$ & 1 \\
\hline
\end{tabular}

Figura 4.9 - Tela da planilha "Otimização" com a tabela de voos

$\mathrm{Na}$ tabela de arcos, ilustrada na Figura 4.10, são criados os conjuntos de arcos: Arco_voo, Arco_base_ida, Arco_base_volta, Arco_reposicionamento.São preenchidos nas colunas o tipo de arco, o nó de origem, o nó de destino, o custo, o horário de partida, o tempo de viagem, o horário de chegada, o tipo de aeronave e as variáveis de fluxo para cada base. A função objetivo é posicionada ao final da tabela de arcos, adicionando o custo de todos os arcos. Os arcos que forem utilizados na solução ótima terão valor de custo positivo e o restante terá valor nulo.

\begin{tabular}{|c|c|c|c|c|c|c|c|c|c|c|c|c|c|c|c|}
\hline Tipo de arco & Origem & Destino & $\begin{array}{c}\text { Distância } \\
\text { (mn) }\end{array}$ & $\begin{array}{l}\text { Tempo } \\
\text { voo(h) }\end{array}$ & Custo (\$) & h1 & Tempo & h2 & \begin{tabular}{|c|} 
h1arco > \\
h2vooant \\
$?$
\end{tabular} & $\begin{array}{c}\text { Tipo } \\
\text { aeronave }\end{array}$ & $\begin{array}{c}\text { Verif. } \\
\text { tipo } \\
\text { aeron. }\end{array}$ & $\begin{array}{c}\text { Fluxo } \\
\mathrm{x}_{\mathrm{ij}}{ }^{1}\end{array}$ & $\begin{array}{c}\text { Fluxo } \\
\mathbf{x}_{i j}^{2}\end{array}$ & $\begin{array}{c}\text { Fluxo } \\
x_{i j}{ }^{3}\end{array}$ & $\begin{array}{l}\text { Custo } \\
\text { arco }\end{array}$ \\
\hline Arcobase tp1 & 100 & 2 & 0,054 & $00: 18: 00$ & 8,507691 & $08: 38: 56$ & $00: 18: 00$ & $08: 56: 56$ & 1 & 1 & -1 & 0 & 0 & 0 & 0 \\
\hline Arcobase tp1 & 100 & 4 & 15,1815 & $00: 18: 37$ & 39,80571 & 10:32:35 & $00: 18: 37$ & 10:51:12 & 1 & 1 & -1 & 0 & 0 & 0 & 0 \\
\hline Arcobase tp1 & 100 & 6 & 0,054 & 00:18:00 & 8,507691 & 10:33:34 & 00:18:00 & 10:51:34 & 1 & 1 & -1 & 0 & 0 & 0 & 0 \\
\hline Arcobase tp1 & 100 & 8 & 0,054 & $00: 18: 00$ & 8,507691 & $12: 33: 38$ & 00:18:00 & $12: 51: 38$ & 1 & 1 & 1 & 1 & 0 & 0 & 8,50769 \\
\hline Arcobase tp1 & 100 & 10 & 0,054 & $00: 18: 00$ & 8,507691 & $16: 35: 17$ & $00: 18: 00$ & $16: 53: 17$ & 1 & 1 & 1 & 0 & 0 & 0 & 0 \\
\hline Arcobase tp1 & 100 & 12 & 0,054 & $00: 18: 00$ & 8,507691 & $16: 41: 40$ & $00: 18: 00$ & $16: 59: 40$ & 1 & 1 & 1 & 1 & 0 & 0 & 8,50769 \\
\hline Arcobase tp1 & 100 & 14 & 407,943 & 01:41:00 & 883,3988 & $15: 36: 02$ & 01:41:00 & $17: 17: 02$ & 1 & 1 & 1 & 0 & 0 & 0 & 0 \\
\hline Arcobase tp1 & 100 & 101 & 0 & 00:00:00 & 0 & 00:00:00 & 00:00:00 & 00:00:00 & 1 & 1 & 1 & 8 & 0 & 0 & 0 \\
\hline Arcobase tp1 & 200 & 2 & 193,926 & $00: 56: 48$ & 424,0447 & 08:00:08 & $00: 56: 48$ & $08: 56: 56$ & 1 & 1 & -1 & 0 & 0 & 0 & 0 \\
\hline Arcobase tp1 & 200 & 4 & 181,604 & $00: 54: 36$ & 397,7601 & $09: 56: 36$ & $00: 54: 36$ & 10:51:12 & 1 & 1 & -1 & 0 & 0 & 0 & 0 \\
\hline Arcobase tp1 & 200 & 6 & 193,926 & $00: 56: 48$ & 424,0447 & $09: 54: 46$ & $00: 56: 48$ & $10: 51: 34$ & 1 & 1 & -1 & 0 & 0 & 0 & 0 \\
\hline Arcobase tp1 & 200 & 8 & 193,926 & $00: 56: 48$ & 424,0447 & $11: 54: 50$ & $00: 56: 48$ & $12: 51: 38$ & 1 & 1 & 1 & 0 & 0 & 0 & 0 \\
\hline Arcobase tp1 & 200 & 10 & 193,926 & $00: 56: 48$ & 424,0447 & $15: 56: 29$ & $00: 56: 48$ & $16: 53: 17$ & 1 & 1 & 1 & 0 & 0 & 0 & 0 \\
\hline Arcobase tp1 & 200 & 12 & 193,926 & $00: 56: 48$ & 424,0447 & $16: 02: 52$ & $00: 56: 48$ & $16: 59: 40$ & 1 & 1 & 1 & 0 & 0 & 0 & 0 \\
\hline Arcobase tp1 & 200 & 14 & 225,487 & 01:03:12 & 491,7306 & $16: 13: 50$ & 01:03:12 & $17: 17: 02$ & 1 & 1 & 1 & 0 & 0 & 0 & 0 \\
\hline Arcobase tp1 & 200 & 201 & 0 & 00:00:00 & 0 & 00:00:00 & 00:00:00 & 00:00:00 & 1 & 1 & 1 & 0 & 10 & 0 & 0 \\
\hline Arcobase tp1 & 300 & 2 & 282,925 & $01: 15: 48$ & 615,356 & 07:41:08 & $01: 15: 48$ & $08: 56: 56$ & 1 & 1 & -1 & 0 & 0 & 0 & 0 \\
\hline Arcobase tp1 & 300 & 4 & 267,948 & 01:11:36 & 582,6957 & 09:39:36 & 01:11:36 & 10:51:12 & 1 & 1 & -1 & 0 & 0 & 0 & 0 \\
\hline Arcobase tp1 & 300 & 6 & 282,925 & $01: 15: 48$ & 615,356 & $09: 35: 46$ & $01: 15: 48$ & $10: 51: 34$ & 1 & 1 & -1 & 0 & 0 & 0 & 0 \\
\hline Arcobase tp1 & 300 & 8 & 282,925 & $01: 15: 48$ & 615,356 & $11: 35: 50$ & $01: 15: 48$ & $12: 51: 38$ & 1 & 1 & 1 & 0 & 0 & 0 & 0 \\
\hline
\end{tabular}


Na sequência, é construída a tabela que representa as restrições de equilíbrio dos nós, mostrada na Figura 4.11, que contém o somatório dos fluxos de chegada e de saída para cada nó da rede: Nós_base e Nós_intermediários. Assim, verifica-se a restrição de que a soma dos fluxos nos nós deve ser igual à soma esperada (determinada pelas restrições de equilíbrio de fluxo nos nós intermediários e nós base, além do limite de aeronaves utilizadas).

\begin{tabular}{|c|c|c|c|c|c|}
\hline \multicolumn{7}{|c|}{ Base 1 frota 1 } \\
\hline Nós & $\begin{array}{c}\text { Fluxo sai } \\
(+)\end{array}$ & $\begin{array}{c}\text { Fluxo } \\
\text { chega (-) }\end{array}$ & $\begin{array}{c}\text { Soma } \\
\text { fluxos }\end{array}$ & & $\begin{array}{c}\text { Soma } \\
\text { esperada }\end{array}$ \\
\hline 100 & 10 & 0 & 10 & $=$ & 10 \\
200 & 0 & 0 & 0 & $=$ & 0 \\
300 & 0 & 0 & 0 & $=$ & 0 \\
2 & 0 & 0 & 0 & $=$ & 0 \\
4 & 0 & 0 & 0 & $=$ & 0 \\
6 & 0 & 0 & 0 & $=$ & 0 \\
8 & 1 & 1 & 0 & $=$ & 0 \\
10 & 0 & 0 & 0 & $=$ & 0 \\
12 & 1 & 1 & 0 & $=$ & 0 \\
14 & 1 & 1 & 0 & $=$ & 0 \\
3 & 0 & 0 & 0 & $=$ & 0 \\
5 & 0 & 0 & 0 & $=$ & 0 \\
7 & 0 & 0 & 0 & $=$ & 0 \\
9 & 1 & 1 & 0 & $=$ & 0 \\
11 & 0 & 0 & 0 & $=$ & 0 \\
13 & 1 & 1 & 0 & $=$ & 0 \\
15 & 1 & 1 & 0 & $=$ & 0 \\
101 & 0 & 10 & -10 & $=$ & -10 \\
201 & 0 & 0 & 0 & $=$ & 0 \\
301 & 0 & 0 & 0 & $=$ & 0 \\
& & & & &
\end{tabular}

\begin{tabular}{|c|c|c|c|c|}
\hline \multicolumn{6}{|c|}{ Base 2 frota 1 } \\
\hline $\begin{array}{c}\text { Fluxo sai } \\
(+)\end{array}$ & $\begin{array}{c}\text { Fluxo } \\
\text { chega (-) }\end{array}$ & $\begin{array}{c}\text { Soma } \\
\text { fluxos }\end{array}$ & & $\begin{array}{c}\text { Soma } \\
\text { esperada }\end{array}$ \\
\hline $\mathbf{0}$ & 0 & 0 & $=$ & 0 \\
$\mathbf{1 0}$ & 0 & 10 & $=$ & 10 \\
$\mathbf{0}$ & 0 & 0 & $=$ & 0 \\
$\mathbf{0}$ & 0 & 0 & $=$ & 0 \\
$\mathbf{0}$ & 0 & 0 & $=$ & 0 \\
$\mathbf{0}$ & 0 & 0 & $=$ & 0 \\
$\mathbf{0}$ & 0 & 0 & $=$ & 0 \\
$\mathbf{0}$ & 0 & 0 & $=$ & 0 \\
$\mathbf{0}$ & 0 & 0 & $=$ & 0 \\
$\mathbf{0}$ & 0 & 0 & $=$ & 0 \\
$\mathbf{0}$ & 0 & 0 & $=$ & 0 \\
$\mathbf{0}$ & 0 & 0 & $=$ & 0 \\
$\mathbf{0}$ & 0 & 0 & $=$ & 0 \\
$\mathbf{0}$ & 0 & 0 & $=$ & 0 \\
$\mathbf{0}$ & 0 & 0 & $=$ & 0 \\
$\mathbf{0}$ & 0 & 0 & $=$ & 0 \\
$\mathbf{0}$ & 0 & 0 & $=$ & 0 \\
$\mathbf{0}$ & 0 & 0 & $=$ & 0 \\
$\mathbf{0}$ & 10 & -10 & $=$ & -10 \\
$\mathbf{0}$ & 0 & 0 & $=$ & 0 \\
& & & & \\
& 0 & 0 & 0
\end{tabular}

\begin{tabular}{|c|c|c|c|c|}
\hline \multicolumn{6}{|c|}{ Base 3 frota 1 } \\
\hline $\begin{array}{c}\text { Fluxo sai } \\
(+)\end{array}$ & $\begin{array}{c}\text { Fluxo } \\
\text { chega (-) }\end{array}$ & $\begin{array}{c}\text { Soma } \\
\text { fluxos }\end{array}$ & & $\begin{array}{c}\text { Soma } \\
\text { esperada }\end{array}$ \\
\hline $\mathbf{0}$ & 0 & 0 & $=$ & 0 \\
$\mathbf{0}$ & 0 & 0 & $=$ & 0 \\
$\mathbf{1 0}$ & 0 & 10 & $=$ & 10 \\
$\mathbf{0}$ & 0 & 0 & $=$ & 0 \\
$\mathbf{0}$ & 0 & 0 & $=$ & 0 \\
$\mathbf{0}$ & 0 & 0 & $=$ & 0 \\
$\mathbf{0}$ & 0 & 0 & $=$ & 0 \\
$\mathbf{1}$ & 1 & 0 & $=$ & 0 \\
$\mathbf{0}$ & 0 & 0 & $=$ & 0 \\
$\mathbf{0}$ & 0 & 0 & $=$ & 0 \\
$\mathbf{0}$ & 0 & 0 & $=$ & 0 \\
$\mathbf{0}$ & 0 & 0 & $=$ & 0 \\
$\mathbf{0}$ & 0 & 0 & $=$ & 0 \\
$\mathbf{0}$ & 0 & 0 & $=$ & 0 \\
$\mathbf{1}$ & 1 & 0 & $=$ & 0 \\
$\mathbf{0}$ & 0 & 0 & $=$ & 0 \\
$\mathbf{0}$ & 0 & 0 & $=$ & 0 \\
$\mathbf{0}$ & 0 & 0 & $=$ & 0 \\
$\mathbf{0}$ & 0 & 0 & $=$ & 0 \\
$\mathbf{0}$ & 10 & -10 & $=$ & -10 \\
& & & &
\end{tabular}

Figura 4.11 - Tela da planilha "Otimização" com parte da tabela de equilíbrio dos nós

Após a construção de todas as tabelas da planilha "Otimização" contendo todos os dados necessários para calcular a função objetivo e definir as restrições, é executado o pacote de otimização. O software What's Best! ${ }^{\circledR}$ é chamado por uma macro que insere automaticamente as variáveis de decisão, a função objetivo e as restrições, sem interferência do usuário da planilha. Determinada a solução ótima para aquele dia, os resultados são armazenados na planilha "Resultados" correspondente à modalidade de operação selecionada pelo usuário. Há 3 planilhas de resultados, uma para a modalidade de operação com frota própria homogênea, outra para frota própria heterogênea e a terceira para frota homogênea com opção de aluguel. Cada planilha de resultado contém uma tabela onde são apresentados os principais valores resultantes da otimização: o número de voos por dia; os custos dos voos com passageiros, dos voos de reposicionamento e dos voos para as 
bases; a frota utilizada por base; o custo de todos os voos vazios (reposicionamento + bases) e o tempo de voos vazios e total.

Finalizado um dia, o processo de construção da rede e otimização do fluxo em rede pelo What's Best! $!^{\circledR}$ é repetido para o dia seguinte sem qualquer interferência do usuário. O processo é finalizado quando todos os dias forem otimizados e para o usuário é apresentada a planilha com todos os resultados. A sequência de procedimentos para operação da ferramenta descrita anteriormente pode ser resumida no roteiro passo a passo apresentado a seguir.

Passo 1.0 usuário insere dados de entrada da ferramenta nas planilhas referentes ao desempenho da frota, às rotas operadas, aos aeroportos que podem servir como bases de operação e aos custos.

Passo 2: Na planilha "Definições do usuário", usuário define os parâmetros da simulação: período de simulação (número de dias), número máximo e mínimo de voos por dia e tipo da frota. Clicar no botão "Ir para simulação".

Passo 3: As macros encaminham o usuário para a planilha "Simulação de Monte Carlo" e preenchem na planilha as informações inseridas pelo usuário no Passo 2. Em seguida, o usuário deve clicar no botão correspondente para iniciar a simulação desejada: Simulação com frota homogênea ou Simulação com frota heterogênea.

Passo 4: A simulação para cada um dos dias do período ocorre automaticamente conforme procedimentos descritos no pseudo-código da Figura 3.2 e, concluída a simulação, o usuário deve clicar no botão "Prosseguir", através do qual retornará à planilha "Definições do usuário".

Passo 5: Na planilha "Definições do usuário" cabe ao usuário definir: as bases da operação e a frota de cada base, discriminada por tipo de aeronave. O usuário deve clicar no botão para prosseguir com a otimização de acordo com a modalidade de operação escolhida.

Passo 6: Após o usuário clicar no botão da planilha de "Definições do usuário" para seguir para a otimização com a modalidade de operação 
desejada, as macros preenchem os custos fixos das bases e da frota na planilha "Custos". O usuário é encaminhado à planilha "Otimização".

Passo 7: O usuário manda executar a otimização. Automaticamente, para cada dia listado na simulação, as macros criam tabelas que organizam os voos, os arcos e o equilíbrio de fluxo nos nós, implantam a função objetivo, definem as restrições e acionam o What's Best! ${ }^{\circledR}$ para resolver o problema diário.

Passo 8: Encontrada a solução ótima, as macros preenchem a planilha com os resultados daquele dia de operação e retorna-se automaticamente ao Passo 7 para otimizar o próximo dia.

Passo 9: Concluída a otimização de todos os dias, o usuário é encaminhado para a planilha de resultados que apresenta os valores de custos e frota utilizada para a solução ótima de cada dia.

\subsection{Exemplo para verificação do modelo}

Após a implementação da metodologia em planilha, incluindo todas as rotinas de automatização em VBA, foram testadas as soluções apresentadas pela ferramenta para verificar se a ferramenta está funcionando corretamente, se a solução correta está sendo obtida e se não há erros na formatação nem na implementação do modelo. Para tanto, foram testados problemas de dimensões reduzidas com número restrito de voos para permitir a comparação com resultados obtidos pela solução da ferramenta com o What's Best! ${ }^{\circledR}$ com a resolução do mesmo problema pelo solver.

A verificação foi feita para problemas com no máximo 5 voos por dia, para gerar redes com número limitado de arcos que pudesse ser solucionada tanto pelo What's Best! ${ }^{\circledR}$ quanto pela versão básica do sistema Solver que está disponível gratuitamente no Excel. A seguir é apresentado um exemplo da verificação feita para um problema de apenas 3 voos, com frota homogênea, apresentado na Tabela 4.1. 
Tabela 4.1 - Lista de arcos do exemplo para verificação do modelo

\begin{tabular}{|c|c|c|c|c|c|c|c|c|}
\hline Vôos & $\begin{array}{c}\text { № nó } \\
(\mathbf{2 i})\end{array}$ & $\begin{array}{c}\text { Origem } \\
(\mathbf{2 i} \mathbf{~})\end{array}$ & $\begin{array}{c}\text { № nó } \\
\mathbf{( 2 \mathbf { i } + \mathbf { 1 } )}\end{array}$ & $\begin{array}{c}\text { Destino } \\
(\mathbf{2} \mathbf{i}+\mathbf{1})\end{array}$ & $\begin{array}{c}\text { Distância } \\
\mathbf{( \mathbf { k m } )}\end{array}$ & $\mathbf{h 1}$ & $\begin{array}{c}\text { Tempo } \\
\text { Viagem }\end{array}$ & h2 \\
\hline 1 & 2 & SBGR & 3 & SBGL & 336,331 & $10: 01$ & $0: 54$ & $10: 56$ \\
\hline 2 & 4 & SBPA & 5 & SBCT & 534,134 & $11: 59$ & $1: 15$ & $13: 15$ \\
\hline 3 & 6 & SBSP & 7 & SBCT & 330,604 & $17: 16$ & $0: 52$ & $18: 08$ \\
\hline
\end{tabular}

Para atender aos 3 voos foram definidas 2 bases, com frota de 3 aeronaves em cada base, mostradas na Tabela 4.2. A quantidade de aeronaves de cada base é igual à quantidade de voos a fim de permitir que todos os voos possam ser atendidos de qualquer base, de modo que a frota de aeronaves disponível não restrinja a solução de menor número de aeronaves e de custo total.

Em seguida, foram criados os arcos apresentados na Tabela 4.3, compostos de Arco_base_ida e Arco_base_volta, ligando as bases aos nós intermediários; Arco_reposicionamento de conexão entre os nós intermediários e que representam voos vazios de reposicionamento das aeronaves; e os Arco_voo propriamente ditos. A Figura 4.12 mostra todos os arcos do exemplo.

Tabela 4.2- Lista de nós das bases do exemplo para verificação do modelo

\begin{tabular}{|c|c|c|c|}
\hline Base (b) & $\begin{array}{c}\text { Nós Origem } \\
\text { (b00) }\end{array}$ & $\begin{array}{c}\text { Nós Destino } \\
\text { (b01) }\end{array}$ & $\begin{array}{c}\text { Frota base } \\
\text { tipo 1 }\end{array}$ \\
\hline SBCR & 100 & 101 & 3 \\
\hline SBGL & 200 & 201 & 3 \\
\hline
\end{tabular}

Tabela 4.3 - Lista de arcos do exemplo de verificação do modelo

\begin{tabular}{|c|c|}
\hline Arcos & Nós (Origem, Destino) \\
\hline Arco_base_ida & $\begin{array}{c}(100,2)(100,4)(100,6) \\
(200,2)(200,4)(2006)\end{array}$ \\
\hline Arco_base_volta & $\begin{array}{l}(3,101)(5,101)(7,101) \\
(3,201)(5,201)(7,201)\end{array}$ \\
\hline Arco_reposicionamento & $(3,4)(3,6)(5,6)$ \\
\hline Arco_voo & $(2,3)(4,5)(6,7)$ \\
\hline
\end{tabular}




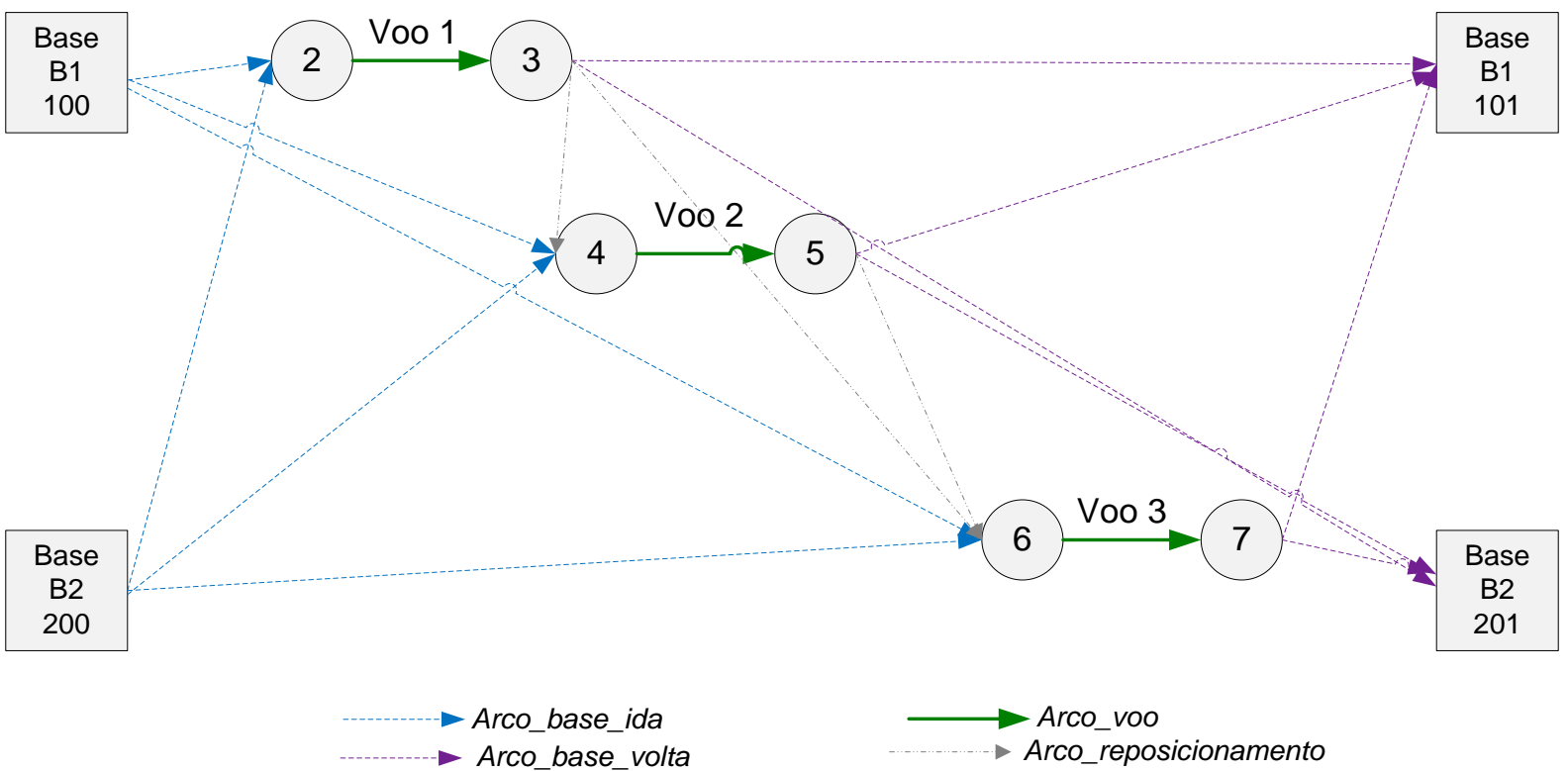

Figura 4.12 - Representação da rede com todos os arcos do exemplo de verificação

A formulação matemática deve seguir as restrições do problema com frota própria homogênea, apresentada no Capítulo 3 e foi aplicada ao problema na Tabela 4.4 a seguir.

Tabela 4.4 - Restrições do exemplo de verificação do modelo

\begin{tabular}{|c|c|c|}
\hline \multicolumn{2}{|c|}{ Frota própria homogênea } & Exemplo de verificação \\
\hline $\begin{array}{l}\text { Função } \\
\text { objetivo }\end{array}$ & $\begin{array}{c}\text { Minimizar } \\
z(x)=\sum_{b \in B} \sum_{(i, j) \in A} c_{i j}^{b} x_{i j}^{b}\end{array}$ & $\begin{aligned} {[\min ] z(x)=} & c_{(100,2)}^{1} x_{(100,2)}^{1}+c_{(100,4)}^{1} x_{(100,4)}^{1}+c_{(100,6)}^{1} x_{(100,6)}^{1}+ \\
& +c_{(2,3)}^{1} x_{(2,3)}^{1}+c_{(3,4)}^{1} x_{(3,4)}^{1}+c_{(3,6)}^{1} x_{(3,6)}^{1}+c_{(3,101)}^{1} x_{(3,101)}^{1}+ \\
& +c_{(4,5)}^{1} x_{(4,5)}^{1}+c_{(5,6)}^{1} x_{(5,6)}^{1}+c_{(5,101)}^{1} x_{(5,101)}^{1}+c_{(6,7)}^{1} x_{(6,7)}^{1}+ \\
& +c_{(7,101)}^{1} x_{(7,101)}^{1}+c_{(200,2)}^{2} x_{(200,2)}^{2}+c_{(200,4)}^{2} x_{(200,4)}^{2}+ \\
& +c_{(200,6)}^{2} x_{(200,6)}^{2}+c_{(2,3)}^{2} x_{(2,3)}^{2}+c_{(3,4)}^{2} x_{(3,4)}^{2}+ \\
& +c_{(3,6)}^{2} x_{(3,6)}^{2}+c_{(3,201)}^{2} x_{(3,201)}^{2}+c_{(4,5)}^{2} x_{(4,5)}^{2}+c_{(5,6)}^{2} x_{(5,6)}^{2}+ \\
& +c_{(5,201)}^{2} x_{(5,201)}^{2}+c_{(6,7)}^{2} x_{(6,7)}^{2}+c_{(7,201)}^{2} x_{(7,201)}^{2}\end{aligned}$ \\
\hline
\end{tabular}

continua 


\begin{tabular}{|c|c|c|}
\hline \multicolumn{2}{|c|}{ Frota própria homogênea } & Exemplo de verificação \\
\hline $\begin{array}{l}\text { Todos os } \\
\text { voos } \\
\text { atendidos por } \\
1 \text { aeronave }\end{array}$ & $\begin{array}{c}\sum_{b \in B} x_{i j}^{b}=1 \\
\forall(i, j) \in A r c o_{-} v o o\end{array}$ & $\begin{array}{l}x_{(2,3)}^{1}+x_{(2,3)}^{2}=1 \\
x_{(4,5)}^{1}+x_{(4,5)}^{2}=1 \\
x_{(6,7)}^{1}+x_{(6,7)}^{2}=1\end{array}$ \\
\hline $\begin{array}{l}\text { Não usar } \\
\text { mais } \\
\text { aeronaves do } \\
\text { que a frota }\end{array}$ & $\sum_{(i, j) \in A r c o \_ \text {base_ida }} x_{i j}^{b} \leq f_{b}$ & $\begin{array}{l}x_{(100,2)}^{1}+x_{(100,4)}^{1}+x_{(100,6)}^{1} \leq f_{1} \\
x_{(200,2)}^{2}+x_{(200,4)}^{2}+x_{(200,6)}^{2} \leq f_{2}\end{array}$ \\
\hline $\begin{array}{l}\text { Equilíbrio de } \\
\text { fluxo nos nós } \\
\text { intermediários }\end{array}$ & $\begin{array}{l}\sum_{b \in B} x_{i j}^{b}=\sum_{b \in B} x_{j i}^{b} \\
\qquad \forall j \in \\
\text { Nós_intermediários; } \\
\forall b \in B ; \forall(i, j) \in A\end{array}$ & $\begin{array}{l}x_{(100,2)}^{1}+x_{(200,2)}^{2}=x_{(2,3)}^{1}+x_{(2,3)}^{2} \\
x_{(2,3)}^{1}+x_{(2,3)}^{2}=x_{(3,101)}^{1}+x_{(3,201)}^{2}+x_{(3,4)}^{1}+x_{(3,4)}^{2}+x_{(3,6)}^{1}+x_{(3,6)}^{2} \\
x_{(100,4)}^{1}+x_{(200,4)}^{2}+x_{(3,4)}^{1}+x_{(3,4)}^{2}=x_{(4,5)}^{1}+x_{(4,5)}^{2} \\
x_{(4,5)}^{1}+x_{(4,5)}^{2}=x_{(5,101)}^{1}+x_{(5,201)}^{2}+x_{(5,6)}^{1}+x_{(5,6)}^{2} \\
x_{(100,6)}^{1}+x_{(200,6)}^{2}+x_{(3,6)}^{1}+x_{(3,6)}^{2}+x_{(5,6)}^{1}+x_{(5,6)}^{2}=x_{(6,7)}^{1}+x_{(6,7)}^{2} \\
x_{(6,7)}^{1}+x_{(6,7)}^{2}=x_{(7,101)}^{1}+x_{(7,201)}^{2}\end{array}$ \\
\hline $\begin{array}{l}\text { Equilíbrio de } \\
\text { fluxo nos nós } \\
\text { base }\end{array}$ & $\begin{array}{c}\sum_{(i, j) \in \text { base_ida }} x_{i j}^{b}=\sum_{(j, i) \in \text { base_volt }} x_{j i}^{b} \\
\forall b \in B\end{array}$ & $\begin{array}{l}x_{(100,2)}^{1}+x_{(100,4)}^{1}+x_{(100,6)}^{1}=x_{(3,101)}^{1}+x_{(5,101)}^{1}+x_{(7,101)}^{1} \\
x_{(200,2)}^{2}+x_{(200,4)}^{2}+x_{(200,6)}^{2}=x_{(3,201)}^{2}+x_{(5,201)}^{2}+x_{(7,201)}^{2}\end{array}$ \\
\hline $\begin{array}{l}\text { Somente } 1 \\
\text { aeronave por } \\
\text { arco }\end{array}$ & $\begin{array}{c}: \sum_{b \in B} x_{i j}^{b} \leq 1 \\
\forall(i, j) \in A-A_{r C o} \text { voo } \\
\forall b \in B\end{array}$ & $\begin{array}{ll}x_{(100,2)}^{1}+x_{(200,2)}^{2} \leq 1 & x_{(5,6)}^{1}+x_{(5,6)}^{2} \leq 1 \\
x_{(100,4)}^{1}+x_{(200,4)}^{2} \leq 1 & x_{(3,101)}^{1}+x_{(3,201)}^{2} \leq 1 \\
x_{(100,6)}^{1}+x_{(200,6)}^{2} \leq 1 & x_{(5,101)}^{1}+x_{(5,201)}^{2} \leq 1 \\
x_{(3,4)}^{1}+x_{(3,4)}^{2}+x_{(3,6)}^{1}+x_{(3,6)}^{2} \leq 1 & x_{(7,101)}^{1}+x_{(7,201)}^{2} \leq 1\end{array}$ \\
\hline $\begin{array}{l}\text { Variáveis } \\
\text { binárias }\end{array}$ & $x_{i j}^{b} \in \theta 1$ & $\begin{array}{l}\left\{x_{(100,2)}^{1}, x_{(100,4)}^{1}, x_{(100,6)}^{1}, x_{(2,3)}^{1}, x_{(3,4)}^{1},\right. \\
x_{(3,6)}^{1}, x_{(3,101)}^{1}, x_{(4,5)}^{1}, x_{(5,6)}^{1}, x_{(5,101)}^{1}, x_{(6,7)}^{1} \\
x_{(7,101)}^{1}, x_{(200,2)}^{2}, x_{(200,4)}^{2}, x_{(200,6)}^{2}, x_{(2,3)}^{2}, x_{(3,4)}^{2} \\
\left.x_{(3,6)}^{2}, x_{(3,201)}^{2}, x_{(4,5)}^{2}, x_{(5,6)}^{2}, x_{(5,201)}^{2}, x_{(6,7)}^{2}, x_{(7,201)}^{2}\right\} \\
\in\{0,1\}\end{array}$ \\
\hline
\end{tabular}

conclusão

Esse problema foi implementado em um arquivo do Microsoft ${ }^{\circledR}$ Excel e resolvido pelo Solver e foi também resolvido automaticamente pela ferramenta de simulação e 
otimização construída neste trabalho, que usa o What's Best! ${ }^{\circledR}$ para encontrar a solução ótima; ambos obtiveram o mesmo resultado, apresentados a seguir. A Figura 4.13 reúne a tela da planilha "Otimização" com a tabela de arcos do problema.

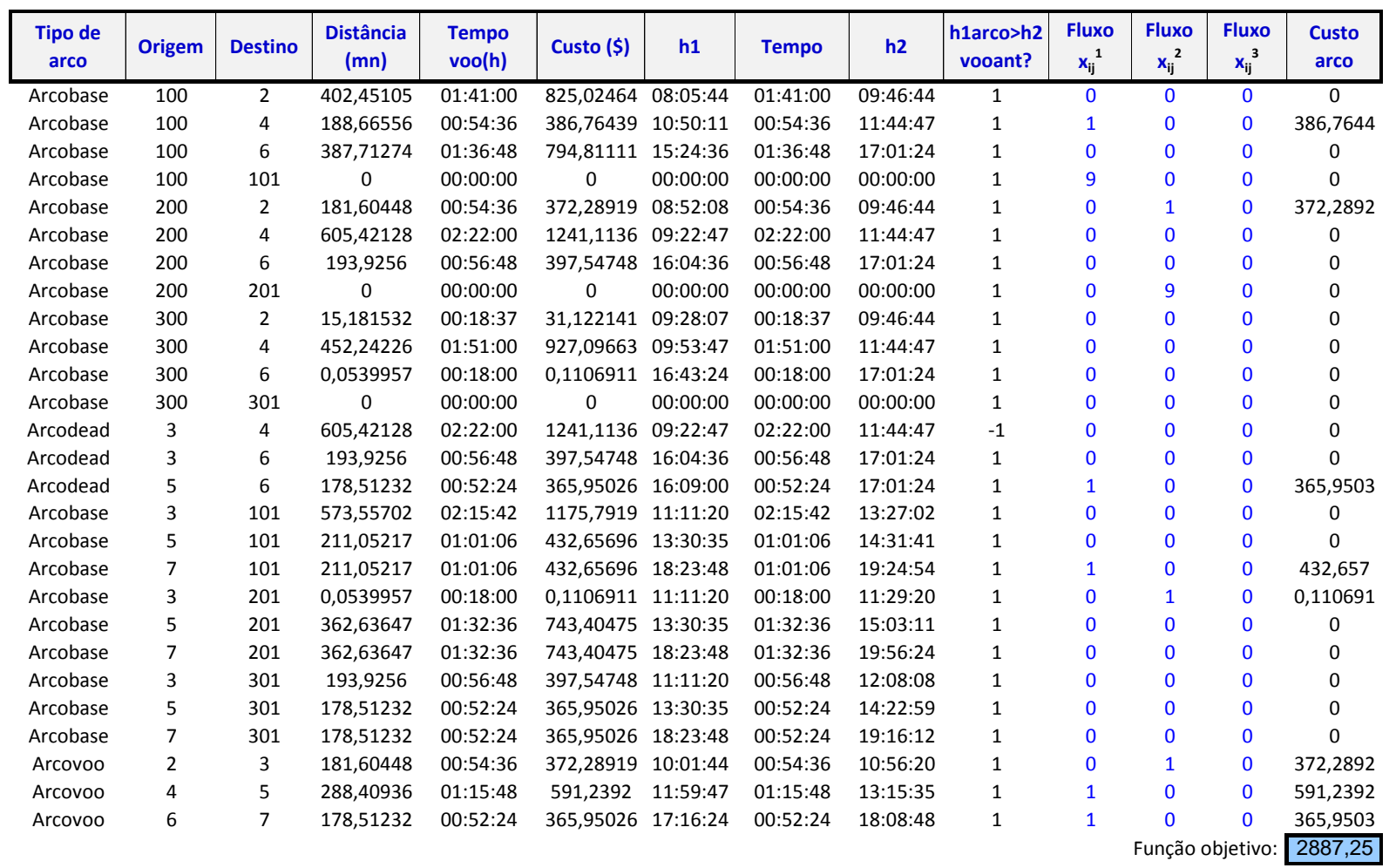

Figura 4.13 - Tela da tabela de arcos do exemplo de verificação

Observa-se que a ferramenta criou corretamente todos os arcos da rede, apresentados anteriormente na Figura 4.12 e na Tabela 4.3. Os arcos escolhidos pelo modelo de otimização obedecem às restrições temporais e são os que apresentam as menores distâncias de voo. A Figura 4.14 mostra a representação da rede da solução ótima fornecida pela ferramenta. Tal solução, idêntica à apresentada pelo solver do Excel, aloca 2 aeronaves, 1 de cada base, para atender aos 3 voos. Da base $B_{2}$ parte uma aeronave para atender ao voo 1 e, após o voo, a mesma aeronave realiza um voo de reposicionamento do aeroporto representado pelo nó 3 até o aeroporto do nó 4, de onde realiza o voo 3. Com a conclusão do voo 3 , a aeronave retorna à base $B_{2}$. $E$, finalmente, da base $B_{1}$ parte a segunda aeronave, que atende somente ao voo 2 e retorna para a base $B_{1}$. 
Inúmeros outros problemas foram elaborados e resolvidos pelas duas maneiras. Com essas comparações dos resultados verificou-se que não há erro nas tabelas construídas automaticamente pelas macros escritas em VBA, as restrições do modelo matemático são inseridas corretamente no What's Best! ${ }^{\circledR}$ e que modelo fornece soluções corretas para todos os problemas elaborados nele, comprovadas através das verificações manuais e pelo Solver.

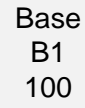

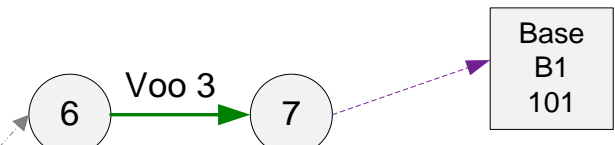
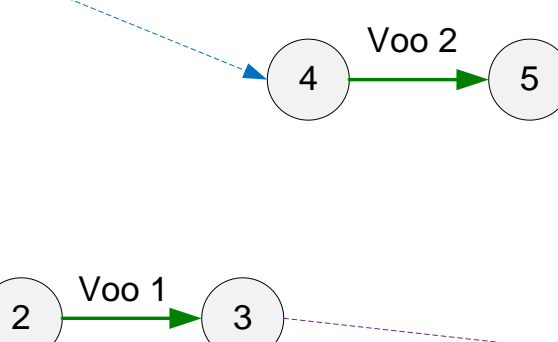

Figura 4.14 - Representação da rede com a solução ótima do exemplo de verificação

\subsection{Considerações finais do capítulo}

Este capítulo descreveu a implementação da ferramenta de otimização e alocação de aeronaves proposta nesta pesquisa.

A opção por construir a ferramenta com o programa Microsoft ${ }^{\circledR}$ Office Excel associado ao pacote de otimização What's Best! ${ }^{\circledR}$ proporciona diversas vantagens para o usuário. O Excel é um programa utilizado em diversas áreas e permite a construção de interfaces e de macros que simplificam sua operação. A apresentação 
dos dados de entrada e dos resultados em tabelas permite integração com outras ferramentas que possam ser utilizadas na análise geral. Pode-se, por exemplo, combinar os resultados desta ferramenta de otimização com outra ferramenta de análise econômico-financeira ou até mesmo integrar as ferramentas para que trabalhem conjuntamente e permitam avaliações mais completas.

A interface em VBA oferece facilidade a operação, pois o usuário não precisa detalhar o modelo matemático todas as vezes, apenas escolher para qual modalidade de operação deseja fazer a otimização. As macros realizam todo o trabalho de construir a rede, nomear nós, arcos, restrições, formular a função objetivo e acionar o What's Best! ${ }^{\circledR}$. Ao usuário são expostos somente os resultados finais de cada dia.

O capítulo seguinte apresenta a utilização da ferramenta em um caso prático e demonstra algumas análises que podem ser realizadas. 


\section{APLICAÇÃO A PROBLEMAS BASEADOS EM SITUAÇÕES REAIS}

A fim de avaliar a metodologia proposta e implantada na ferramenta desenvolvida nesta pesquisa, bem como demonstrar sua aplicabilidade prática, descreve-se neste capítulo a sua aplicação a dois casos inspirados em situações reais.

No primeiro caso, de uma empresa de jatos compartilhados pretende operar com rotas exclusivamente no Brasil, o objetivo é determinar quais dos 13 aeroportos servirão de base de operação e quantas aeronaves devem ser alocadas para cada base, considerando-se operação com frota homogênea e com frota heterogênea. $O$ segundo caso, de uma empresa que pretende trabalhar nos EUA, com operação em 29 aeroportos distribuídos em 100 rotas, visa avaliar se a operação deve ser feita somente com frota própria ou se a opção de alugar frota de terceiros deve ser adotada.

Para ambos os casos, os dados de entrada dos problemas não podem ser divulgados, pois algumas informações são sigilosas por questões de mercado. Os dados do caso prático brasileiro foram inspirados em um caso real e adaptados para a aplicação neste trabalho. Entretanto, os dados do caso prático norte-americano não podem ser transcritos. Por outro lado, tais impedimentos não atrapalham a compreensão deste texto, que objetiva demonstrar a aplicabilidade da ferramenta desenvolvida. Mais especificamente, a aplicação da ferramenta nos casos práticos pretende ilustrar que tipos de análises podem ser feitas e os resultados transcritos neste trabalho não refletem a realidade.

Para o caso prático do Brasil, foram determinadas 5 configurações de bases,ou seja, 5 combinações diferentes de quantidade e localização de bases. Foram realizadas análises variando o tipo de operação e a quantidade de voos. Já para o caso prático dos EUA foram feitas 6 configurações de localização de bases, variando-se também o tipo de operação. 


\subsection{Caso prático do Brasil com frota própria homogênea}

O caso prático em questão representa uma empresa que administra de aeronaves compartilhadas que pretende operar no Brasil. A operação pretende abranger 40 rotas distribuídas entre os 13 aeroportos apresentados na Tabela 5.1. As rotas com suas respectivas informações de origem, destino, distância e probabilidade de ocorrência são mostradas no mapa da Figura 5.1 e na Tabela 5.2.

Tabela 5.1- Lista de aeroportos do caso prático

\begin{tabular}{|l|l|l|l|l|l|l|l|}
\cline { 6 - 8 } \multicolumn{1}{c|}{} & Base & Longitude & Latitude & & Base & Longitude & Latitude \\
\hline $\mathbf{1}$ & SBSP & $-46,6558$ & $-23,6256$ & $\mathbf{8}$ & SBGR & $-46,4727$ & $-23,4350$ \\
\hline $\mathbf{2}$ & SBRJ & $-43,1622$ & $-22,9097$ & $\mathbf{9}$ & SBFL & $-48,5517$ & $-27,6697$ \\
\hline $\mathbf{3}$ & SBBR & $-47,9122$ & $-15,8622$ & $\mathbf{1 0}$ & SBVT & $-40,2864$ & $-20,2578$ \\
\hline $\mathbf{4}$ & SBCT & $-49,1730$ & $-25,5275$ & $\mathbf{1 1}$ & SBGO & $-49,2261$ & $-16,6294$ \\
\hline $\mathbf{5}$ & SBPA & $-51,1711$ & $-29,9939$ & $\mathbf{1 2}$ & SBNF & $-48,6481$ & $-26,8797$ \\
\hline $\mathbf{6}$ & SBGL & $-43,2500$ & $-22,8094$ & $\mathbf{1 3}$ & SBBH & $-43,9508$ & $-19,8517$ \\
\hline $\mathbf{7}$ & SBCF & $-43,9713$ & $-19,6239$ & & & & \\
\hline
\end{tabular}

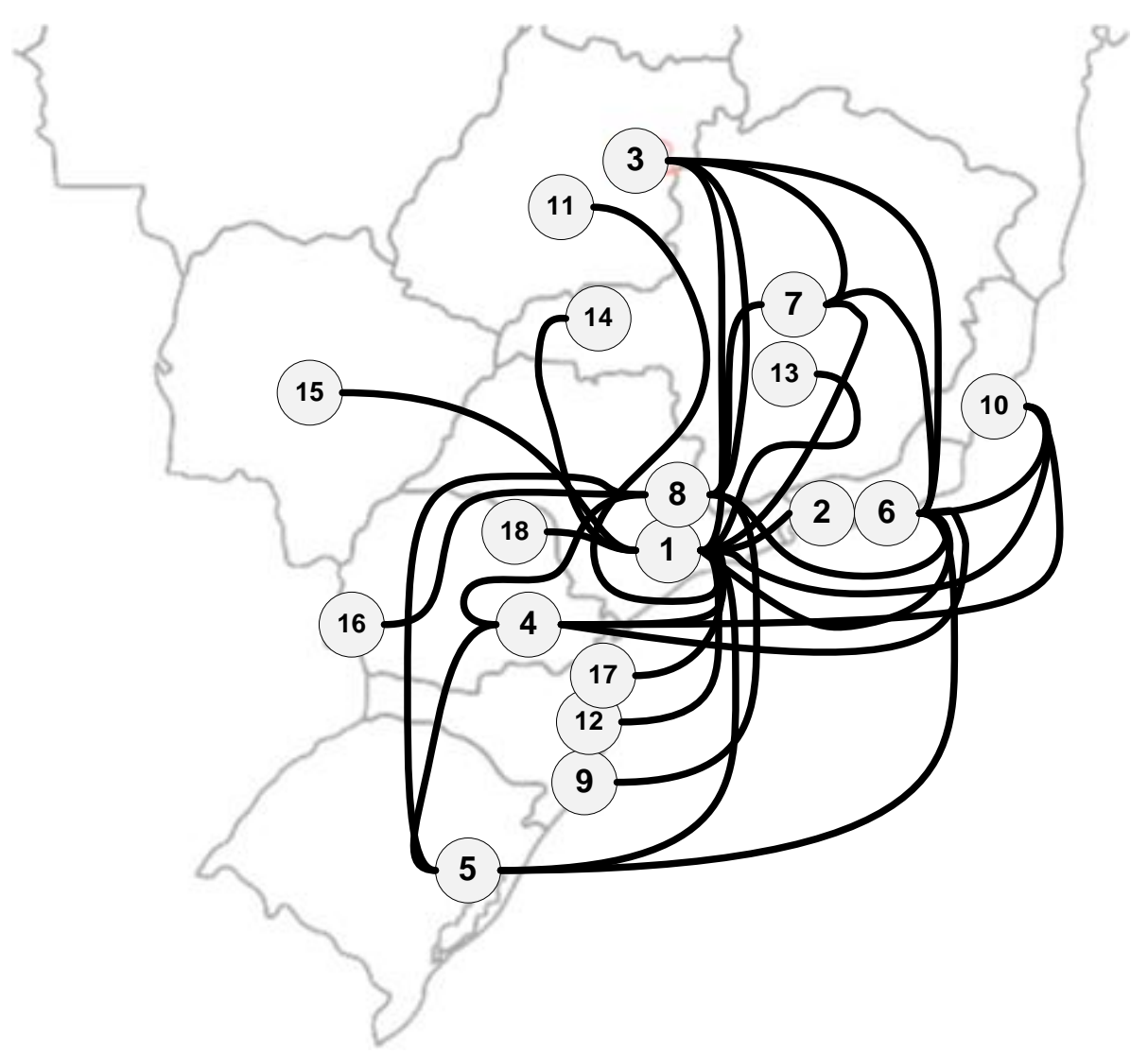

Figura 5.1- Mapa com as rotas do caso prático 
Tabela 5.2- Rotas do caso prático

\begin{tabular}{|c|c|c|c|c|c|c|}
\hline № Rota & Rota & Origem & Destino & $\begin{array}{l}\text { Distância da } \\
\text { Rota }(\mathrm{km})\end{array}$ & $\begin{array}{l}\text { Prob. } \\
\text { Rota }\end{array}$ & $\begin{array}{c}\text { Prob. } \\
\text { Acumulada }\end{array}$ \\
\hline 1 & SBSP-SBRJ & SBSP & SBRJ & 365,439 & $11,457 \%$ & $11,457 \%$ \\
\hline 2 & SBRJ-SBSP & SBRJ & SBSP & 365,439 & $10,312 \%$ & $21,769 \%$ \\
\hline 3 & SBSP-SBBR & SBSP & SBBR & 872,685 & $4,703 \%$ & $26,472 \%$ \\
\hline 4 & SBBR-SBSP & SBBR & SBSP & 872,685 & $4,233 \%$ & $30,705 \%$ \\
\hline 5 & SBSP-SBCT & SBSP & SBCT & 330,605 & $4,102 \%$ & $34,807 \%$ \\
\hline 6 & SBSP-SBPA & SBSP & SBPA & 837,553 & $3,851 \%$ & $38,658 \%$ \\
\hline 7 & SBCT-SBSP & SBCT & SBSP & 330,605 & $3,692 \%$ & $42,350 \%$ \\
\hline 8 & SBPA-SBSP & SBPA & SBSP & 837,553 & $3,466 \%$ & $45,816 \%$ \\
\hline 9 & SBGL-SBBR & SBGL & SBBR & 913,638 & $3,211 \%$ & $49,026 \%$ \\
\hline 10 & SBSP-SBCF & SBSP & SBCF & 523,976 & $2,908 \%$ & $51,934 \%$ \\
\hline 11 & SBBR-SBGL & SBBR & SBGL & 913,638 & $2,890 \%$ & $54,824 \%$ \\
\hline 12 & SBCF-SBSP & SBCF & SBSP & 523,976 & $2,617 \%$ & $57,441 \%$ \\
\hline 13 & SBGR-SBGL & SBGR & SBGL & 336,332 & $2,613 \%$ & $60,054 \%$ \\
\hline 14 & SBGL-SBGR & SBGL & SBGR & 336,332 & $2,352 \%$ & $62,406 \%$ \\
\hline 15 & SBSP-SBFL & SBSP & SBFL & 488,013 & $2,173 \%$ & $64,579 \%$ \\
\hline 16 & SBPA-SBGR & SBPA & SBGR & 865,225 & $1,997 \%$ & $66,576 \%$ \\
\hline 17 & SBFL-SBSP & SBFL & SBSP & 488,013 & $1,956 \%$ & $68,532 \%$ \\
\hline 18 & SBVT-SBGL & SBVT & SBGL & 417,601 & $1,915 \%$ & $70,447 \%$ \\
\hline 19 & SBGR-SBPA & SBGR & SBPA & 865,225 & $1,797 \%$ & $72,244 \%$ \\
\hline 20 & SBGL-SBVT & SBGL & SBVT & 417,601 & $1,723 \%$ & $73,968 \%$ \\
\hline 21 & SBSP-SBGO & SBSP & SBGO & 822,418 & $1,647 \%$ & $75,615 \%$ \\
\hline 22 & SBGL-SBCF & SBGL & SBCF & 361,715 & $1,535 \%$ & $77,150 \%$ \\
\hline 23 & SBSP-SBGL & SBSP & SBGL & 359,150 & $1,492 \%$ & $78,642 \%$ \\
\hline 24 & SBGO-SBSP & SBGO & SBSP & 822,418 & $1,483 \%$ & $80,124 \%$ \\
\hline 25 & SBSP-SBNF & SBSP & SBNF & 413,461 & $1,391 \%$ & $81,515 \%$ \\
\hline 26 & SBGL-SBCF & SBCF & SBGL & 361,715 & $1,381 \%$ & $82,896 \%$ \\
\hline 27 & SBGL-SBSP & SBGL & SBSP & 359,150 & $1,343 \%$ & $84,239 \%$ \\
\hline 28 & SBSP-SBBH & SBSP & SBBH & 503,418 & $1,332 \%$ & $85,571 \%$ \\
\hline 29 & SBGR-SBBR & SBGR & SBBR & 855,092 & $1,320 \%$ & $86,891 \%$ \\
\hline 30 & SBGR-SBCT & SBGR & SBCT & 358,465 & $1,309 \%$ & $88,200 \%$ \\
\hline 31 & SBPA-SBGL & SBPA & SBGL & 1121,240 & $1,288 \%$ & $89,487 \%$ \\
\hline 32 & SBNF-SBSP & SBNF & SBSP & 413,461 & $1,252 \%$ & $90,739 \%$ \\
\hline 33 & SBPA-SBCT & SBPA & SBCT & 534,134 & $1,218 \%$ & $91,957 \%$ \\
\hline 34 & SBBH-SBSP & SBBH & SBSP & 503,418 & $1,198 \%$ & $93,156 \%$ \\
\hline 35 & SBBR-SBGR & SBBR & SBGR & 855,092 & $1,188 \%$ & $94,344 \%$ \\
\hline 36 & SBCT-SBGR & SBCT & SBGR & 358,465 & $1,178 \%$ & $95,522 \%$ \\
\hline 37 & SBCF-SBBR & SBCF & SBBR & 590,768 & $1,170 \%$ & $96,692 \%$ \\
\hline 38 & SBGL-SBPA & SBGL & SBPA & 1121,240 & $1,159 \%$ & $97,851 \%$ \\
\hline 39 & SBCT-SBPA & SBCT & SBPA & 534,134 & $1,097 \%$ & $98,947 \%$ \\
\hline 40 & SBBR-SBCF & SBBR & SBCF & 590,768 & $1,053 \%$ & $100,000 \%$ \\
\hline
\end{tabular}

Fonte: Adaptado de Embraer 
Na planilha "Definições do usuário" são determinados o número de dias simulados e os valores mínimo e máximo de voos por dia. Para ilustrar as análises que podem ser feitas com a ferramenta e a apresentação dos resultados, diferentes períodos de simulação foram estabelecidos para cada caso. Para o caso prático da operação no Brasil com frota homogênea, foi estipulado 1 dia de simulação, com no mínimo 10 e no máximo 20 voos, conforme mostra a Figura 5.2. As conclusões resultantes quanto à localização das bases e ao número de aeronaves necessárias para somente 1 dia de operação em um modelo onde há tantas incertezas e aleatoriedade não são, de maneira alguma, representativos. Entretanto, serão apresentados para a aplicação da ferramenta a um problema real.

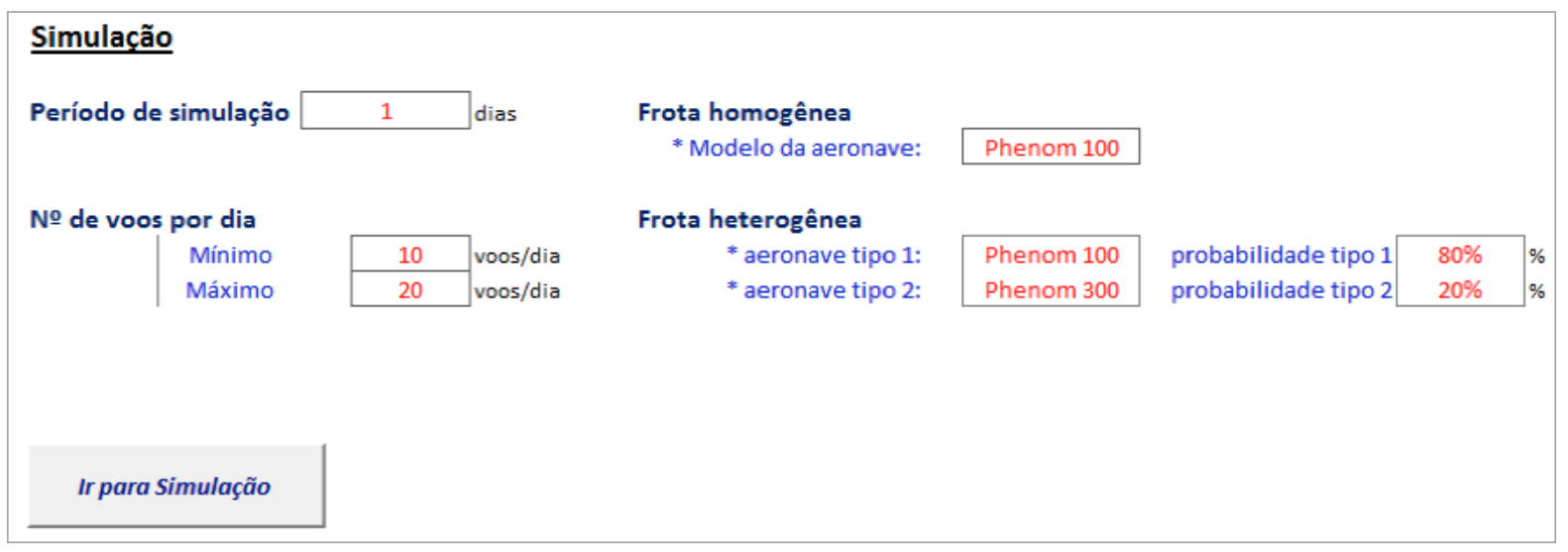

Figura 5.2- Entrada de dados para a simulação

Foi gerada uma lista com quantidade de voos determinada aleatoriamente entre os valores mínimo de 10 voos e máximo de 20 voos, estipulados anteriormente.Neste caso foram sorteados os 15 voos, explícitos na Tabela 5.3. As quantidades mínima e máxima de voos por dia foram estipuladas com base no tamanho da operação desejada pela empresa. Caso fosse feita outra rodada da simulação para a mesma situação, a quantidade de voos para esse dia simulado poderia não ser a mesma, dada a aleatoriedade dos voos.

Todos os voos têm como origem e destino aeroportos apresentados na Tabela 5.1, pois foram sorteadas as rotas fornecidas na Tabela 5.2. 
- Tabela 5.3- Resultados da simulação com frota própria homogênea - 15 voos

\begin{tabular}{|c|c|c|c|c|c|c|c|c|}
\hline Dia & $\begin{array}{c}\text { Vôos/ } \\
\text { dia }\end{array}$ & No vôo & $\begin{array}{c}\text { Hora } \\
\text { partida }\end{array}$ & $\begin{array}{c}\text { No } \\
\text { Rota }\end{array}$ & Origem & Destino & $\begin{array}{c}\text { Distância } \\
\mathbf{( k m})\end{array}$ & $\begin{array}{c}\text { Tempo } \\
\text { Viagem } \\
\mathbf{( h )}\end{array}$ \\
\hline 1 & 15 & 1 & $08: 53: 47$ & 40 & SBBR & SBCF & 590,7683 & 1,3683 \\
\hline & & 2 & $06: 19: 42$ & 40 & SBBR & SBCF & 590,7683 & 1,3683 \\
\hline & & 3 & $12: 06: 06$ & 3 & SBSP & SBBR & 872,6846 & 1,9167 \\
\hline & & 4 & $14: 23: 51$ & 2 & SBRJ & SBSP & 365,4392 & 0,9467 \\
\hline & & 5 & $14: 47: 55$ & 25 & SBSP & SBNF & 413,4606 & 1,0533 \\
\hline & & 6 & $16: 36: 06$ & 25 & SBSP & SBNF & 413,4606 & 1,0533 \\
\hline & & 7 & $15: 31: 30$ & 1 & SBSP & SBRJ & 365,4392 & 0,9467 \\
\hline & & 8 & $07: 49: 52$ & 1 & SBSP & SBRJ & 365,4392 & 0,9467 \\
\hline & & 9 & $15: 32: 14$ & 32 & SBNF & SBSP & 413,4606 & 1,0533 \\
\hline & & 10 & $12: 24: 54$ & 27 & SBGL & SBSP & 359,1502 & 0,9467 \\
\hline & & 11 & $19: 39: 29$ & 35 & SBBR & SBGR & 855,0916 & 1,8833 \\
\hline & & 12 & $14: 16: 53$ & 1 & SBSP & SBRJ & 365,4392 & 0,9467 \\
\hline & & 13 & $06: 13: 14$ & 23 & SBSP & SBGL & 359,1502 & 0,9467 \\
\hline & & 14 & $10: 32: 26$ & 10 & SBSP & SBCF & 523,9763 & 1,2633 \\
\hline & & $18: 51: 34$ & 16 & SBPA & SBGR & 865,2254 & 1,8833 \\
\hline
\end{tabular}

Após a simulação de Monte Carlo, onde foram gerados os voos a serem atendidos naquele dia, foram escolhidas as bases e a distribuição da frota de aeronaves. Neste caso foram testadas cinco configurações de bases, apresentadas na Tabela 5.4, sempre para o mesmo cenário de 1 dia com 15 voos.

Para a configuração 1, a operação contaria com 3 bases, nos aeroportos com maior freqüência de rotas: SBSP, SBGL e SBCF. As configurações 2, 3 e 4, compostas de apenas 2 bases, alternam os três aeroportos anteriores e a configuração 5 compreende somente uma base, no aeroporto mais movimentado.

Tabela 5.4- Configurações de bases para a otimização de frota própria homogênea - 15 voos

\begin{tabular}{|c|c|c|c|c|c|}
\hline Configurações & $\begin{array}{c}\text { Config. 1 } \\
\mathbf{3} \text { bases }\end{array}$ & $\begin{array}{c}\text { Config. 2 } \\
\mathbf{2} \text { bases }\end{array}$ & $\begin{array}{c}\text { Config. 3 } \\
\mathbf{2} \text { bases }\end{array}$ & $\begin{array}{c}\text { Config. } \mathbf{2} \\
\mathbf{2} \text { bases }\end{array}$ & $\begin{array}{c}\text { Config. } \mathbf{5} \\
\mathbf{1} \text { base }\end{array}$ \\
\hline Base 1 & SBSP & SBSP & SBSP & - & SBSP \\
\hline Base 2 & SBGL & - & SBGL & SBGL & - \\
\hline Base 3 & SBCF & SBCF & - & SBCF & - \\
\hline
\end{tabular}


Vale ressaltar que os custos das bases adotados nos casos práticos são todos iguais, independente da localização dos aeroportos. Em uma hipótese de teste, e não necessariamente realista, esses valores não prejudicam o que se pretende demonstrar, que é a utilidade prática da ferramenta. Entretanto, não se deve tirar conclusões de localização de bases a partir dos resultados apresentados.

Em todas as configurações, a frota alocada em cada base era composta de 15 aeronaves (valor correspondente à quantidade de voos a serem atendidos). Esse valor foi estipulado a fim de permitir ao modelo de otimização a liberdade de encontrar a solução ótima sem restrições de tamanho de frota para atender a todos os voos.

Os resultados dos processamentos para as cinco configurações testadas estão sumarizados na Tabela 5.5. Para cada configuração, são apresentadas a quantidade de aeronaves utilizadas de cada base para atender aos voos. Além disso, a tabela mostra o número de voos de reposicionamento e sua representação no total de voos realizados (que incluem os voos programados, os voos de reposicionamento e os voos para as bases). Também são apresentados os custos para os voos agendados (referidos na tabela apenas como "Custos dos voos"), para os voos de reposicionamento e para os voos das bases, assim como o custo de todos os voos. Do mesmo modo, constam na Tabela 5.5 os custos médios diários de operação das bases e os custos médios diários totais, obtidos pela adição dos custos médios diários das bases com os dos voos. A tabela é finalizada com a variação dos custos médios diários totais de cada configuração em relação ao mínimo desses valores.

Iniciou-se com a otimização para a configuração 1 com 3 bases: SBSP, SBGL e SBCF. Os resultados para aquele dia e aquela grade de voos indicaram a necessidade de 5 aeronaves da base SBSP, 1 da base SBGL e 2 da base SBCF. Para atender aos 15 voos utilizando 8 aeronaves, foram necessários 7 voos de reposicionamento

Com base nesses resultados, removeu-se da operação a base SBGL, que foi a que teve menos aeronaves utilizadas, criando-se a configuração 2. Apesar de contar com uma base a menos do que a configuração 1, a solução ótima deste caso requereu a mesma quantidade de aeronaves e resultou o mesmo número de voos 
de reposicionamento. Entretanto, a diferença entre as soluções das duas configurações mostra-se significativa quando se analisa o custo médio diário total, que foi $25 \%$ maior para a configuração 1 , devido à exclusão de uma base de operação na configuração 2. Em outras palavras, com duas bases apenas aumenta a distância de reposicionamento total voada e não a quantidade de aeronaves necessárias.

Outra configuração testada foi a operação com as bases SBSP e SBGL, eliminandose a base SBCF (configuração 3), que utilizou duas aeronaves a menos do que as configurações 1 e 2, testadas anteriormente. Entretanto, o menor número de aeronaves resultou na necessidade de dois voos de reposicionamento. Essa diferença no número de voos de reposicionamento provocou um aumento de cerca de $8 \%$ nos custos de todos os voos. Porém, em relação ao custo médio diário total (que engloba os voos e a operação das bases), a configuração 3 que trocou a base SBCF pelo aeroporto SBGL, com menos rotas, apresentou valor $23 \%$ menor do que a configuração $1 \mathrm{com}$ as 3 bases e 3\% maior do que a configuração 2 com as bases SBSP e SBCF.

Ainda para a mesma lista de 15 voos, otimizou-se também a alocação de aeronaves para configuração 4, sem a base SBSP, que é o aeroporto que mais concentra rotas de voos. Esta configuração 4, que conta somente com as bases SBGL e SBCF, apresentou solução ótima com o menor custo de voos de reposicionamento dentre todas as configurações. Também obteve um valor de custo médio diário total $20 \%$ menor do que a configuração $1 \mathrm{com} 3$ bases, porém teve o maior custo médio diário total dentre as configurações com duas bases.

Finalmente, testou-se a configuração 5, com apenas a base SBSP, que apresentou a necessidade de 9 voos de reposicionamento e um valor de custo de todos os voos $13 \%$ maior do que a configuração $1 \mathrm{com}$ as 3 bases. Apesar disso, em relação ao custo médio diário total, mostrou-se a opção mais econômica, com diferença de $48 \%$ a menos em relação à configuração 1 .

Analisando-se os resultados da otimização de cada configuração, percebe-se que a exclusão de uma base de operação mostrou ter maior impacto nos custos médios diários totais, que incluem a operação das bases, do que na quantidade de voos de 
reposicionamento. A retirada de uma base de operação provocou redução de $48 \%$ nos custo total em contrapartida ao acréscimo de $22 \%$ nos voos de reposicionamento. Em contrapartida, vale ressaltar que esses valores foram obtidos para somente 1 dia de operação, o que impede conclusões quanto à melhor configuração de bases. Evidentemente, os mesmos testes podem ser realizados para um longo horizonte de planejamento.

Tabela 5.5- Resultados das configurações com frota própria homogênea para 15 voos

\begin{tabular}{|c|c|c|c|c|c|}
\hline Configurações & $\begin{array}{c}\text { Config. } 1 \\
\text { SPSP/SBGL/SBCF }\end{array}$ & $\begin{array}{c}\text { Config. } 2 \\
\text { SBSP/-/SBCF }\end{array}$ & $\begin{array}{c}\text { Config. } 3 \\
\text { SBSP/SBGL/- }\end{array}$ & $\begin{array}{c}\text { Config. } 4 \\
\text {-/SBGL/SBCF }\end{array}$ & $\begin{array}{l}\text { Config. } 5 \\
\text { SBSP/-/- }\end{array}$ \\
\hline $\begin{array}{c}\text { Frota utilizada } \\
\text { SBSP/SBGL/SBCF }\end{array}$ & $5 / 1 / 2$ & $6 /-/ 2$ & $4 / 2 /-$ & $-/ 6 / 2$ & $6 /-/-$ \\
\hline $\begin{array}{c}\mathbf{N}^{\circ} \text { de voos de } \\
\text { reposicionamento } \\
\text { (e \% em relação } \\
\text { ao total de voos) }\end{array}$ & $7(18 \%)$ & $7(18 \%)$ & $9(25 \%)$ & $7(18 \%)$ & $9(25 \%)$ \\
\hline Custos dos voos & $\$ 8.544$ & $\$ 8.544$ & $\$ 8.544$ & $\$ 8.544$ & $\$ 8.544$ \\
\hline $\begin{array}{l}\text { Custos dos voos } \\
\text { de reposicion. }\end{array}$ & $\$ 2.238$ & $\$ 1.508$ & $\$ 2.668$ & $\$ 1.051$ & $\$ 2.668$ \\
\hline $\begin{array}{l}\text { Custos dos voos } \\
\text { para as bases }\end{array}$ & $\$ 1.845$ & $\$ 2.637$ & $\$ 2.575$ & $\$ 6.036$ & $\$ 3.261$ \\
\hline $\begin{array}{c}\text { Custos de todos } \\
\text { os voos (voos + } \\
\text { voos de } \\
\text { reposicion. }+ \\
\text { voos para bases) }\end{array}$ & $\$ 12.627$ & $\$ 12.690$ & $\$ 13.788$ & $\$ 15.631$ & $\$ 14.473$ \\
\hline $\begin{array}{l}\text { Custo médio } \\
\text { diário de } \\
\text { operação das } \\
\text { bases }\end{array}$ & $\$ 41.279$ & $\$ 27.519$ & $\$ 27.519$ & $\$ 27.519$ & $\$ 13.759$ \\
\hline $\begin{array}{c}\text { Custo médio } \\
\text { diário total } \\
\text { (custos dos voos + } \\
\text { custos das bases) }\end{array}$ & $\$ 53.907$ & $\$ 40.209$ & $\$ 41.307$ & $\$ 43.151$ & $\$ 28.233$ \\
\hline $\begin{array}{l}\text { \% de acréscimo } \\
\text { do custo médio } \\
\text { diário total em } \\
\text { relação ao } \\
\text { mínimo }\end{array}$ & $48 \%$ & $30 \%$ & $32 \%$ & $35 \%$ & $0 \%$ \\
\hline
\end{tabular}


Foi realizada uma nova simulação onde se ampliou a quantidade de voos. Assumindo-se valores de no mínimo 20 voos e no máximo 50 voos por dia, a simulação gerou uma lista de 30 voos, apresentada na Tabela 5.6.

- Tabela 5.6- Resultados da simulação com frota própria homogênea - 30 voos

\begin{tabular}{|c|c|c|c|c|c|c|c|c|}
\hline Dia & Vôos/dia & № vôo & $\begin{array}{c}\text { Hora } \\
\text { partida }\end{array}$ & № Rota & Origem & Destino & $\begin{array}{l}\text { Distância } \\
(\mathbf{k m})\end{array}$ & $\begin{array}{l}\text { Tempo } \\
\text { Viagem } \\
\text { (h) }\end{array}$ \\
\hline \multirow[t]{30}{*}{1} & 30 & 1 & $07: 25: 15$ & 37 & SBCF & SBBR & 590,7683 & 1,3683 \\
\hline & & 2 & $14: 27: 40$ & 16 & SBPA & SBGR & 865,2254 & 1,8833 \\
\hline & & 3 & $19: 47: 38$ & 19 & SBGR & SBPA & 865,2254 & 1,8833 \\
\hline & & 4 & 07:46:00 & 27 & SBGL & SBSP & 359,1502 & 0,9467 \\
\hline & & 5 & 11:52:34 & 34 & SBBH & SBSP & 503,4182 & 1,2283 \\
\hline & & 6 & $14: 20: 14$ & 21 & SBSP & SBGO & 822,4181 & 1,8167 \\
\hline & & 7 & 09:32:18 & 5 & SBSP & SBCT & 330,6048 & 0,8733 \\
\hline & & 8 & 13:39:01 & 23 & SBSP & SBGL & 359,1502 & 0,9467 \\
\hline & & 9 & $11: 23: 39$ & 15 & SBSP & SBFL & 488,0128 & 1,1933 \\
\hline & & 10 & $11: 13: 40$ & 40 & SBBR & SBCF & 590,7683 & 1,3683 \\
\hline & & 11 & $13: 40: 33$ & 20 & SBGL & SBVT & 417,6014 & 1,0533 \\
\hline & & 12 & 10:10:01 & 27 & SBGL & SBSP & 359,1502 & 0,9467 \\
\hline & & 13 & 07:08:30 & 19 & SBGR & SBPA & 865,2254 & 1,8833 \\
\hline & & 14 & $16: 19: 31$ & 24 & SBGO & SBSP & 822,4181 & 1,8167 \\
\hline & & 15 & $11: 57: 15$ & 40 & SBBR & SBCF & 590,7683 & 1,3683 \\
\hline & & 16 & $16: 18: 30$ & 29 & SBGR & SBBR & 855,0916 & 1,8833 \\
\hline & & 17 & $14: 10: 40$ & 1 & SBSP & SBRJ & 365,4392 & 0,9467 \\
\hline & & 18 & $17: 46: 05$ & 16 & SBPA & SBGR & 865,2254 & 1,8833 \\
\hline & & 19 & 15:39:11 & 28 & SBSP & SBBH & 503,4182 & 1,2283 \\
\hline & & 20 & $17: 42: 20$ & 11 & SBBR & SBGL & 913,6379 & 1,9833 \\
\hline & & 21 & 06:59:10 & 19 & SBGR & SBPA & 865,2254 & 1,8833 \\
\hline & & 22 & 08:36:59 & 15 & SBSP & SBFL & 488,0128 & 1,1933 \\
\hline & & 23 & $16: 42: 22$ & 7 & SBCT & SBSP & 330,6048 & 0,8733 \\
\hline & & 24 & 07:08:30 & 28 & SBSP & SBBH & 503,4182 & 1,2283 \\
\hline & & 25 & $06: 31: 51$ & 40 & SBBR & SBCF & 590,7683 & 1,3683 \\
\hline & & 26 & 19:04:09 & 12 & SBCF & SBSP & 523,9763 & 1,2633 \\
\hline & & 27 & $06: 00: 52$ & 6 & SBSP & SBPA & 837,5527 & 1,8500 \\
\hline & & 28 & $11: 43: 34$ & 28 & SBSP & SBBH & 503,4182 & 1,2283 \\
\hline & & 29 & $06: 26: 36$ & 27 & SBGL & SBSP & 359,1502 & 0,9467 \\
\hline & & 30 & $17: 39: 20$ & 24 & SBGO & SBSP & 822,4181 & 1,8167 \\
\hline
\end{tabular}


Para a lista de 30 voos, repetiram-se as mesmas 5 configurações elaboradas para a análise com 15 voos com o objetivo de avaliar como a duplicação da quantidade de voos influencia o número de aeronaves utilizadas e de voos de reposicionamento necessários. Os resultados da otimização para as 5 configurações com 30 voos pode ser observado na Tabela 5.7.

- Tabela 5.7- Resultados cenários com frota própria homogênea para 30 voos

\begin{tabular}{|c|c|c|c|c|c|}
\hline Configurações & $\begin{array}{c}\text { Config. } 1 \\
\text { SPSP/SBGL } \\
\text { /SBCF }\end{array}$ & $\begin{array}{c}\text { Config. } 2 \\
\text { SBSP/-/SBCF }\end{array}$ & $\begin{array}{c}\text { Config. } 3 \\
\text { SBSP/SBGL/- }\end{array}$ & $\begin{array}{c}\text { Config. } 4 \\
\text {-/SBGL/SBCF }\end{array}$ & $\begin{array}{l}\text { Config. } 5 \\
\text { SBSP/-/- }\end{array}$ \\
\hline $\begin{array}{c}\text { Frota utilizada } \\
\text { SBSP/SBGL/SB } \\
\text { CF }\end{array}$ & $6 / 4 / 3$ & $8 /-/ 3$ & $7 / 5 /-$ & $-/ 9 / 2$ & $11 /-/-$ \\
\hline $\begin{array}{l}\mathrm{N}^{\circ} \text { de voos de } \\
\text { reposicioname } \\
\text { nto (e \% em } \\
\text { relação ao } \\
\text { total de voos) }\end{array}$ & $17(23 \%)$ & $19(27 \%)$ & $18(25 \%)$ & $19(27 \%)$ & $19(27 \%)$ \\
\hline $\begin{array}{l}\text { Custos dos } \\
\text { voos }\end{array}$ & $\$ 20.098$ & $\$ 20.098$ & $\$ 20.098$ & $\$ 20.098$ & $\$ 20.098$ \\
\hline $\begin{array}{l}\text { Custos dos } \\
\text { voos de } \\
\text { reposicion. }\end{array}$ & $\$ 3.505$ & $\$ 5.138$ & $\$ 4.079$ & $\$ 4.507$ & $\$ 4.721$ \\
\hline $\begin{array}{c}\text { Custos dos } \\
\text { voos para as } \\
\text { bases }\end{array}$ & $\$ 3.463$ & $\$ 4.327$ & $\$ 4.205$ & $\$ 6.912$ & $\$ 6.922$ \\
\hline $\begin{array}{l}\text { Custos totais } \\
\text { dos voos }\end{array}$ & $\$ 27.066$ & $\$ 29.564$ & $\$ 28.383$ & $\$ 31.518$ & $\$ 31.741$ \\
\hline $\begin{array}{c}\text { Custo médio } \\
\text { diário de } \\
\text { operação das } \\
\text { bases }\end{array}$ & $\$ 82.559$ & $\$ 55.039$ & $\$ 55.039$ & $\$ 55.039$ & $\$ 27.520$ \\
\hline $\begin{array}{l}\text { Custo médio } \\
\text { diário total }\end{array}$ & $\$ 109.624$ & $\$ 84.603$ & $\$ 83.422$ & $\$ 86.557$ & $\$ 59.261$ \\
\hline $\begin{array}{l}\text { \% do custo } \\
\text { médio diário } \\
\text { total em } \\
\text { relação ao } \\
\text { mínimo }\end{array}$ & $46 \%$ & $30 \%$ & $29 \%$ & $32 \%$ & $0 \%$ \\
\hline
\end{tabular}


Assim como na simulação para 15 voos, a configuração 1, com 3 bases, foi a que apresentou maior custo diário médio total e a configuração 5, com 1 base apenas, a de menor custo diário médio total. A quantidade de voos é exatamente o dobro em relação à lista anterior de voos. Em contrapartida, a quantidade de aeronaves utilizadas para atender aos 30 voos é, em média, 38\% maior do que a quantidade para atender à metade dos voos.

Observa-se ainda que para estes 30 voos foram realizados $58 \%$ a mais de voos de reposicionamento em relação à lista anterior de 15 voos. E o custo médio diário total para os 30 voos foi $51 \%$ maior do que o custo médio diário total para 15 voos.

\subsection{Caso prático do Brasil com frota própria heterogênea}

Outro recurso disponível para análises com a ferramenta de simulação e otimização de aeronaves é a possibilidade de avaliar diferentes políticas operacionais, como a adoção de frota homogênea ou heterogênea.

Para este caso valem os mesmo dados de entrada (aeroportos e rotas) utilizados na seção 5.1 Caso prático do Brasil com frota própria homogênea. A aeronave padrão para a frota homogênea é a Phenom 100 e para a operação com frota própria heterogênea, as aeronaves que podem ser utilizadas são a Phenom 100 e a Phenom 300, ambas da fabricante brasileira Embraer. Os valores de custos aplicados neste caso foram retirados no relatório "Aircraft Operating Costs Guide" publicado por ARG/US (2009) para missões de $300 \mathrm{mn}$, utilizando-se o custo por milha voada especificado no relatório. Como no relatório não constam valores para a aeronave Phenom 300, estipulou-se que os custos da Phenom 300 são $43 \%$ maiores do os custos da Phenom 100.

Assim, os dados de entrada foram inseridos na ferramenta e para uma operação com no mínimo 20 e no máximo 30 voos por dia, foi gerada pela simulação de Monte Carlo uma lista de 25 voos, apresentada na Tabela 5.8. 
Tabela 5.8- Resultados da simulação com frota própria heterogênea - 25 voos

\begin{tabular}{|c|c|c|c|c|c|c|c|c|c|}
\hline Dia & $\begin{array}{l}\text { Vôos/ } \\
\text { dia }\end{array}$ & $\begin{array}{c}\text { № } \\
\text { vôo }\end{array}$ & $\begin{array}{c}\text { Hora } \\
\text { partida }\end{array}$ & $\begin{array}{c}\text { № } \\
\text { Rota }\end{array}$ & Origem & Destino & $\begin{array}{l}\text { Distância } \\
\text { (km) }\end{array}$ & $\begin{array}{c}\text { Tempo } \\
\text { Viagem } \\
\text { (h) }\end{array}$ & $\begin{array}{l}\text { Tipo de } \\
\text { aeronave }\end{array}$ \\
\hline \multirow[t]{25}{*}{1} & 25 & 1 & 16:09:58 & 9 & SBGL & SBBR & 913,6379 & 1,9833 & 2 \\
\hline & & 2 & $13: 00: 24$ & 19 & SBGR & SBPA & 865,2254 & 1,8833 & 1 \\
\hline & & 3 & 14:14:31 & 3 & SBSP & SBBR & 872,6846 & 1,9167 & 1 \\
\hline & & 4 & 11:39:19 & 31 & SBPA & SBGL & 1121,2402 & 2,3667 & 2 \\
\hline & & 5 & 09:51:34 & 11 & SBBR & SBGL & 913,6379 & 1,9833 & 2 \\
\hline & & 6 & 07:03:38 & 11 & SBBR & SBGL & 913,6379 & 1,9833 & 1 \\
\hline & & 7 & $16: 52: 13$ & 14 & SBGL & SBGR & 336,3315 & 0,9100 & 1 \\
\hline & & 8 & $16: 24: 24$ & 26 & SBCF & SBGL & 361,7149 & 0,9467 & 1 \\
\hline & & 9 & 11:49:37 & 5 & SBSP & SBCT & 330,6048 & 0,8733 & 2 \\
\hline & & 10 & $17: 00: 24$ & 40 & SBBR & SBCF & 590,7683 & 1,3683 & 1 \\
\hline & & 11 & 14:54:04 & 26 & SBCF & SBGL & 361,7149 & 0,9467 & 1 \\
\hline & & 12 & $15: 34: 47$ & 7 & SBCT & SBSP & 330,6048 & 0,8733 & 1 \\
\hline & & 13 & $08: 26: 24$ & 31 & SBPA & SBGL & 1121,2402 & 2,3667 & 1 \\
\hline & & 14 & 09:38:19 & 28 & SBSP & SBBH & 503,4182 & 1,2283 & 2 \\
\hline & & 15 & 09:00:52 & 6 & SBSP & SBPA & 837,5527 & 1,8500 & 1 \\
\hline & & 16 & 17:36:01 & 2 & SBRJ & SBSP & 365,4392 & 0,9467 & 1 \\
\hline & & 17 & $06: 08: 27$ & 7 & SBCT & SBSP & 330,6048 & 0,8733 & 1 \\
\hline & & 18 & $16: 37: 55$ & 5 & SBSP & SBCT & 330,6048 & 0,8733 & 1 \\
\hline & & 19 & 18:11:02 & 1 & SBSP & SBRJ & 365,4392 & 0,9467 & 1 \\
\hline & & 20 & $18: 55: 37$ & 40 & SBBR & SBCF & 590,7683 & 1,3683 & 2 \\
\hline & & 21 & $14: 45: 30$ & 33 & SBPA & SBCT & 534,1341 & 1,2633 & 1 \\
\hline & & 22 & $12: 26: 22$ & 1 & SBSP & SBRJ & 365,4392 & 0,9467 & 1 \\
\hline & & 23 & $11: 37: 25$ & 15 & SBSP & SBFL & 488,0128 & 1,1933 & 1 \\
\hline & & 24 & $17: 24: 36$ & 1 & SBSP & SBRJ & 365,4392 & 0,9467 & 1 \\
\hline & & 25 & $06: 11: 18$ & 13 & SBGR & SBGL & 336,3315 & 0,9100 & 1 \\
\hline
\end{tabular}

Para essa lista de 25 voos com frota heterogênea, otimizou-se a alocação de aeronaves para 3 configurações das bases:

- Configuração 6, com 3 bases:SBSP, SBGL e SBCF

- Configuração 7, com 2 bases: SBGL e SBCF

- Configuração 8, com 1 base: SBSP

De forma análoga à situação com frota homogênea, assumiu-se que em casa base há um número de aeronaves de cada tipo igual ao número de voos, ou seja, 25. Os resultados da otimização para frota heterogênea estão apresentados na Tabela 5.9. 
Observa-se que, ao contrário do que ocorreu na operação com frota homogênea em que o menor custo total foi o da configuração com 1 base, neste caso, o menor custo total é o apresentado pela configuração 6 , com 3 bases: é $12 \%$ menor do que 0 custo total da configuração 7, com 2 bases e 7\% menor do que o custo total da configuração 13, com 1 base. A configuração 6 com 3 bases foi a que necessitou do maior número de aeronaves; uma a mais do que nos outros dois cenários. Entretanto, foi a que teve o menor custo de voos de reposicionamento.

É interessante observar que na configuração 7 com 2 bases o número de voos por tipo de aeronave diferiu dos demais cenários. Isso é justificado pelo fato de uma aeronave do tipo 2 ter sido utilizada para atender a um voo que requisitou aeronave do tipo 1. O modelo de otimização determinou ser essa a solução ótima apesar de ter utilizado uma aeronave mais cara para fazer um voo em substituição a uma mais barata, pois o custo de alocar mais uma aeronave mostrou-se superior ao custo do reposicionamento neste caso. Tal situação não ocorreu nas outras configurações, onde os voos foram atendidos pelas aeronaves do tipo solicitado.

Realizou-se outro tipo de análise com a mesma lista de 25 voos com frota heterogênea. Nessa análise, foi imposta uma distância máxima de voos de reposicionamento nula. Ou seja, as aeronaves que foram alocadas para um voo só poderiam realizar outro sem retornar para a base caso o próximo voo tivesse origem no aeroporto em que a aeronave se encontrasse. Essa análise objetiva avaliar o impacto que os voos de reposicionamento têm no custo total da operação e na quantidade de aeronaves utilizadas. Dessa forma imposta, a única maneira de aproveitar a mesma aeronave para dois voos é se a aeronave ficar esperando no aeroporto.

Os resultados para a otimização com essa restrição de voos de reposicionamento estão apresentados na Tabela 5.10. Nesse caso, os valores que aparecem como voos de reposicionamento representam somente os voos que as aeronaves fizeram para suas respectivas bases. Os voos vazios entre nós intermediários da rede não existiram.

O menor custo total da Tabela 5.10 é o apresentado pela configuração 6 , com 3 bases, que é 15\% menor do que o da configuração 7 com 2 bases e $8 \%$ menor do 
que o da configuração 8 com 1 base. Observa-se que todos os cenários utilizaram a mesma quantidade de aeronaves.

$\mathrm{Na}$ comparação dos resultados para a otimização com e sem restrição de voos de reposicionamento, percebe-se que a proibição dos voos vazios provoca um aumento de $9 \%$, em média, no custo total dos voos. Nota-se também que, além do incremento nos custos dos voos, a quantidade de aeronaves utilizadas aumenta em $38 \%$.

Tabela 5.9- Resultados dos cenários com frota própria heterogênea - 25 voos

\begin{tabular}{|c|c|c|c|}
\hline & $\begin{array}{c}\text { Config. } 6 \\
\text { SBSP/SBGL/SBCF }\end{array}$ & $\begin{array}{c}\text { Config. } 7 \\
\text { - / SBGL / SBCF }\end{array}$ & $\begin{array}{l}\text { Config. } 8 \\
\text { SBSP / - / - }\end{array}$ \\
\hline Frota utilizada tipo 1 & $4 / 2 / 2$ & $-/ 4 / 3$ & $7 /-/-$ \\
\hline Frota utilizada tipo 2 & $2 / 1 / 0$ & $-/ 3 / 0$ & $3 /-/-$ \\
\hline $\begin{array}{l}\text { Frota total utilizada } \\
\text { considerando os dois } \\
\text { tipos de aeronaves }\end{array}$ & 11 & 10 & 10 \\
\hline $\begin{array}{l}\text { Custos dos voos de } \\
\text { reposicionamento da } \\
\text { frota tipo } 1\end{array}$ & $\$ 4.992$ & $\$ 6.674$ & $\$ 6.501$ \\
\hline $\begin{array}{l}\text { Custos totais de voos } \\
\text { com frota tipo } 1\end{array}$ & $\$ 15.703$ & $\$ 16.981$ & $\$ 17.213$ \\
\hline $\begin{array}{l}\text { Custos dos voos de } \\
\text { reposicionamento da } \\
\text { frota tipo } 2\end{array}$ & $\$ 4.226$ & $\$ 6.215$ & $\$ 4.373$ \\
\hline $\begin{array}{l}\text { Custos totais de voos } \\
\text { com frota tipo } 2\end{array}$ & $\$ 13.497$ & $\$ 16.196$ & $\$ 13.643$ \\
\hline $\begin{array}{l}\text { Custos dos voos totais } \\
\text { considerando os dois } \\
\text { tipos de aeronaves }\end{array}$ & $\$ 29.200$ & $\$ 33.176$ & $\$ 30.856$ \\
\hline $\begin{array}{l}\text { Custo médio diário de } \\
\text { operação das bases }\end{array}$ & $\$ 156.786,8$ & $\$ 104.524,5$ & $\$ 52.262,3$ \\
\hline Custo médio diário total & $\$ 185.986,7$ & $\$ 137.701,0$ & $\$ 83.118,2$ \\
\hline
\end{tabular}


Tabela 5.10- Resultados das configurações com frota própria heterogênea com restrição de distancia de voos de reposicionamento - 25 voos

\begin{tabular}{|c|c|c|c|}
\cline { 2 - 4 } \multicolumn{1}{c|}{} & $\begin{array}{c}\text { Config. 6 } \\
\text { SBSP/SBGL/SBCF }\end{array}$ & $\begin{array}{c}\text { Config. } 7 \\
-/ \text { SBGL / SBCF }\end{array}$ & $\begin{array}{c}\text { Config. } 8 \\
\text { SBSP } /-/-\end{array}$ \\
\hline Frota utilizada tipo 1 & $7 / 2 / 4$ & $-/ 8 / 5$ & $13 /-/-$ \\
\hline Frota utilizada tipo 2 & $2 / 1 / 4$ & $-/ 3 / 0$ & $3 /-/-$ \\
\hline $\begin{array}{c}\text { Frota total utilizada } \\
\text { considerando os dois } \\
\text { tipos de aeronaves }\end{array}$ & 16 & 16 & 16 \\
\hline $\begin{array}{c}\text { Custos dos voos de } \\
\text { reposicionamento da } \\
\text { frota tipo 1 }\end{array}$ & $\$ 6.651$ & $\$ 9.642$ & $\$ 9.105$ \\
\hline $\begin{array}{c}\text { Custos totais de voos } \\
\text { com frota tipo 1 }\end{array}$ & $\$ 17.903$ & $\$ 20.894$ & $\$ 20.357$ \\
\hline $\begin{array}{c}\text { Custos dos voos de } \\
\text { reposicionamento da } \\
\text { frota tipo 2 }\end{array}$ & $\$ 5.148$ & $\$ 7.625$ & $\$ 5.295$ \\
\hline $\begin{array}{c}\text { Custos totais de voos } \\
\text { com frota tipo 2 }\end{array}$ & $\$ 13.470$ & $\$ 15.946$ & $\$ 13.617$ \\
\hline $\begin{array}{c}\text { Custos dos voos totais } \\
\text { considerando os dois } \\
\text { tipos de aeronaves }\end{array}$ & $\$ 31.373$ & $\$ 36.840$ & $\$ 33.974$ \\
\hline $\begin{array}{c}\text { Custo médio diário de } \\
\text { operação das bases }\end{array}$ & $\$ 156.787$ & $\$ 104.525$ & $\$ 52.262$ \\
\hline Custo médio diário total & $\$ 188.160$ & $\$ 141.365$ & $\$ 86.236$ \\
\hline
\end{tabular}

\subsection{Caso prático EUA com frota homogênea com opção de aluguel}

A última modalidade de operação que pode ser analisada é a que envolve utilizar aeronaves da frota própria com a opção de alugar aeronaves de terceiros.

O caso, com operação nos EUA, envolve 100 rotas que abrangem 29 aeroportos. Por questões de confidencialidade, não podem ser explicitados no texto desta pesquisa as origens e os destinos reais dessas rotas.

Dessa vez, optou-se por utilizar um período de simulação para um horizonte de planejamento de 30 dias, com no mínimo 15 e no máximo 20 voos em cada dia. A 
lista de voos, para efeito de comparação, foi otimizada para 6 configurações de bases. Nas 3 primeiras, a operação é realizada somente com a frota própria homogênea, sem a utilização do recurso de alugar aeronaves. E as 3 últimas são semelhantes às anteriores, porém possuem a opção do aluguel de aeronaves de terceiros.

As 3 primeiras configurações foram as seguintes:

- Configuração 9: com os 3 aeroportos que concentram mais rotas adotados como bases onde estão alocadas as aeronaves da frota própria

- Configuração 10: com duas bases nos mesmos aeroportos concentradores, excluindo-se o aeroporto com mais rotas

- Configuração 11: com uma base, somente no aeroporto com mais rotas.

A Tabela 5.11 apresenta os resultados da otimização para as configurações 9,10 e 11.

A configuração 9 com as 3 bases apresentou o menor custo médio de voos de reposicionamento por dia, sendo $18 \%$ menor do que a configuração $11 \mathrm{com}$ apenas uma base, que apresentou o maior custo.

A configuração 11 com apenas 1 base proporcionou os maiores custos médios diários de voos, enquanto a operação com as 3 bases mostrou-se a mais econômica nesse aspecto.

Entretanto, a operação com apenas uma base foi o cenário que utilizou menos aeronaves dentre as três configurações estudadas para este caso. A configuração 9 com as 3 bases foi a que utilizou mais aeronaves da frota disponível. 
Tabela 5.11- Resultados das configurações nos EUA com frota homogênea

\begin{tabular}{|c|c|c|c|}
\cline { 2 - 4 } \multicolumn{1}{c|}{} & $\begin{array}{c}\text { Configuração } 9 \\
\text { A /B /C }\end{array}$ & $\begin{array}{c}\text { Configuração 10 } \\
\text { - / B / C }\end{array}$ & $\begin{array}{c}\text { Configuração 11 } \\
\text { A / - / - }\end{array}$ \\
\hline Total de dias simulados & 30 & 30 & 30 \\
\hline Média de voos/dia & 17,57 & 17,57 & 17,57 \\
\hline $\begin{array}{c}\text { Frota média utilizada } \\
\text { por base }\end{array}$ & $2,97 / 2,83 / 1,47$ & $-/ 3,43 / 3,7$ & $6,4 /-/-$ \\
\hline $\begin{array}{c}\text { Frota média utilizada } \\
\text { total }\end{array}$ & 7,27 & 7,13 & 6,4 \\
\hline $\begin{array}{c}\text { Média de voos de } \\
\text { reposicionamento/dia } \\
\text { (e \% média em relação } \\
\text { ao total de voos/dia) }\end{array}$ & $10,30(24 \%)$ & $10,43(25 \%)$ & $11,17(27 \%)$ \\
\hline $\begin{array}{c}\text { Custo médio dos voos } \\
\text { de reposic./dia }\end{array}$ & $\$ 1.886,77$ & $\$ 2040,96$ & $\$ 2351,14$ \\
\hline $\begin{array}{c}\text { Custo médio dos voos } \\
\text { para bases/dia }\end{array}$ & $\$ 3.251,95$ & $\$ 3.570,32$ & $\$ 4.264,89$ \\
\hline $\begin{array}{c}\text { Custo médio total dos } \\
\text { voos/dia }\end{array}$ & $\$ 12.867,35$ & $\$ 13.339,91$ & $\$ 14.308,66$ \\
\hline
\end{tabular}

Para a mesma lista de 30 voos com frota homogênea, realizou-se uma nova rodada de otimização, com as 3 últimas configurações, que consideram a opção de aluguel:

- Configuração 12: com os 2 aeroportos com maior concentração de rotas como bases para a frota própria e o terceiro aeroporto mais movimento como base de aluguel de frota de terceiros

- Configuração 13: com o aeroporto mais movimento como base de frota alugada e os outros dois aeroportos como base de frota própria

- Configuração 14: com somente uma base no aeroporto com mais rotas

Os resultados, apresentados na Tabela 5.12, mostram a configuração 12 como uma alternativa para a configuração 9 . Ao invés de utilizar 3 bases com frota própria, 
pode optar-se por utilizar somente os dois aeroportos mais movimentados como base e alugar aeronaves da base menos movimentada e assim, economizar com os custos de instalação e operação da terceira base.

Tabela 5.12 - Resultados das configurações nos EUA com frota homogênea e opção de aluguel

\begin{tabular}{|c|c|c|c|}
\cline { 2 - 4 } \multicolumn{1}{c|}{} & \multicolumn{3}{|c|}{ Frota própria } \\
\hline Configurações & Média de voos/dia & $\begin{array}{c}\text { Custo médio dos } \\
\text { voos/dia }\end{array}$ & $\begin{array}{c}\text { Custo médio dos voos de } \\
\text { reposicionamento/dia }\end{array}$ \\
\hline Configuração 12 & 17,57 & $\$ 13.023,89$ & $\$ 5.295,26$ \\
\hline Configuração 13 & 17,43 & $\$ 13.293,97$ & $\$ 5.576,24$ \\
\hline Configuração 14 & 17,37 & $\$ 14.656,40$ & $\$ 6.944,40$ \\
\hline
\end{tabular}

\begin{tabular}{|c|c|c|c|}
\cline { 2 - 4 } \multicolumn{1}{c|}{} & \multicolumn{3}{|c|}{ Frota alugada } \\
\hline Cenários & Média de voos/dia & $\begin{array}{c}\text { Custo médio dos } \\
\text { voos/dia }\end{array}$ & $\begin{array}{c}\text { Custo médio dos voos } \\
\text { vazios/dia }\end{array}$ \\
\hline Configuração 12 & 0,00 & - & - \\
\hline Configuração 13 & 0,13 & $\$ 32,28$ & $\$ 16,33$ \\
\hline Configuração 14 & 0,20 & $\$ 49,36$ & $\$ 25,01$ \\
\hline
\end{tabular}

\begin{tabular}{|c|c|c|c|}
\cline { 2 - 4 } \multicolumn{1}{c|}{ Cenários } & $\begin{array}{c}\text { Frota média } \\
\text { utilizada da base 1 }\end{array}$ & $\begin{array}{c}\text { Frota média } \\
\text { utilizada da base 2 }\end{array}$ & $\begin{array}{c}\text { Frota média utilizada de } \\
\text { aluguel }\end{array}$ \\
\hline Configuração 12 & 4,13 & 3,00 & 0,00 \\
\hline Configuração 13 & 3,57 & 3,43 & 0,13 \\
\hline Configuração 14 & 6,23 & 0,00 & 0,20 \\
\hline
\end{tabular}

A análise desse caso prático pretendeu avaliar a viabilidade da substituição de uma ou mais bases de operação com frota própria por uma base somente com aluguel de aeronaves. Dessa forma, seriam poupados os custos com administração das bases que, como foi visto nos casos anteriores, representam uma parcela significativa do custo total da operação. Entretanto, em nenhuma das configurações testadas, o aluguel de frota externa mostrou-se uma opção viável, o que pode ser explicado 
tanto pelo custo do aluguel como pelo fato de que não foram considerados no caso os custos de implantação da base.

Note-se que, apesar de não terem sido aplicados, a metodologia e a ferramenta desenvolvida permitem que sejam inseridos sem maiores dificuldades os custos de implantação das bases. Tais custos não entraram na ponderação desse caso por falta de dados. Porém, vale ressaltar que, por serem valores elevados, o horizonte de planejamento para uma análise significativa considerando esses custos deve abranger um período mais longo, de alguns anos.

\subsection{Considerações finais do capítulo}

Este capítulo apresentou a análise das possíveis aplicações da ferramenta de simulação e otimização de aeronaves compartilhadas desenvolvida nesta pesquisa.

De acordo com o que foi visto neste capítulo, a ferramenta possibilita avaliar a operação do negócio com diversas abordagens. A simulação pode ser feita para períodos de tempo maiores, de até 100 dias ou mais, de forma a permitir que sejam analisadas as tendências de comportamento do modelo. Com testes para períodos maiores e com mais voos por dia (até 50 voos diários com frota homogênea), o tempo de processamento da planilha é de cerca de 1 minuto por dia. Entretanto, o tempo de processamento da planilha não se mostrou como fator limitante para a aplicação da ferramenta, pois atende ao propósito de ser uma ferramenta de

planejamento e não de operação. Apesar disso, deve-se notar que quando o número de arcos é muito grande são geradas muitas variáveis de decisão e restrições, o que pode ultrapassar o limite da versão do software What's Best! ${ }^{\circledR}$ utilizada e inviabilizar a otimização.

Conforme foi demonstrado, os dados de entrada podem ser facilmente modificados nas planilhas de maneira a permitir uma sofisticação na ferramenta. Por exemplo, poderia haver uma diferenciação nas rotas e nas suas probabilidades para distintos horários no dia, para dias da semana ou para períodos do ano, sem perda da 
generalidade do modelo aqui proposto. A grande dificuldade ficaria em obter os dados para um negócio não existente, pois a escassez de informações gera ressalvas na interpretação dos resultados.

Não obstante, vale destacar que, para cada caso apresentado neste capítulo, gerouse uma única lista de voos na simulação. Da mesma maneira em que variaram-se os cenários de operação para atender aos mesmos voos, a ferramenta proporciona que, ao invés de gerar os voos ela simulação, o usuário insira diretamente na planilha os voos a serem atendidos. Tal característica permite que a ferramenta seja utilizada não só para o planejamento de novos negócios, mas também para análise de negócios já existentes que visem melhorar sua operação ou planejar expansões.

Os resultados permitem ponderar dentre as diversas configurações testadas, qual é mais estável a longo prazo, qual aloca menos aeronaves, qual economiza mais combustível, qual alteração de base de maior impacto, e assim por diante. Ou seja, o planejador pode obter os dados necessários da operação para que seja possível decidir o que é melhor para seu negócio, ponderando fatores subjetivos que não fazem parte do problema matemático. 


\section{CONCLUSÕES E RECOMENDAÇÕES}

\section{1 - Conclusões}

Esta pesquisa de mestrado tratou de uma ferramenta de planejamento que engloba um modelo de simulação e alocação de aeronaves de propriedade compartilhada e foi implementada e testada com dados de casos práticos do Brasil e dos EUA. Com o objetivo de auxiliar no planejamento de uma empresa de jatos compartilhados, a ferramenta desenvolvida permite análises referentes à localização das bases e à distribuição da frota de aeronaves entre as bases escolhidas.

Como foi visto no Capítulo 1, o negócio de jatos compartilhados, apesar de ter sofrido com a recente crise econômica, integra um mercado de grande potencial de crescimento dentro da indústria de aeronaves executivas, inclusive no Brasil. Ferramentas de auxílio a tomada de decisões estratégicas que tratam do problema , tal qual a elaborada nesta pesquisa, são interessantes não só para empresas que pretendem implantar o serviço, mas também para fabricantes de aeronaves que podem auxiliar e priorizar seus clientes frotistas. E, de acordo com o que foi mostrado no Capítulo 2, as pesquisas que tratam do assunto focam na operação de um serviço de jatos compartilhados. Não foram encontradas referências na literatura que abordem o assunto com ênfase na etapa de planejamento.

As características do problema, apresentadas no Capítulo 3, compõem um sistema abrangente das principais restrições do modelo de negócio de jatos executivos compartilhados. Essa abrangência permite que a metodologia de solução proposta, que integra Simulação de Monte Carlo e modelagem como fluxo em rede, possa ser empregada para outros casos de alocação de veículos com demanda variável com as mesmas características, feitas as devidas considerações sobre as particularidades de cada caso.

A atuação conjunta e complementar de simulação e otimização é uma abordagem de grande potencial que tem sido estudada para diversos tipos de problemas logísticos. Neste caso, a simulação pelo método de Monte Carlo permite representar a variação da demanda por viagens de maneira coerente com as probabilidades de ocorrência das rotas de voos. Essa variação é essencial para representar a 
aleatoriedade do problema. A estruturação do problema como um caso de fluxo em rede de mínimo custo permite que seja encontrada a solução ótima para a alocação diária das aeronaves.

Através da construção do modelo em ambiente de planilha eletrônica, constituiu-se uma ferramenta acessível para que o usuário possa realizar as análises sem a necessidade de adquirir um software especial que requeira treinamento para operação. O suplemento What's Best! ${ }^{\circledR} 9.0$ realiza com sucesso a solução do problema linear de minimização da função objetivo de custo total e a escrita do código em linguagem de programação VBA permite ajustes nas restrições e adaptações do modelo para outros casos.

Durante a operação da planilha, o analista pode alterar configurações do modelo de negócio para obtenção dos dados requeridos. Como foi mostrado nos Capítulos 4 e 5 , podem ser facilmente modificados os dados de entrada da ferramenta para testar as mais diversas políticas de operação da empresa sem alterações na formulação matemática. Adicionalmente, a metodologia proposta pode ser utilizada para análise de uma situação em que a demanda seja conhecida, o que eliminaria a etapa da simulação e geraria uma ferramenta de otimização com flexibilidade para gerar diversos cenários de análise.

\section{2 - Recomendações}

O modelo de simulação e alocação de aeronaves mostrou-se robusto, capaz de resolver problemas de grande porte, com grande quantidade de voos diários e um longo período de simulação, e apresentar a solução ótima para cada caso. Entretanto, o problema de jatos compartilhados é complexo e dinâmico, com muitas restrições e variáveis.

Neste trabalho foram incluídas as restrições básicas de operação. Em uma extensão desta pesquisa, generalizações podem ser feitas para, por exemplo, impor uma frota mínima a ser utilizada de cada base para evitar bases ociosas e garantir alta utilização da frota. 
Outro aprimoramento possível consiste em considerar regras de trabalho da tripulação. No modelo desenvolvido, ao inserir restrições de tempo de voo para cada aeronave pode-se restringir a jornada da tripulação e assim atender à legislação regulamentadora, que varia para cada país.

O modelo de simulação também pode ser aprimorado. A simulação pode distinguir picos de demanda que podem ser representadas em épocas do ano, dias da semana ou até mesmo horários de partida em que as solicitações por viagens são mais freqüentes. A análise pode considerar cobrar mais para períodos de maior demanda, ou pedir flexibilidade nos horários de partida dos voos ou ainda requerer maior antecedência no agendamento das viagens.

O modelo de otimização da alocação de aeronaves tem como objetivo minimizar o custo total da operação. Entretanto, os parâmetros podem ser modificados de acordo com a análise pretendida. Por exemplo, podem-se alterar as restrições do modelo matemático de forma a trabalhar com uma porcentagem mínima de voos de reposicionamento. Neste caso, durante a construção da rede, basta penalizar os arcos de reposicionamento com um tempo a mais de voo ou um custo maior.

O modelo também pode ser complementado a fim de considerar os custos de operação nos aeroportos, já que os aeroportos mais movimentados geralmente têm pouca disponibilidade para operação de novos negócios e na prática torna-se inviável sua utilização. Assim, o modelo pode considerar as particularidades de cada local e refletir essa consideração na localização das bases.

Os resultados apresentados pela ferramenta devem ser refinados. Além da obtenção de dados de entrada precisos e confiáveis, deve-se também aplicar tratamentos estatísticos que permitam, por exemplo, reduzir incertezas na simulação da demanda e extrair mais informações nas análises dos resultados, principalmente nas que se referem à localização das bases.

A flexibilidade promovida pela construção da ferramenta em ambiente de planilha eletrônica também permite a integração com outras ferramentas utilizadas no planejamento. Há a possibilidade de associar o uso desta ferramenta com outras de análise de fatores econômicos ou de gerenciamento de tripulação, por exemplo. 


\section{REFERÊNCIAS BIBLIOGRÁFICAS}

Ahuja, R. K.;Magnanti, T. L. e Orlin, J.B. (1993).Network Flows: Theory, Algorithms and Applications, Prentice Hall, NJ.

Ahuja, R. K.; Cunha, C. B.; Sahin, G. (2005). Network Models in Railroad Planning and Scheduling. In: Tutorials in Operations Research 2005, H. J. Greenberg, J. Cole Smith (Eds), Informs, Hanoves, MD, p. 54-101.

Borin, B.; Ribeiro, E. (2010). Céu de brigadeiro. Meio \& Mensagem. Publicada em 02 de Agosto de 2010. Disponível em: < http://www.abag.org.br/entrevista_lyra_3.html>. Acesso em 18 de outubro de 2010.

Butler, J. D. (2008). Buyer's Guide - The fundamentals of fractional ownership. Business Jet Traveler Online. Artigo publicado em 07 de janeiro de 2008. Disponível em: < http://www.bjtonline.com/flying/inside-fractionals/s/p/1/article/the-fundamentalsof-fractional-ownership-512.html>. Acesso em 13 de Abril de 2009.

Butler, J. D. (2009). Fractional Jet Ownership - Protecting yourself against liability. Business Jet Traveler Online. Artigo publicado em 01 de fevereiro de 2009. Disponível em: <http://www.bjtonline.com/flying/insidefractionals/s/p/1/article/protecting-yourself-against-liability-2009.html>. Acesso em 20 de Maio de 2010.

Caetano, D. J.; Gualda, N. D. F. (2009) Modelo para programação de voos e alocação de frotas. In XXIII ANPET - Congresso de Pesquisa e Ensino em Transportes, 2009, Vitória - ES. Panorama Nacional da Pesquisa em Transportes 2009. Rio de Janeiro : ANPET, 2009. v. 1. p. 1-12.

Cunha, C B. (2000). Aspectos práticos da aplicação de modelos de roteirização de veículos a problemas reais. Transportes, v. 8, n. 2, p. 51-74.

Cunha, C. B. (2003). Um Modelo Matemático para o Problema de Seqüenciamento e Programação de Visitas de Gerentes de Banco. Gestão \& Produção. n. 2, 10, 183196. São Carlos. 
Cunha, C. B. (2006). Uma contribuição à modelagem de problemas em logística e transportes: texto de sistematização crítica de parte da obra do candidato. $315 \mathrm{p}$. Tese (Livre Docência) - Escola Politécnica da Universidade de São Paulo. Departamento de Engenharia de Transportes. São Paulo.

Cordeau, J.-F.; Stojkovic, G.; Soumis, F. e Desrosiers, J. (2001). Benders Decomposition for Simultaneous Aircraft Routing and Crew Scheduling. Transportation Science v. 35, p. 375-388.

Cortes, C. S.; Cunha, C. B. (2010). Modelo de decisão para a programação de entrega de concreto produzido em centrais. In: XVI Congresso Pan-Americano em Engenharia de Tráfego e Transporte e Logística 2010. Lisboa. Anais do XVI Congresso Pan-Americano em Engenharia de Tráfego e Transporte e Logística 2010.

Diáz J. A.; e Pérez I. G.; Simulation and optimization of sugar cane transportation in harvest season. In: Winter Simulation Conference, v.2, p. 1114-1117. Orlando, Dec. 2000.

Dupim, T. (2010). Aviação executiva: fundamental no mundo moderno (parte 2). Artigo publicado em 18 de setembro de 2008. Disponível em: < http://aviaorevue.terra.com.br/index.asp?codc=696>. Acesso em 18 de outubro de 2010.

Espinoza, D.; Garcia, R.; Goycoolea, M.; Nemhauser, G.L. e Savelsbergh, M. W. P. (2008). Per-seat, On-Demand Air Transportation Part I: Problem Description and an Integer Multicommodity Flow Model. Transportation Science v. 42, n. 3, p. 263-278.

Ernst, A. T.; Gavriliouk, E. O.; Marquez, L. (2010). An efficient Lagrangean heuristic for rental vehicle scheduling. Computers \& Operational Research, n. 38, p.216-222

Fink, A.; Reiners, T. (2006). Modeling and solving the short-term car rental logistics problem. Transportation Research, Part E: Logistics and Transportation Review n.42, p. 272-292. 
Fractional Life (2009). How private aviation works. Disponível em:< http://fractionallife.com/articles_how_private_aviation_works.asp >. Acesso em . 5 de Maio de 2010.

Galvão Junior, F. A. (2004). Otimização do sistema de coleta de resíduos de biomassa de Madeira para fins energéticos. 196p. Dissertação (Mestrado) - Escola Politécnica da Universidade de São Paulo, Programa de Mestrado em Engenharia de Sistemas Logísticos. São Paulo.

Gualda, N. D. F. (1995). Terminais de transportes: contribuição ao planejamento e ao dimensionamento operacional. 277p. Tese (Livre Docência) - Escola Politécnica da Universidade de São Paulo. Departamento de Engenharia de Transportes. São Paulo.

Hicks, R.; Madrid, R.; Milligan, C.; Pruneau, R.; Kanaley, M.; Dumas, Y.; Lacroix, B.; Desrosiers, J. e Soumis, F. (2005). Bombardier flexjet significantly improves its fractional ownership operations. Interfaces v. 35, n. 1, p. 49-60.

Keskinocak, P. e Tayur, S. (1998). Scheduling of time-shared jet aircraft. Transportation Science v. 32, n. 3, p. 227-294.

Lawley, M.; Parmshwaran, V.; Richard, J.; Turkcan, A.; Dalal, M.; Ramcharan, D. (2008). A time-space scheduling model for optimizing recurring bulk railcar deliveries. Transportation Research, part B, 42, p. 438-454

LeBlanc, L. J.; Grossman, T. A. (2008). Introduction: The Use of Spreadsheet Software in the Application of Management and Operations Research. Interfaces v.38, n. 4 , p. $225--227$

Long, D.; Lee, D.; Johnson, J. e Kostuck, P., (2001). Small Aircraft Transportation System (SATS) Demand Model .NASA/CR-2001-210874 77p.

Martin, C.; Jones, D. e Keskinocak, P. (2003). Optimizing on-demand aircraft schedules for fractional aircraft operators. Interfaces v. 33, n.5, p. 22-35.

Morito, S.; Koida, J.; Iwama, T.; Sato, M.; Tamura, Y. (1999). Simulation-based constraint generation with applications to optimization of logistic system design. In 
Proceedings of the 1999 Winter Simulation Conference (Eds R. A. Farrington, H. B. Nembhard, D. T. Sturrock and G. W. Evans), 1999 (Institute of Electrical and Electronic Engineers, Piscataway, New Jersey).

Morrison, M. (2009). NBAA 09: Believing the dream. Artigo publicado em 12 de outubro de 2009.2 Disponível em: <http://www.flightglobal.com/articles/2009/10/12/333287/nbaa-09-believing-thedream.html>. Acesso em 20 de Maio de 2010.

NetJets Inc (2008). The buyers guide to fractional aircraft ownership including Jet Card Programs: Questions to ask and issues to consider before you buy. Disponível em: <http://www.netjets.com/>. Acesso em: 22 de abril de 2009.

Preston, H. H. (2009). Private Jet cards emerge as alternative to ownership. The New York Times. Artigo publicado em 28 de agosto de 2009. Disponível em: <http://www.nytimes.com/2008/08/29/business/worldbusiness/29iht-mjets3. 4.15748655.html?pagewanted=1\&_r=1>. Acesso em 15 de maio de 2010.

Seshadri, A.; Baik, H.; Trani, A. e Hinze, N.(2006). Evaluating the efficiency of a small aircraft transportation system network using planning and simulation models. $6^{\text {th }}$ AIAA Aviation Technology, Integration and Operations Conference. 25-27 september, Wichita, Kansas.

Shamblin, J. E. e Stevens, G. T. (1979). Pesquisa Operacional. Atlas, São Paulo.

Sharkey, J. (2006). Big battles in small-jet skies. The New York Times. Artigo publicado em 29 de agosto de 2008. Disponível em: <http://www.nytimes.com/2008/05/20/business/20taxi.html> Acesso em: 13 de abril 2009.

Sharkey, J. (2008) .Air taxis fly into financial turbulence. The New York Times. Artigo publicado em 20 de maio de 2008. Disponível em: <http://www.nytimes.com/2008/05/20/business/20taxi.html> Acesso em: 13 de abril 2009.

Sherali, H. D.; Bish, E. K.; Zhu, X. (2006). Airline fleet assignment concepts, models, and algorithms. European Journal of Operational Research. n. 172, p. 1-30. 
Silva, G. P. (2001). Uma metodologia baseada na técnica de geração de arcos para o problema de programação de veículos. 146p. Tese (Doutorado) - Escola Politécnica da Universidade de São Paulo, Departamento de Engenharia de Transportes. São Paulo.

Stojkovic, G.; Soumis, F.; Desrosiers, J.; Solomon, M. M. (2002). An optimization model for a real-time flight scheduling problem. Transportation Research Part A 36, p. 779-788.

Thurber, M. (2009). The fractional market special report. AIN Online. Artigo publicado em outubro de 2009.

Thurber, M. (2009). Special Reports - 15 Business Aviation Milestones. Business Jet Traveler. Artigo publicado em dezembro de 2009, Disponível em: <http://www.bjtonline.com/special-reports/s/article/15-business-aviation-milestones2207.html> Acesso em 15 de Maio de 2010.

Thurber, M. (2010).Buyers' Guide Articles: You Don't Have to Buy an Airplane. Artigo publicado em 01 de Julho de 2010. Disponível em: $<$ http://www.bjtonline.com/special-reports/s/p/1/article/you-donat-have-to-buy-anairplane-2452.html>. Acesso em 13 de setembro de 2010.

Thurber, M. (2010). A peek ahead. Business Jet Traveler. Artigo publicado em 01 de agosto de 2010. Disponível em: <http://www.bjtonline.com/specialreports/s/p/1/article/a-peek-ahead-2492.html>. Acesso em 13 de setembro de 2010.

Trautvetter, C. (2010). On more solid footing, NetJets posts $\$ 114 \mathrm{M}$ profit. AIN Online. Artigo publicado em 10 de agosto de 2010. Disponível em: <http://www.ainonline.com/news/single-news-page/article/on-more-solid-footingnetjets-posts-114m-profit-25795/>. Acesso em 11 de novembro de 2010.

Vashi, V. H.; e Bienstock, C. C. (1995). The use of response surface methodology to optimize logistics simulation models. Journal of Business Logistics, 16.

Yan, S.; Lai, C. H.; Chen, C.H. (2005). A short-term scheduling model for international express package delivery. Journal of Air Transport Management n.11, p. 368-374. 
Yang, W.; Karaesmen, I. Z.; Keskinocak, P. (2010). Managing uncertainty in ondemand air travel. Transportation Research Part E 46, p.1169-1179.

Yao, Y.; Ergun, Ö.; Johnson, E.; Schultz, W. e Singleton, J. M. (2007). Strategic Planning in Fractional Aircraft Ownership Programs. European Journal of Operation Research n. 189(2), p. 526-539.

Zambuzi, N. C. (2010). Modelo de decisão para o planejamento da movimentação de contêineres vazios. 179p. Dissertação (Mestrado) - Escola Politécnica da Universidade de São Paulo, Programa de Mestrado em Engenharia de Sistemas Logísticos. São Paulo. 